\title{
WestVirginiaUniversity
}

THE RESEARCH REPOSITORY @ WVU

Graduate Theses, Dissertations, and Problem Reports

2016

\section{Three Essays on Energy Economics}

\section{Seth Wiggins}

Follow this and additional works at: https://researchrepository.wvu.edu/etd

\section{Recommended Citation}

Wiggins, Seth, "Three Essays on Energy Economics" (2016). Graduate Theses, Dissertations, and Problem Reports. 6948.

https://researchrepository.wvu.edu/etd/6948

This Dissertation is protected by copyright and/or related rights. It has been brought to you by the The Research Repository @ WVU with permission from the rights-holder(s). You are free to use this Dissertation in any way that is permitted by the copyright and related rights legislation that applies to your use. For other uses you must obtain permission from the rights-holder(s) directly, unless additional rights are indicated by a Creative Commons license in the record and/ or on the work itself. This Dissertation has been accepted for inclusion in WVU Graduate Theses, Dissertations, and Problem Reports collection by an authorized administrator of The Research Repository @ WVU.

For more information, please contact researchrepository@mail.wvu.edu. 


\title{
Three Essays on Energy Economics
}

\author{
Seth Wiggins
}

\author{
Dissertation submitted \\ to the Davis College of Agriculture, Natural Resources and Design \\ at West Virginia University \\ in partial fulfillment of the requirements for the degree of \\ Doctor of Philosophy in \\ Natural Resource Economics \\ Xiaoli Etienne, Ph.D., Chair \\ Stratford Douglas, Ph.D. \\ Donald Lacombe, Ph.D. \\ Levan Elbakidze, Ph.D. \\ Gerard D'Souza, Ph.D.
}

Division of Resource Management

Morgantown, West Virginia

2016

Keywords: Energy economics, coal production, natural gas market, residential solar, time-series econometrics, TVP-VAR, spatial econometrics

Copyright 2016 Seth Wiggins 


\section{ABSTRACT \\ Three Essays on Energy Economics}

\section{Seth Wiggins}

This dissertation focuses on the economics of electricity generation. I aim to answer three main questions: After controlling for outside market forces, how did acid rain regulation impact Eastern coal production? How have the fundamental relationships in the natural gas market changed since deregulation, especially given the rise of production from shale resources? And how have sub-state policies affected the adoption of residential solar generation installations? For each question, I use economic tools to provide empirical answers which will contribute both to the academic literature as well as energy policy.

My first essay looks at the coal production in the Eastern US from 1983-2012. It is widely understood that the quantity of coal produced in this region declined during this time period, though its causes are debated. While some have identified the cause to be outside economic forces, the prevailing view is that federal regulation was the main driver. By controlling for outside market forces, this paper is able to estimate the effect that the differing regulatory periods have had on coal production. Results demonstrate how in general the regulatory phases of the Acid Rain Program are associated with decreases in production in the Illinois and Appalachian basins, however with varying magnitudes. Further, there are some areas that saw some increases. The essay also measure the mitigating impact that the installation of 'scrubber' units had on production. Overall, this essay provides a more nuanced look at the relationship between coal production and regulation during this time period.

The second essay in this dissertation models the natural gas market. Since the complete deregulation of the market in 1993, there have been significant changes. Most notably, the rapid rise of production from shale resources has greatly increased the supply and decreased the price of the commodity. Where for many years a net importer, the US is now predicted to be a net exporter of natural gas within the next year. This massive change has altered the fundamental relationships in the market. This essay utilizes recently developed methodology to estimate how these relationships have changed over time. Further, given our research design we are able to estimate how the supply and demand elasticities have been influenced in the new era of abundant and cheap natural gas. Results provide a more nuanced view of the natural gas market, and allow for a better understanding of its drivers.

My third essay measures the impact that certain policies have had in the residential solar market. Specifically, I estimate the impact on residential solar adoption associated with sub-state policies, enacted at the municipal, county, or utility level. To capture the clustering and peer effects in the adoption of residential solar that have been described in the literature, I utilize spatial econometric methods. To better model the nested nature of state and county renewable policies, a Bayesian hierarchical model is used. Results suggest that sub-state policies are associated with positive and significant increases in per-capita residential solar installations and capacity additions. 


\section{Acknowledgments}

You learn a lot getting a $\mathrm{PhD}$. I mean, that's kind of the point. But along with all the math and theory, you're given ample time to learn about the life choice you're making. And now on my way out, I can tell you with a high degree of certainty: it's a bad one.

It's not that the costs outweigh the benefits, though they are formidable: low pay, geographic and social isolation, being sent to the back of the prestige line. These of course were all known prior and definitely realized during. But while most say the long-term benefits will eventually pay off, it's important to consider that they're all conditional on passing. This is not the slightest bit guaranteed, much less in any reasonable time-frame. Pursing a doctorate is a bad choice because of how unbelievably lucky you need to be to actually finish.

See, the thing is, your ideas are probably terrible. Solidarity: mine are too. We all tend to enjoy our own because we don't really like to consider whether we're wrong. The academic market for bad ideas is highly saturated, and to create anything different, you need a lot of help. Throughout my doctorate, I was extremely fortunate to have a small group of people who were willing and able to provide direction, clarification, and assistance. Without them, I would have been lost.

I am forever indebted to Xiaoli. Obviously she managed to drag me through all the intellectual and administrative hurdles that accompany a dissertation, which by itself is no doubt an impressive feat. However my debt goes further. It is said that experts seek out those who are willing to be critical of them. This relationship being endogenous I guess is sort of the point of academia. On the other hand, like most novices I was incredibly receptive to any sort of positive encouragement, which she gave often. It is easy to say that without her constant support both my chances of completion and the quality of my work would have been significantly lower.

The same can be said of the rest of my committee. Most of what I've learned about research and the field has come from working with Strat. His insights toward both remain invaluable. Don was by far the best teacher I've had in grad school, imparting more in one class than what I gained from most others. Levan was always supportive and helpful, particularly so with the job market. And Gerard consistently helped with all things departmental, providing both opportunity and resources a number of times over the past few years. I am grateful to have worked with each.

While this professional guidance was necessary, it was certainly not sufficient. Grad school can be souldraining, and above all else I was extremely lucky to have a partner who supported me during these years. By providing a welcome distraction as well as mitigating both distance and stress, she provided a way to maintain sanity through all the volatility. To call her a diamond in the rough would involve two severe understatements.

Having seen the risks associated with a doctorate, I maintain that pursing one was a bad choice. It would have been far too easy to fail or stagnate, as many have. Only with a considerable amount of assistance, support, and encouragement was I able to finish. For this, I send a heartfelt thanks to each of you. 
Chapter 1: Introduction 1

Chapter 2 - Essay \#1: Effects of Acid Rain Regulations on Production of Eastern Coals 5

of Varying Sulfur Content

1. Introduction

2. Background $\quad 8$

3. Data 10

3.1 Megawatt Demand and Geographic Distance $\quad 12$

4. Empirical Model 15

4.1 First Stage Probit $\quad 15$

4.2 Estimation of Coal Demand 16

4.3 Regulation Year Specification 20

5. Sulfur Price Elasticity 22

6. Conclusions 24

7. References

Chapter 3 - Essay \#2: Turbulent Times: Uncovering the Origins of US Natural Gas 26

Price Fluctuations Since 1993

1. Introduction 27

2. Brief Literature Review

3. Methodology 31

3.1 Precautionary Demand 33

3.2 A Time-Varying Parameter VAR Model with Stochastic Volatility 34

3.3 Identification of Structural Shocks

3.4 Implementation of the Estimation and Identification Procedure 37

4. Data $\quad 39$

5. Estimation Results $\quad 40$

5.1 Responses to Natural Gas Supply and Demand Shocks 40

5.2 Estimating Supply and Demand Elasticities in the US Natural Gas Market 43

5.3 Robustness Checks $\quad 45$

6. What Drives Variations in the Real Price of Natural Gas?

6.1 How Much Did Shale Production Contribute to the Collapse of Natural Gas Prices? 50

6.2 The Price Escalation in 2007-2008 51

6.3 Hurricanes Katrina and Rita in 2005

7. Conclusions 53

8. References 56

Chapter 4 - Essay \#3: How Sub-State Policies Affect the Western US Residential Solar 59

Market: an Application of a Bayesian Spatial Hierarchical Model

$\begin{array}{ll}\text { 1. Introduction } & 60\end{array}$

2. Hypothesized Model $\quad 63$

3. Data 64

3.1 Solar Installations $\quad 64$

3.2 Policy Variables $\quad 65$

3.3 Solar Insolation $\quad 66$

$\begin{array}{ll}3.4 \text { Environmental Preference } & 67\end{array}$

3.5 Electricity Prices, County Demographics 68

4. Empirical Model 68

4.1 Spatial Hierarchical Methodology $\quad 69$

4.2 Estimation Results

5. Conclusions 75

6. References 76

Chapter 5: Conclusions 


\section{Essay \#2:}

\section{List of Figures}

Figure 1: Total Coal Produced, by Basin: 6

Figure 2: Fluid Gas Desulfurization (Scrubber) Installation 9

Figure 3: Appalachian and Illinois Basin Coal Sulfur Content 11

Figure 4: Estimated Effects of Clean Air Act Policy on Coal Production 18

Figure 5: Estimated Percentage Increase of Coal Production Due to Scrubbers 19

Figure 6: Estimated Overall Effects of CAA Policy and Scrubbers on Coal Production 19

Figure 7: Year and Year* $\mathrm{SO}_{2}$ Coefficients, with 95\% Confidence Intervals 20

Essay \#3

Figure 1. Natural Gas Producer Price Index in the US and Its One-Year CVs (1975-2015) 28

Figure 2. Median Cumulative Impulse Reponses of Aggregate Demand, Inventory Demand, 41 and Price to Structural Shocks Normalized on 1\% Supply Shortfalls

Figure 3. Median Impulse Reponses of Aggregate Demand, Inventory Demand, 43

and Price to Structural Shocks Normalized on 10\% Price Increase

Figure 4. Median Natural Gas Price Elasticities of Demand and Supply 44

Derived from Impulse Responses Estimates (1993-2015)

Figure 5. Robustness Check - Median Cumulative Impulse to Structural Shocks 47

Normalized on $1 \%$ Supply Shortfalls after Imposing Elasticity Bounds

Figure 6. Medium FEVD of Real Natural Gas Prices in the US (1993-2015) 48

Figure 7. Historical Decomposition of Demeaned Real Natural Gas Price Changes 50

(Demeaned Data in Black and Contribution of the Structural Shock in Blue)

\section{Essay \#4}

Figure 1: Costs of Residential Solar PV Installations 61

Figure 2: Residential Solar PV Capacity and Number of Installations, 2016

Figure 3: Number of Solar Incentivizing Policies 66

Figure 4: Average Solar Insolation $\quad 67$

Figure 5: Distribution of $\beta$ 2, Sub-State Policies $\quad 72$ 


\section{Essay \#1:}

\section{List of Tables}

Table 1: Capacity Factor Summary Statistics

Table 2: Capacity Factor Regression Results

Table 3: Full Model Summary Statistics

Table 4: First Stage Probit Results

Table 5: Full Model Regression Results

Table 6: Sulfur Elasticity Regression Results

Essay \#2:

Table 1. Sign Restrictions Imposed in the Structural VAR Model

Essay \#3:

Table 1: Summary Statistics

Table 2: Bayesian Coefficient Estimates

Table 3: Marginal Effects 


\section{Chapter 1: Introduction}

In the electricity market, demand must be met by supply in every region at all times. Nearly all of the US economy is to some degree dependent on electricity being reliably available. This is true despite wide fluctuations in demand: daily, weekly, and seasonally as a whole consumers choose to use electricity at different rates. Meeting this demand involves a tremendous amount of financial resources. From the primary fuel discovery all the way to the transmission of electrons, the generation of electricity involves entire industries. In the latest data available from the US Energy Information Agency (EIA), energy expenditures represent $8.3 \%$ of all GDP in the US. Historically, this value is higher: consumers have always been willing to trade other consumption for reliable heat and light. Demand is only projected to increase, as the EIA predicts residential, commercial, and industrial consumption to increase steadily through 2040 (EIA, 2015). There are significant revenues to be earned in meeting this demand.

In this effort, the state of West Virginia has been front and center. The state has historically been in the center of a major producing region, the Appalachian basin. Its thick coal seams were relatively easy to exploit, and the coal produced fueled the industrialization of the US, as well as its westward expansion. Similar to its earlier era of timber production, laborers migrating to West Virginia had origins from all parts of the country and beyond. The extraction of coal made some rich, and provided many others a steady standard of living.

However the state's economy has suffered in the latter 20th and 21st centuries. Alongside the number of both direct and indirect jobs that were lost due to declining coal demand, there is a significant geographical component to the state's problems as well. For the ease of access to coal resources, towns were built in remote locations with difficult access to other population centers. With that stream of revenue severely decreased, cities have a much harder time connecting with the main drivers of economic growth. Also with falling incomes and tax revenue from coal production social services like education and health care have declined. According to the Appalachian Regional Commission, 9 of West Virginia's 55 counties are considered 'distressed'.

The coal industry has faced increasing scrutiny as understanding of the non-market costs of electricity production grows. There are important trade-offs between the generation electricity from nearly all sources and environmental quality, however those associated with the burning of coal. Air and water quality are severely impacted from both the extraction and burning of coal. Both of which have led to negative consequences to human health. Further, we now understand how the emission of carbon-dioxide

\footnotetext{
${ }^{1} \mathrm{http}: / / \mathrm{www}$. arc.gov/distressedcounties
} 
and other heat-trapping greenhouse gasses (GHGs), in large from the burning of carbon-based fossil fuels, is causing global average temperatures to rise. Appropriately, significant attention is being paid to generation from coal-fired power plants, and numerous regulations now control most aspects of its production.

The degree of which regulation affected the production of Appalachian and Illinois basin coal production is the subject of my second chapter. I examine the effects of regulation created by the US Environmental Protection Agency (EPA) to combat acid rain. Created in the early 1990's, the Acid Rain Program (ARP) limited the allowable levels of Sulfur Dioxide $\left(\mathrm{SO}_{2}\right)$ content emittable by the worst polluting coal-fired power plants in Phase I, and the entirety of the market in Phase II. Unique to this program was the creation of a $\mathrm{SO}_{2}$ allowance permit market: firms with marginal costs of abatement higher than the permit price could by permits instead, while plants with lower marginal abatement costs could sell their permits. This ensured that abatement would come from the lowest cost producers.

With Stratford Douglas, we measure the regulatory phase' impact on coal production. While it is well established that the Eastern coal industry in the last 30 years has been in steady decline, it is less well understood whether market forces or regulation has been the cause. By controlling for market forces in a number of ways, we empirically demonstrate how most regulatory periods in most areas are associated with significant decreases. However we also demonstrate how the sulfur content dictated the magnitude of these decreases. In fact, some areas with sufficiently low sulfur content benefited from this regulation. These results provide a richer and more nuanced examination of the coal production market as well as the regulatory period's effects.

Looking forward, this general decline is projected to continue. At a time when electricity demand is expected to rise, expectations for coal demand do not (EIA, 2015). While some effort has been put forth towards the diversification of West Virginia's economy, many here support the continued development of natural resources. Technology has helped. In 2007, the combined use of hydraulic fracturing and horizontal drilling made the extraction of natural gas and later oil from shale resources profitable. This has revolutionized the natural gas industry in the US: where once were predicted to need large imports of natural gas to meet demand, the US is now predicted to be a net exporter by 2017 (EIA, 2015). West Virginia sits on top of two shale plays, the Marcellus and Utica. Both the land purchases and the revenues generated from production have increased both employment and income in the Appalachian region (Padres et al, 2012). 
However the impacts of this rapid increase in production on the US market have not been well studied. My third chapter aims to fill this gap. Together with Xiaoli Etienne, I apply recently developed techniques in time-series econometrics to the natural gas market. Using quarterly data from 1976-2015, we evaluate how the drivers of the natural gas market have changed since complete market deregulation, and disentangle supply and demand shocks in the market. Our results demonstrate the effects of unanticipated supply disruptions and price surges, as well as how they have changed over time. Through our research design we are also able to model the changes in the elasticities of demand and supply. These results provide a better picture of the natural gas market since the rise of domestic shale production, and help identify likely responses given future market disruptions.

While arguably cleaner than coal, natural gas still is a non-renewable resource that emits climate-warming GHG's into the atmosphere. Electricity generation from renewable sources is receiving significant attention. West Virginia does have a very small share of its electricity from hydroelectric and wind generation, however the opportunities for increased capacity are small: most optimal dam sites are already dammed, and only a small share of mountaintops provide sufficient wind potential to be attractive. Producing electricity from solar energy could be an attractive option for West Virginia. While not endowed with solar resources similar to the southwest part of the nation, there is sufficient potential to greatly increase capacity: Germany, with the resource potential roughly equivalent to Seattle or Anchorage, leads the world in installed solar capacity.

To spur the installation of solar capacity, governments at various levels have enacted various policies aimed at solar adoption. Offering financial incentives has been one such policy: these subsidies effectively lower costs to consumers, which increased adoption. As the number of installations increased, economies of scale have led to costs reductions in solar panel production and installation, creating a positive feedback loop. Financial incentives and other policy instruments have been enacted from the federal government down to the municipality level.

Chapter 4 examines the effectiveness of sub-state policies at incentivizing solar adoption. As a number of previous studies have noted the geographic neighborhood and peer-effects in solar adoption, I model this market using spatial econometric methods. Given the nested nature of renewable policies at the county and state level, I use a hierarchical model. Results suggest that municipal, county, and utility policies have a positive and significant effects on the adoption of residential solar adoption. Further, the residential solar market exhibits a moderate but significant amount of spatial autocorrelation. These results help identify a previously overlooked main driver of the residential market, and suggest that it may be more beneficial for policy efforts be directed towards local governments. 
This dissertation has taken a comprehensive view of the West Virginia energy production landscape. Historically, coal production has been dominant. My second chapter attempts to better understand how much of a role regulation has played in this decline, while controlling for market forces. An important market force in recent years has been the sharp increase in the production of natural gas, a topic at the heart of my third chapter. Here I comprehensively model the US natural gas market, and evaluate how the fundamental relationships have changed since the development of shale. If these two generation methods represent the past and present of West Virginia's electricity production portfolio, renewables could be considered as its future. However the economics of renewable generation would need to change, as currently natural gas is generally a cheaper and a more reliable option. Inventive policies are needed to increase renewable generation. In my fourth chapter, I focus on the effect that municipal, county, and utility policies have on residential solar adoption. With this dissertation, researchers and policymakers will have a better understanding of West Virginia's electricity production, and can better address the challenges and opportunities offered by being a producing state. 


\title{
Chapter 2 - Essay \#2: Effects of Acid Rain Regulations on Production of Eastern Coals of Varying Sulfur Content
}

With Stratford Douglas

\begin{abstract}
We analyze the effects of the EPA's Acid Rain Program on county-level production of coals of varying sulfur content in the Appalachian and Illinois basins, controlling for Powder River Basin production, proximity of power plants to mines, and scrubber installation. Using a thirty-year panel data set, we find that during the Acid Rain Program coal sulfur content positively affected mine closure and negatively affected production in most coal-producing counties, with the greatest effect from 1995-2000. Estimated effects of power plant flue gas desulfurization equipment installation are substantial, and depend on coal sulfur content, scrubber unit size, and distance from the mines. The estimated elasticity of coal mine output to sulfur allowance price varies widely by coal sulfur content and is negative for mines producing coals above the 51th percentile in sulfur content. Our results complement previous studies of regulatory effectiveness, limiting the degree to which reductions in acid rain may be attributed to market rather than regulatory factors.
\end{abstract}




\section{Introduction}

By any measure, the U.S. coal industry has experienced an extended period of decline. Coal's share of its primary U.S. market, electric power generation, declined from 57\% in 1985 to $33 \%$ in 2015 (EIA). ${ }^{2}$ As figure 1 illustrates, coal production in the Appalachian and Illinois basins has declined since 1995, when Phase 1 of the EPA's Acid Rain Program began. The decline of the industry has not been uniform, however. While overall Eastern coal production declined by 22\% between 1990 and 2008, production of low-sulfur Western coal increased by $70 \%$ over the same period (EIA 2014a). Both regions have experienced a decline in production since 2007.

Figure 1: Total Coal Produced, by Basin:

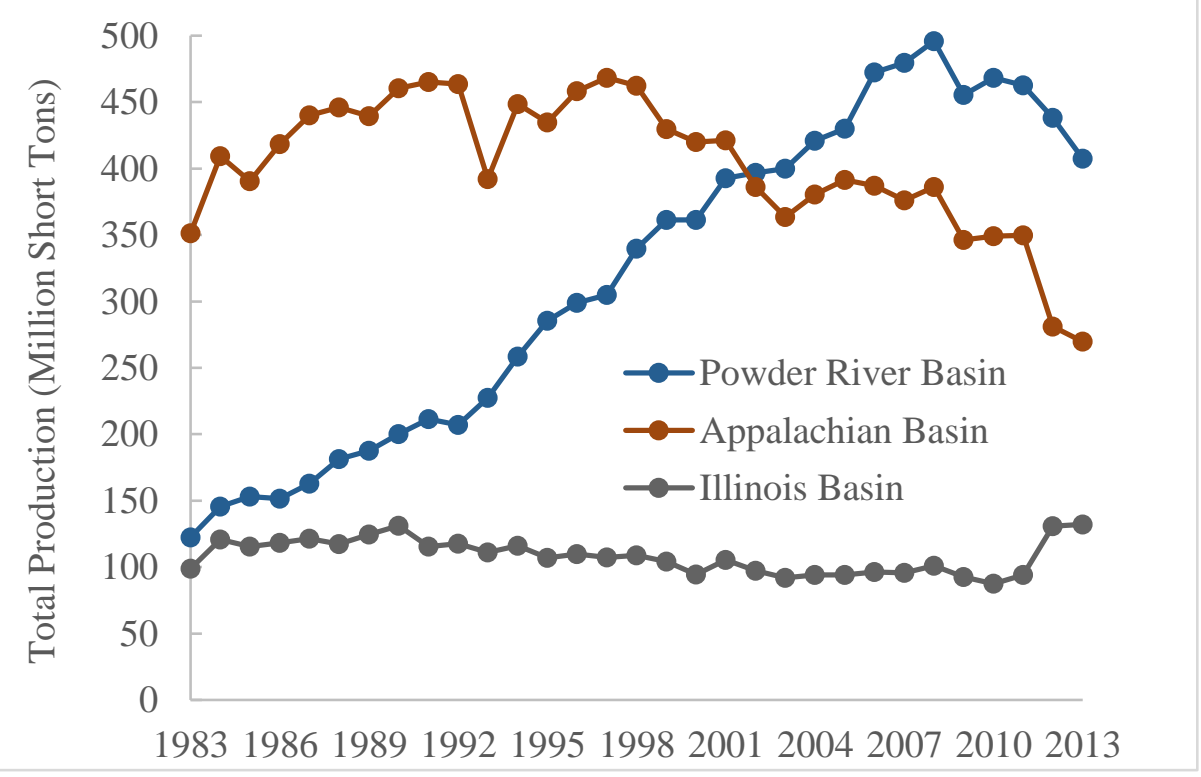

Source: EIA

The decline in coal's overall electricity market share, and the displacement of Eastern coal by Western coal, coincided with the imposition of stricter air-quality regulations. Many residents of Eastern coalproducing states attribute these changes to a "war on coal" perpetrated by the U.S. Environmental Protection Agency and other federal agencies. But market forces have also driven both the decline of Eastern coal and the rise of low-sulfur Western coal. Wyoming's Powder River Basin (PRB) coal mines are nearly ten times as productive as Appalachian mines on a tonnage basis (EIA 2014a), and PRB production costs are much lower. Furthermore, after 1980 railroad deregulation and technological innovation drove down the cost of long-haul rail transport, and operators of Midwestern and Eastern

\footnotetext{
${ }^{2}$ Despite the recent decline, power generation accounted for $92 \%$ of all coal consumption in the U.S. in 2015 .
} 
power plants adapted them to burn PRB coal more easily than some had expected. In the past ten years, market forces have continued to favor cleaner fuels as the shale gas revolution has driven natural gas prices down and production up.

The economics literature has noted the role of market forces in the decline of sulfur emissions and the coal industry. In particular, Ellerman and Montero (1998) observed that many power plants not subject to clean-air regulations reduced their sulfur emissions voluntarily by switching to Wyoming coal between 1985 and 1993, and concluded that economic forces were far more important than clean air regulations in motivating the move to Western coal. This conclusion has influenced subsequent researchers, surveyed in Schmalansee and Stavins (2013). The question of whether markets or regulation are more to blame for the decline of Eastern coal production is, however, still open.

The literature has examined the effect of clean air regulations using data on power plant emissions, and on the eastward movement of Powder River Basin coal. We take a different approach, concentrating instead on county-level coal production within Eastern coal basins. Specifically, we examine county-level data on coal production within the Illinois and Appalachian basins from 1983-2012, taking into account variation in both sulfur content of coal mines in each county and installation of emissions control equipment in nearby power plants. This county-level "micro" approach has some advantages over studies such as Ellerman and Montero (1998) that focused on "macro" trends of Western versus Eastern coal production. On the macro level, it is especially difficult to empirically identify the separate effects of market and regulatory forces because both regulatory and market forces favor low-cost, low-sulfur Western coal. In contrast, production and transport cost differences within the Illinois and Appalachian basins are not so strongly biased in favor of low-sulfur coals. ${ }^{3}$ Consequently, it is easier to identify the effect of clean air regulations on coal production if the analysis concentrates on Eastern coal basins rather than the national market, as fewer confounding factors affect the analysis.

If the shift to low-sulfur coal (and consequent reduction in acidic precipitation) were primarily driven by the lower cost of Western coals rather than Clean Air Act regulations, we would expect little variation in impact of regulations on production of Eastern coals of different sulfur content. On the contrary, our results indicate that clean air regulations had a significantly different impact on high-sulfur and low-sulfur coal mines in the Appalachian and Illinois basins. We present evidence that sulfur content positively affected mine closure in all regulatory phases after 1995. We also find evidence of a greater impact on production of coals of higher sulfur content over the entire period, with the greatest effect occurring from

\footnotetext{
3 Transport costs are a much smaller portion of the total cost of Eastern coals than Western coal. As to production costs, Eastern coals of all sulfur grades are mined in both open and underground mines, and the cost differences are much smaller within the Eastern basins than between Eastern and Western basins.
} 
1995-2000. We estimate that clean air regulations were associated with reduced output in at least $86 \%$ of coal-producing counties in both Eastern basins during all regulatory periods. Estimated effects of power plant flue gas desulfurization equipment installation on coal production are very substantial, particularly in the Ohio River Valley, and depend on coal sulfur content, scrubber unit size, and distance from the mines. Finally, in separate estimates examining the relationship between coal mine output and the price of sulfur emissions allowances, and we find that the cross-price elasticity ranges from -0.5 to +1.0 depending on sulfur content, with a negative elasticity appearing only for counties whose mines are above the 77 th percentile in sulfur content.

\section{Background}

Congress passed Clean Air Act legislation in 1963 and 1970, and added significant amendments to the 1970 Clean Air Act in 1977 and 1990. We focus on the consequences of the 1990 amendments, specifically the EPA's implementation of those amendments in its Acid Rain Program (ARP) and successors. Our analysis distinguishes three distinct regulatory periods: Phase 1 (1995-1999), Phase 2 (2000-2008), and the period we term "Post-2008," extending from 2009 to the end of our data set in 2012. During Phase 1, the EPA required reduced $\mathrm{SO}_{2}$ emissions from fossil electric generating units in 110 power plants, mostly older units, coal-fired, and lacking in pollution control equipment (Lange and Bellas, 2007). In Phase 2, the EPA widened its reach and tightened its standards, implementing a national emissions cap affecting 3200 units in nearly all US fossil-fuels plants (see Ellerman et al., 2000).

Accompanying the emissions caps was an $\mathrm{SO}_{2}$ emissions trading program, authorized under Title IV of the 1990 Clean Air Act Amendments, as described by Schmalensee and Stavins (2013). This trading program functioned effectively from 1995 through 2007, and then declined in relevance after the D.C. Circuit Court's ruling in State of North Carolina vs. EPA (2008), which vacated the EPA's Clean Air Interstate Rule (CAIR) and led to the formulation of the Cross-State Air Pollution Rule (CSAPR). During this Post-2008 period, regulators' increasing reliance on state-level emissions caps and command-andcontrol regulatory methods to meet National Ambient Air Quality Standards caused average allowance prices to plunge from almost $\$ 400$ in 2008 , to $\$ 70$ in 2009 , to under $\$ 3$ by 2011 (EIA, 2011). Technically, generators must still obtain allowances in order to emit $\mathrm{SO}_{2}$, but this requirement is non-binding, as available allowances provide for more emissions than are allowed under other regulations.

To comply with acid rain regulations, electric utilities have employed two principal strategies: fuelswitching and installing emissions scrubber units. Fuel-switching involves substitution away from coals containing high amounts of sulfur and toward coals with lower sulfur content and natural gas. Scrubbers (also known as flue-gas desulfurization, or FGD, equipment) typically remove about $90 \%$ of all sulfur 
dioxide from a plant's emissions, allowing it to comply with regulations regardless of the sulfur content of the fuel it burns.

As of 2012 there were 335 scrubber units in operation (US EIA 2014c), with an additional 67 units planned, retired, or standby. Figure 2 indicates the dates of installation of FGD units, clearly showing their relationship to major Clean Air Act regulatory initiatives in 1977, 1990-1995, and 2010. Scrubbers are expensive and highly capital-intensive, and therefore financially risky for their owners, but they are politically popular because of their perceived ability to protect high-sulfur mining jobs, as noted by Hoag (1995), among others. Lile and Burtraw (1998) document actions taken by state legislatures and regulators to encourage scrubber installation following passage of the 1990 Clean Air Act Amendments. In particular, the high-sulfur coal mining states of Tennessee, West Virginia, Kentucky, Ohio, Indiana, and Illinois passed laws and crafted regulations designed to allow early and more certain recovery of scrubber costs, with the (usually explicit) intent to mitigate the effects of the Acid Rain Program on local coal mines. Cicala (2015) provides evidence that coal-fired power plants subject to rate-of-return regulation were more likely to install scrubbers than divested plants facing a competitive wholesale electric power market. Frey (2013) found that large plants that can take advantage of economies of scale are more likely to install scrubbers, but her empirical results confirm that federal and state air quality regulations were the most important factor driving the wide adoption of scrubber technology since 1978.

Figure 2: Fluid Gas Desulfurization (Scrubber) Installation

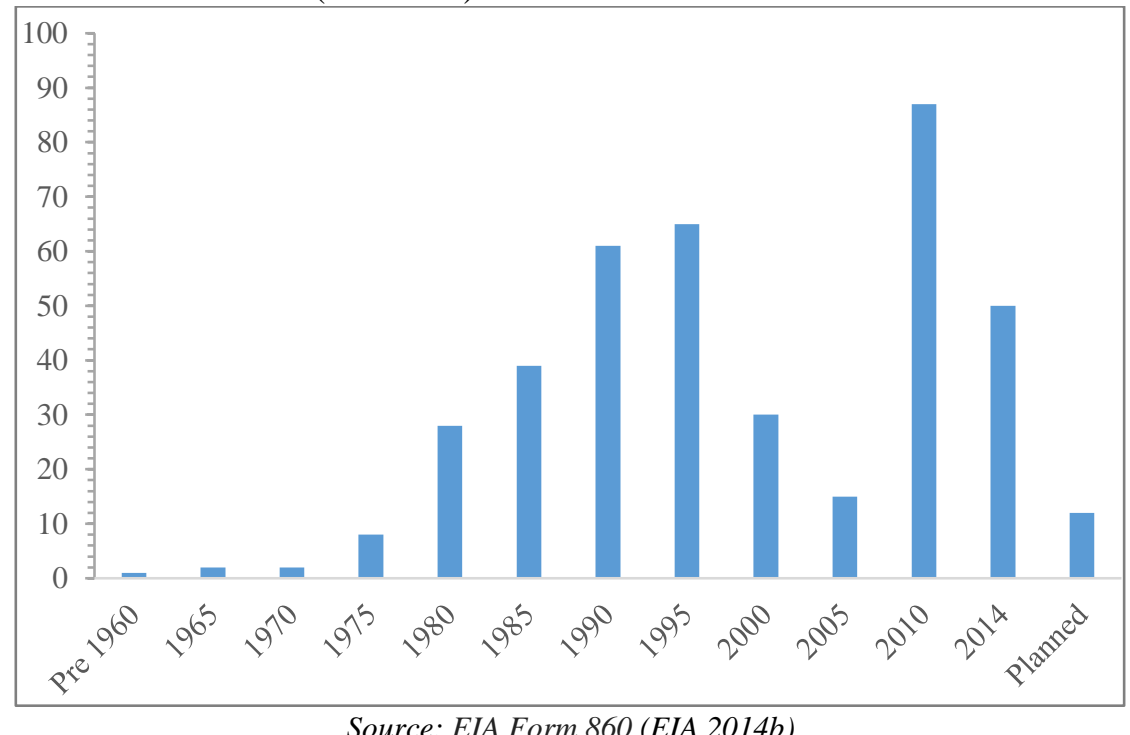

Scrubber installation as an alternative to fuel-switching has faced increasing market headwinds over the past 30 years. Productivity increases in low-sulfur coal mines, most obviously in the Powder River Basin (PRB) of Wyoming, encouraged fuel switching by driving down the price of low-sulfur coal. Carlson et al. (2000) provide evidence that these changes, plus technological advances in equipment and methods for 
burning low-sulfur coals, halved marginal abatement costs from fuel-switching between 1985 and 2000 . Technological improvements and deregulation in the rail transport system have also favored fuelswitching over scrubber installation, as documented by Schmalansee and Stavins (2013) and Ellerman and Montero (1998), among others. Busse and Keohane (2007) provide evidence that railroads used monopoly power to capture some of the rents created from increased PRB coal mining productivity over this period. Gerking and Hamilton (2009) provide evidence that railroads are strategic price discriminators, implying that, despite railroad monopoly power, PRB coal reaches about as wide a geographic area as it would in a fully competitive rail market.

This literature on fuel-switching in coal-fired power plants has until now focused on the interregional substitution of low-sulfur Western coal for Eastern coals of higher sulfur content. But Illinois and especially Appalachian coals exhibit considerable intra-regional variation in sulfur content as well, and the differential effects of $\mathrm{SO}_{2}$ regulations on these various subregions within the Eastern coalfields is much less well studied. Hoag (1995) used state-level data and a simple regression model to examine impacts of 1970 and 1977 legislation on Eastern coal production, with some emphasis on the sulfurcontent question. Hoag and Reed (2002) performed time-series regressions on quarterly aggregated county-level employment data to find significant negative impacts of the 1977 legislation on coal mining in West Kentucky, but not East Kentucky. The current paper contributes to this literature by using countylevel panel data to quantify local variation in coal production associated with air quality policy changes, taking into account the sulfur content of coal deposits, the distance between mines and power plants, and the use of scrubbers.

\section{Data}

Historical coal mine production data (1983-2012) are available from the Energy Information Administration's coal production database (US EIA 2014a). We collected detailed mine-level data from states in the Appalachian (Pennsylvania, West Virginia, Ohio, eastern Kentucky, Maryland, Tennessee, Georgia) and Illinois (Illinois, Indiana, western Kentucky) basins, creating a 30 year panel for 188 counties. Because the individual mines in our data set produced for an average of only 4.82 years each, we aggregated our data to the county level. Sulfur (percent by weight) and heat content (mmBtu/ton) data come from the USGS Coal Quality database, which contains over 13,000 bore-hole samples of coal and associated rocks (Bragg et al, 1998). Using ArcGIS Kriging, we interpolated a raster from these borehole points. ArcGIS's 'Extract Values to Points' tool produces county-level estimates of average sulfur content ${ }^{4}$. The geographical distribution of sulfur content in the Appalachian and Illinois coalfields is

$4 \quad$ This method presents two main limitations: within-county and between-year variation is missed. For example, the average sulfur content a county with two mines will change if one of them closes. However the within- 
shown in figure 3. Higher sulfur content is generally found in coals throughout the Illinois Basin and Ohio, along the Ohio River, and to a somewhat lesser extent in parts of Pennsylvania, northern West Virginia, Tennessee, and Alabama. To control for differences in the costs of production between counties, we use data from FERC form $423^{5}$ and EIA Form 923 to construct a relative ratio of average costs between each individual county and the Powder River Basin.

Figure 3: Appalachian and Illinois Basin Coal Sulfur Content

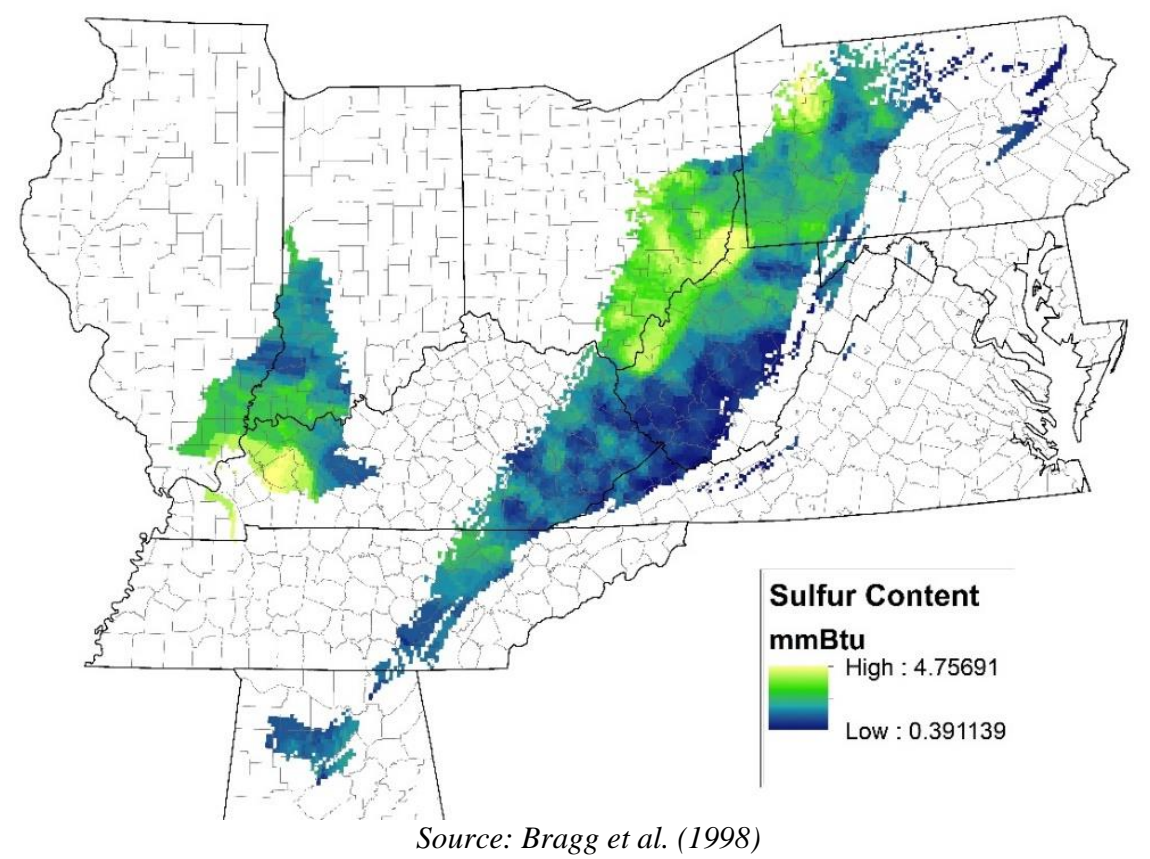

We distinguish four time periods in our analysis: Pre-Regulation ${ }^{6}$ (1983-1994), Phase 1 (1995-1999), Phase 2 (2000-2008), and the 'Post-2008' period (2009-2012). The exact timing of these regulations is known, however it is less clear when plants began to adjust to them. An examination of the exact timing of the regulatory periods is discussed below in section 4.3. Coal prices come from the EIA's database of historical coal prices, displayed in 2005 dollars. We use average bituminous and sub-bituminous coal (free-on-board) prices to capture the relative prices between the Eastern and Western coals. Natural gas price data come from US Bureau of Labor Statistics' Producer Price Index (PPI), which denotes the price of natural gas paid by producers. The PPI is used instead of other natural gas prices such as Henry Hub

county variation in quite small. The average coefficient of variation is below $.05 \mathrm{mmBtu}$, while sample area county averages vary between $.48-4.63 \mathrm{mmBtu}$. This suggests that between-year variation, even with a significant number of mine closures, is likely low, especially relative to county average distribution.

$5 \quad$ Collected by the EIA, available: https://www.eia.gov/electricity/data/eia423/

6 There were clean-air regulations in place prior to 1995, but these lacked the focus on sulfur emissions of the EPA's Acid Rain Program, Phase I of which began in 1995. 
because it is a national index of all U.S. regional natural gas prices, it has a longer history than other

prices, and because it does not need to be deflated. The price of $\mathrm{SO}_{2}$ emissions permits come from the annual EPA allowance auction results (US EPA 2014).

\subsection{Megawatt Demand and Geographic Distance}

Demand for coal is influenced by the geographic distance between the purchasing plant and the producing mine as well as the capacity of the purchasing plant. Transportation costs increase with distance, so other things equal, a plant will demand more coal from nearby mines.

The EIA (Form 923, Schedule 2) publishes mine-plant contract information (US EIA 2014c), including specific tonnage, heat content, ash content, and sulfur content for each contract. In the Illinois and Appalachian basins, mines generally have multiple contracts with a single plant, with varying coal characteristics. From 2008-2013, 16\% of mines sold to only one plant. On average, each mine served 16 power plants, though the distribution of this variable is highly skewed, and a few mines served more than 100 plants. About $89 \%$ of the Eastern coal mines serving any given plant are located within 350 miles of that plant. Prior to 2008, FERC form 423 provides similarly descriptive contract information.

Each mine faces a demand curve determined by the geographic proximity of coal-fired power plants and the demand for electricity production from those plants. We therefore constructed a county-specific coal demand variable that takes both power plant capacity and distance into account. We calculated the rail distance from every regional coal-fired power plant to every regional coal-producing county. In counties where the location of the mines is unknown, we calculated distances from the county's geographic center. In counties where mine location is known, we used a mean-center calculation based on existing mine locations within the county.

In describing demand from an individual power plant, we had the choice of using its energy production measured in megawatt-hours (MWh), or potential energy production based on megawatts (MW) of nameplate capacity. We chose not to use the former measure because of the endogenous nature of energy production. However, a large, new, and efficient plant is more likely to be dispatched than an older, smaller, and less efficient one, and hence will demand more coal. We use each boiler's characteristics to generate a predicted capacity factor for each boiler. In our sample time period and area, there were 182 coal plants, with a total of 517 boilers. A total of 10248 contracts from coal plants within the study area are available from FERC Form 423 and EIA Form 923 between 1983 and 2012. 
Table 1: Capacity Factor Summary Statistics

\begin{tabular}{lccccc}
\multicolumn{1}{c}{ Variable } & N & Mean & StDev & Min & Max \\
\hline CapFac & 10248 & 0.5195285 & 0.1971746 & 0.114469 & 0.9561644 \\
NPC & 10248 & 313.8606 & 287.2837 & 0.7 & 1425.6 \\
Age & 10248 & 46.754 & 13.09477 & 1 & 87 \\
NSR5 & 10248 & 0.0070258 & 0.0835289 & 0 & 1 \\
NSR10 & 10248 & 0.0040984 & 0.0638902 & 0 & 1 \\
NSR15 & 10248 & 0.0039032 & 0.0623566 & 0 & 1 \\
NSRBig & 10248 & 0.0133685 & 0.1148522 & 0 & 1 \\
SERC2005 & 10248 & 0.132904 & 0.3394875 & 0 & 1 \\
RFC2005 & 10248 & 0.2056987 & 0.404231 & 0 & 1 \\
SERC2004 & 10248 & 0.153103 & 0.3601044 & 0 & 1 \\
ECAR2004 & 10248 & 0.3393833 & 0.4735231 & 0 & 1 \\
MAAC2004 & 10248 & 0.1039227 & 0.3051752 & 0 & 1 \\
MAIN2004 & 10248 & 0.0201991 & 0.1406876 & 0 & 1 \\
Bitum & 10248 & 0.850605 & 0.3564948 & 0 & 1 \\
SubBit & 10248 & 0.1258782 & 0.3317283 & 0 & 1 \\
RPxSERC2005 & 10248 & 0.5305945 & 1.358374 & 0 & 4.3155 \\
RPxRFC2005 & 10248 & 0.8215551 & 1.618396 & 0 & 4.3155 \\
RPxMAAC2004 & 10248 & 0.3201805 & 0.9530813 & 0 & 3.802721 \\
RPxMAIN2004 & 10248 & 0.0740541 & 0.5161361 & 0 & 3.802721 \\
RPxSERC2004 & 10248 & 0.4760105 & 1.135545 & 0 & 3.802721
\end{tabular}

We regress capacity factor by regressing its capacity factor (MWh produced / nameplate capacity) on its age, nameplate capacity, relative price of coal (average bituminous /sub-bituminous price in the given year), fuel type, federal NERC region, and binary variables indicating time since a New Source Review (NSR):

$$
C F_{i, t}=\beta_{0}+\beta_{1} A_{i, t}+\beta_{2} C_{i}+\beta_{3} N S R_{i, t}+\beta_{4} N c_{i, t}+\beta_{5} C T_{i, t}+\beta_{6}\left(R P_{t} * N c_{i}\right)+\varepsilon_{i, t}
$$

Where:

$C F_{i, t}=$ Boiler $i$ 's Capacity Factor at time $t$

$A_{i, t}=$ Boiler $i$ 's Age at time $t$

$C_{i}=$ Boiler $i$ 's Nameplate Capacity

$N S R_{i, t}=$ An nx4 matrix indicating whether boiler $i$ had a NSR within 5, 10,15, and more years at time $t$ $N c_{i, t}=$ a nx 5 matrix of federal National Energy Regulatory Commission (NERC) regions (time variant as in 2006 the geographic boundaries of eastern NERC regions changed)

$C T_{i, t}=$ the type of coal being burned (bituminous, sub-bituminous, or waste-coal) at boiler $i$ at time $t$ $R P_{t}=$ the relative price of bituminous and sub-bituminous coal

Results from this regression are displayed in table $3^{7}$. Using these coefficients, we generated each boiler's predicted capacity factor from these and each boiler's specific characteristics in each time period.

Multiplying this predicted capacity factor by the boiler's nameplate capacity generates each boiler's 'weighted capacity'.

\footnotetext{
${ }^{7}$ An alternative specification, using policy dummies for policy years rather than individual year dummies produces nearly identical results
} 
We use the weighted capacity to gauge the importance of scrubbers in determining a plant's demand for higher-sulfur coal. Here we developed two separate demand variables, one for scrubbed and a separate one for non-scrubbed capacity, using the following equation:

$$
\text { MW Demand }_{j t s}=\sum_{i=1}^{N} \text { WeightedCapacity }_{i t s} / \text { Raildistance }_{i}
$$

The weighted capacity generated from each boiler in county $j$ divided by its Raildistance, the distance between generation unit and mine county along existing rail networks ${ }^{8}$. These are summed for each county. We do this twice: One for all boilers, and the other for only boilers that have scrubbers installed, creating Total and Scrubbered MW Demand variables.

In a regression on county coal production, the expected sign of a county's MW Demand coefficient is positive: both increasing capacity and decreasing transport distance should increase the marketability of the produced coal. Table 2 displays summary statistics for variables used in the estimation.

Table 2: Capacity Factor Regression Results

\begin{tabular}{|c|c|c|c|}
\hline \multicolumn{4}{|c|}{ Dependent Variable: Boiler Capaciticy Factor } \\
\hline Independent Variables & Yearly Fixed Effects & Independent Variables & Yearly Fixed Effects \\
\hline NamePlateCap & $\begin{array}{l}0.000165 * * * \\
(7.08 \mathrm{e}-06)\end{array}$ & MAAC2004 & $\begin{array}{c}-0.252 * * \\
(0.123)\end{array}$ \\
\hline Age & $\begin{array}{c}-0.000630 * * * \\
(0.000161)\end{array}$ & MAIN2004 & $\begin{array}{c}-0.337 * * \\
(0.134)\end{array}$ \\
\hline NSR5 & $\begin{array}{c}0.0732 * * * \\
(0.0207)\end{array}$ & Bitum & $\begin{array}{c}-0.225^{* * *} \\
(0.0124)\end{array}$ \\
\hline NSR10 & $\begin{array}{c}0.0333 \\
(0.0269)\end{array}$ & Sub-Bitum & $\begin{array}{c}-0.168 * * * \\
(0.0133)\end{array}$ \\
\hline NSR15 & $\begin{array}{c}-0.134 * * * \\
(0.0277)\end{array}$ & RPxSERC2005 & $\begin{array}{c}0.0140 * * * \\
(0.00250)\end{array}$ \\
\hline NSRBig & $\begin{array}{c}-0.125^{* * *} \\
(0.0156)\end{array}$ & RPxRFC2005 & $\begin{array}{c}0.0118 * * * \\
(0.00238)\end{array}$ \\
\hline SERC2005 & $\begin{array}{l}-0.00546 \\
(0.0234)\end{array}$ & RPxMAAC2004 & $\begin{array}{l}-0.0111^{* * *} \\
(0.00190)\end{array}$ \\
\hline RFC2005 & $\begin{array}{c}-0.0896^{* * *} \\
(0.0223)\end{array}$ & RPxMAIN2004 & $\begin{array}{l}-0.00947 * \\
(0.00571)\end{array}$ \\
\hline SERC2004 & $\begin{array}{c}-0.341 * * * \\
(0.123)\end{array}$ & RPxSERC2004 & $\begin{array}{l}0.00901 * * * \\
(0.00161)\end{array}$ \\
\hline ECAR2004 & $\begin{array}{c}-0.326 * * * \\
(0.122)\end{array}$ & Constant & $\begin{array}{l}0.890 * * * \\
(0.0759)\end{array}$ \\
\hline \multicolumn{2}{|c|}{ Observations } & \multicolumn{2}{|c|}{10,248} \\
\hline \multicolumn{2}{|c|}{ Number of Years } & \multicolumn{2}{|c|}{30} \\
\hline \multicolumn{2}{|c|}{ R-squared } & \multicolumn{2}{|c|}{0.151} \\
\hline \multicolumn{4}{|c|}{$\begin{array}{l}\text { Standard errors in parentheses } \\
* * * \mathrm{p}<0.01, * * \mathrm{p}<0.05, * \mathrm{p}<0.1\end{array}$} \\
\hline
\end{tabular}

\section{Empirical Model}

With mine production aggregated to the county level, $18 \%$ of the county-years in this study had no production. Because the decision to produce and the quantity of production are related, we employ a twostage Heckman sample selection model. Summary statistics are displayed in table 3.

\footnotetext{
${ }^{8}$ Calculated using ArcGIS
} 
Table 3: Full Model Summary Statistics

\begin{tabular}{lccccc}
\multicolumn{1}{c}{ Variable } & N & Mean & StDev & Min & Max \\
\hline Total Coal Production (short Tons) & 5640 & 2736747 & 4824727 & 0 & $4.27 \mathrm{E}+07$ \\
ln(Total Coal Production) & 4610 & 13.6961 & 2.069643 & 3.401197 & 17.56971 \\
ARP Phase I & 5640 & 0.1666667 & 0.372711 & 0 & 1 \\
ARP Phase II & 5640 & 0.3 & 0.4582982 & 0 & 1 \\
Post 2008 & 5640 & 0.1333333 & 0.3399648 & 0 & 1 \\
Sulfur Content & 5640 & 1.7765 & 0.9172763 & 0.4781538 & 4.628617 \\
Total MWD & 5640 & 379.2342 & 134.8486 & 0 & 934.1699 \\
Scrubbered MWD & 5640 & 92.80156 & 63.59492 & 0 & 534.7488 \\
Relative Production Costs & 5640 & 1.182559 & 0.3841866 & 0.3692269 & 4.40113 \\
Total PRB Production & 30 & 315.7501 & 120.8213 & 122.4655 & 495.9642 \\
ln(Total PRB Production) & 30 & 5.669785 & 0.4294673 & 4.807829 & 6.206504 \\
Natural Gas / Coal Price & 30 & 5.596567 & 3.625301 & 2.233773 & 14.21612
\end{tabular}

\subsection{First Stage Probit}

The first stage of the Heckman selection model uses a probit regression to estimate the probability $p_{i t}$ that a county's coal mines produce in a given year. The probit regressors include the county's sulfur content interacted with the policy time period, total MW/distance for both scrubbed and non-scrubbed plants, and total PRB production. Because natural gas can be used as a substitute for coal in electricity production, the relative price ratio of natural gas to the yearly average of national bituminous coal prices is also included.

Table 4: First Stage Probit Results

Dependent Variable: Producer (1/0)

\begin{tabular}{|c|c|c|c|}
\hline Independent Variables & Probit & Independent Variables & Probit \\
\hline ARP Phase I & $\begin{array}{l}-0.111 \\
(0.220)\end{array}$ & Scrub MWD & $\begin{array}{c}0.00384 * * * \\
(0.00116)\end{array}$ \\
\hline ARP Phase II & $\begin{array}{c}0.393 \\
(0.273)\end{array}$ & Total MWD & $\begin{array}{c}4.52 \mathrm{e}-05 \\
(0.000861)\end{array}$ \\
\hline Post 2008 & $\begin{array}{c}0.825^{* *} \\
(0.323)\end{array}$ & Natural Gas / Coal Price & $\begin{array}{c}0.0328 \\
(0.0371)\end{array}$ \\
\hline SO $2 \times$ Phase I & $\begin{array}{c}-0.270^{* * *} \\
(0.104)\end{array}$ & $\ln$ (Total PRB Production) & $\begin{array}{l}0.000641 \\
(0.00196)\end{array}$ \\
\hline SO2 x Phase II & $\begin{array}{c}-0.567 * * * \\
(0.0936)\end{array}$ & SO2 Content & $\begin{array}{c}0.277 \\
(0.172)\end{array}$ \\
\hline SO 2 x Post 2008 & $\begin{array}{c}-0.612 * * * \\
(0.112)\end{array}$ & Year & $\begin{array}{c}-0.0832 * * * \\
(0.0262)\end{array}$ \\
\hline Relative Production Costs & $\begin{array}{c}-0.263^{* *} \\
(0.106)\end{array}$ & Constant & $\begin{array}{c}167.6 * * * \\
(51.87)\end{array}$ \\
\hline $\begin{array}{c}\text { Observations } \\
\mathrm{N}\end{array}$ & & $\begin{array}{c}5,640 \\
188\end{array}$ & \\
\hline & $\begin{array}{l}\text { Standard er } \\
* * * p<0.01 \text {, }\end{array}$ & $\begin{array}{l}\text { in parentheses } \\
<0.05, * \mathrm{p}<0.1\end{array}$ & \\
\hline
\end{tabular}

Results shown in Table 3 indicate strong relationship between the probability of mine shutdowns and sulfur content. To illustrate, if all other variables are held at mean levels, a one standard deviation increase of sulfur content reduces the probability of producing in the Post-2008 period by an estimated 
14\%. The negative and significant coefficient on PRB production is consistent with fuel-switching from Eastern to Western coals. The significant and positive coefficient on the scrubbed MW Demand variable indicates that scrubbers in coal plant boilers may have reduced the incidence of mine closures, as was intended by the state legislators and regulators who formulated policies to encourage scrubber installation.

\subsection{Estimation of Coal Demand}

In the second stage of the Heckman selection model, we regressed the log of coal production in county $i$ and year $t$ on policy variables, our measure of distance-attenuated megawatt demand, price, and the inverse Mills ratio generated from the probit estimation. These relationships are modeled as:

$$
\begin{aligned}
& \ln \left(y_{i t}\right)=\beta_{0}+\beta_{1}\left(P 1_{t}\right)+\beta_{2}\left(P 2_{t}\right)+\beta_{3}\left(P C_{t}\right)+\beta_{4}\left(S C_{i} * P 1_{t}\right)+\beta_{5}\left(S C_{i} * P 2_{t}\right)+ \\
& \beta_{6}\left(S C_{i} * P C_{t}\right)+\beta_{7}\left(T M W D_{i t}\right)+\beta_{8}\left(S C_{i} * S M W D_{i t} * P 1_{t}\right)+\beta_{9}\left(S C_{i} * S M W D_{i t} * P 2_{t}\right)+ \\
& \beta_{10}\left(S C_{i} * S M W D_{i t} * P C_{t}\right)+\beta_{11}\left(\ln \left(T P R B_{t}\right)\right)+\beta_{12}\left(R P C_{i, t}\right)+\beta_{13}\left(R P r_{t}\right)+\beta_{14}\left(Y r_{t}\right)+ \\
& \beta_{15}\left(I M R_{i, t}\right)+u_{i, t}
\end{aligned}
$$

where

$y_{i t} \quad$ Logged production in tons of mine county $i$ in year $t$

$S C_{i} \quad$ Sulfur content (lbs/mmBtu) at mine county $i$

$P 1_{t} \quad$ Binary variable, 1 when ARP Phase 1 was in place (1995-1999), zero otherwise

$P 2_{t} \quad$ Binary variable, 1 when ARP Phase 2 was in place (2000-2008), zero otherwise

$P C_{t} \quad$ Binary variable, 1 after the 2008 US Circuit Court ruling (2009-2012), zero otherwise

TMWD $\quad$ Total MW Demand in year $t$ / Miles from mine county $i$

$S M W D_{i t} \quad$ Total FGD-installed MW Demand in year $t /$ Miles from mine county $i$

$\ln \left(\operatorname{Tot}_{P} R B_{t}\right) \quad$ Logged total PRB coal production

$R P C_{i, t} \quad$ Relative production costs between county $i$ and the PRB in year $t$

$R P r_{t} \quad$ Natural gas/coal price ratio in year $t$

$\mathrm{Yr}_{t} \quad$ Yearly trend

$I M R_{i, t} \quad$ Inverse Mills Ratio for county $i$ in year $t$

Regression results reported in table 4 show statistically significant relationships of the expected signs between coal production and all but one of the explanatory variables. ${ }^{9}$ The coefficient on Powder River Basin production is both negative and significant, indicating a nearly one-for-one substitution of PRB production for study-area coal production. The inverse Mills ratio coefficient is positive and significant, indicating the expected positive relationship between mine activity and output. Perhaps surprisingly, the addition of county-level fixed effects causes very little change in coefficients of any variables except distance-adjusted MW Demand. This result suggests that our MW-Demand variable is effective in capturing relevant county-specific effects. The lack of significance of the MW-Demand variable in the

$9 \quad$ An alternative specification using a Tobit model produced qualitatively similar results 
fixed-effects results may simply reflect the tendency for power plants to be located near the coalfields, a tendency that is largely captured by the county fixed effects.

Table 5: Full Model Regression Results

\begin{tabular}{|c|c|c|}
\hline Independent Variables & County Fixed Effects & Random Effects \\
\hline \multirow[t]{2}{*}{ ARP Phase I } & 0.0816 & 0.109 \\
\hline & $(0.127)$ & $(0.128)$ \\
\hline \multirow[t]{2}{*}{ ARP Phase II } & $0.444 * * *$ & $0.504 * * *$ \\
\hline & $(0.157)$ & $(0.156)$ \\
\hline \multirow[t]{2}{*}{ Post 2008} & 0.198 & 0.327 \\
\hline & $(0.218)$ & $(0.213)$ \\
\hline \multirow[t]{2}{*}{ SO2 $x$ Phase I } & $-0.442 * * *$ & $-0.441 * * *$ \\
\hline & $(0.100)$ & $(0.101)$ \\
\hline \multirow[t]{2}{*}{ SO2 x Phase II } & $-0.544 * * *$ & $-0.577 * * *$ \\
\hline & $(0.0986)$ & $(0.0978)$ \\
\hline \multirow[t]{2}{*}{ SO 2 x Post 2008} & $-0.304 * *$ & $-0.347 * *$ \\
\hline & $(0.154)$ & $(0.152)$ \\
\hline \multirow[t]{2}{*}{ Total MWD } & 0.00116 & $0.00256^{* * *}$ \\
\hline & $(0.000868)$ & $(0.000626)$ \\
\hline \multirow[t]{2}{*}{ SO2 x Phase I x ScrubMWD } & $0.00289 * * *$ & $0.00279^{* * *}$ \\
\hline & $(0.000552)$ & $(0.000557)$ \\
\hline \multirow[t]{2}{*}{ SO2 x Phase II x ScrubMWD } & $0.00203 * * *$ & $0.00213^{* * *}$ \\
\hline & $(0.000391)$ & $(0.000389)$ \\
\hline \multirow{2}{*}{ SO2 x Post 2008 x ScrubMWD } & $0.000832 *$ & $0.00105 * *$ \\
\hline & $(0.000475)$ & $(0.000456)$ \\
\hline \multirow[t]{2}{*}{$\ln$ (Total PRB Production) } & $-1.390 * * *$ & $-1.715 * * *$ \\
\hline & $(0.415)$ & $(0.388)$ \\
\hline \multirow[t]{2}{*}{ Relative Production Costs } & $-0.434 * * *$ & $-0.395 * * *$ \\
\hline & $(0.0774)$ & $(0.0766)$ \\
\hline \multirow[t]{2}{*}{ Natural Gas / Coal Price } & 0.0284 & $0.0389 *$ \\
\hline & $(0.0212)$ & $(0.0208)$ \\
\hline \multirow[t]{2}{*}{ Year } & $1.855^{* * *}$ & $1.992 * * *$ \\
\hline & $(0.594)$ & $(0.590)$ \\
\hline \multirow[t]{2}{*}{ Inverse Mills Ratio } & $1.855^{* * *}$ & $1.992 * * *$ \\
\hline & $(0.594)$ & $(0.590)$ \\
\hline \multirow[t]{2}{*}{ Constant } & -35.21 & -55.22 \\
\hline & $(40.28)$ & $(39.55)$ \\
\hline Observations & 4,610 & 4,610 \\
\hline Number of fips & 188 & 188 \\
\hline R-squared & 0.088 & 0.087 \\
\hline
\end{tabular}

Although the three policy period binary variables have positive and significant coefficients, interacting sulfur content with the policy variables yields negative and significant coefficients, so the estimated net effect of sulfur regulations on coal production was negative for most counties for most regulatory time periods, as shown in figure 4 . Colors in figure 4 correspond to the value $\beta_{1}\left(P 1_{t}\right)+\beta_{2}\left(P 2_{t}\right)+$ $\beta_{3}\left(P C_{t}\right)+\beta_{4}\left(S C_{i} * P 1_{t}\right)+\beta_{5}\left(S C_{i} * P 2_{t}\right)+\beta_{6}\left(S C_{i} * P C_{t}\right)$, a log difference expressed as a percentage. 
This number may be interpreted as a "pure sulfur regulation effect," net of the effects of both scrubber installation and Powder River Basin coal production. In Phase $1(P 1=1, P 2=P C=0)$, all 188 coalproducing counties show an estimated decrease in coal production associated with the policy change. The estimated effect on coal production is negative in Phase $2(P 2=1, P 1=P C=0)$ for the 168 counties $(89 \%)$ whose coals contain at least $0.78 \mathrm{lbs} / \mathrm{mmBtu}$ of sulfur; in the Post-2008 period $(P C=1)$ the 176 counties (94\%) whose coals contain more than $0.67 \mathrm{lbs} / \mathrm{mmBtu}$ are estimated to have lost production as a consequence of the regulations. The biggest "losers" from regulations in each case are concentrated along the Ohio River and in the Illinois Basin, while the "winners" are in southeastern West Virginia, western Virginia, and eastern Pennsylvania.

Figure 4: Estimated Effects of Clean Air Act Policy on Coal Production
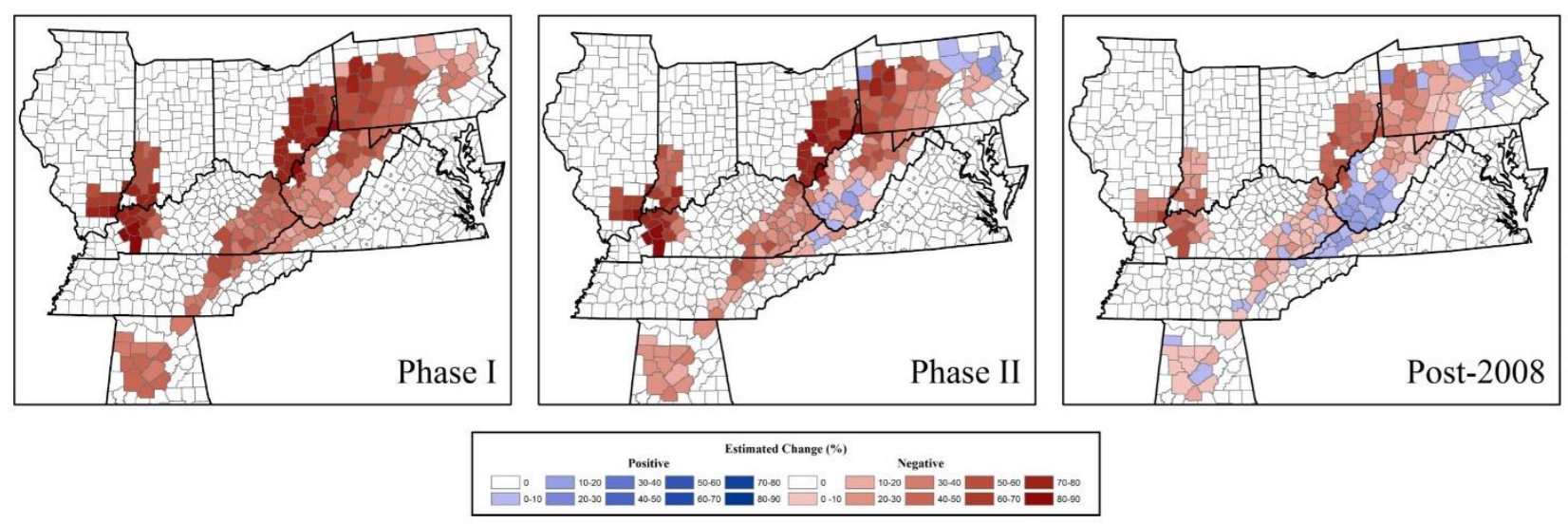

The installation of scrubbers in coal plants is also associated with increases in high-sulfur coal production, as indicated by the positive and significant coefficient on the interaction variable of scrubbed capacity, regulatory regime, and sulfur content. Thus, the higher the sulfur content in a county's coals, the larger the effect of scrubbed capacity on coal production, and the more scrubbed capacity in a mine's neighborhood, the greater the marginal ameliorative effect on its high-sulfur coal production loss. The magnitude of the scrubber effect is largest in Phase 1, when only the highest emitters were regulated and the technology of fuel-switching was less well-developed. The geographic impact of scrubbers is illustrated in figure 5, in which the shading indicates the value $\beta_{8}\left(S C_{i} * S c b M W D_{i t} * P 1_{t}\right)$ for Phase I, $\beta_{9}\left(S C_{i} * S c b M W D_{i t} * P 2_{t}\right)$ for Phase II, and $\beta_{10}\left(S C_{i} * S c b M W D_{i t} * P C_{t}\right)$ for the Post-2008 era, with the $\log$ difference expressed as a percentage. Effects are large, and are near 100\% in the Ohio River Valley, where coals tend to be high in sulfur content and both the number and size of installed scrubber units are high. 
Figure 5: Estimated Percentage Increase of Coal Production Due to Scrubbers
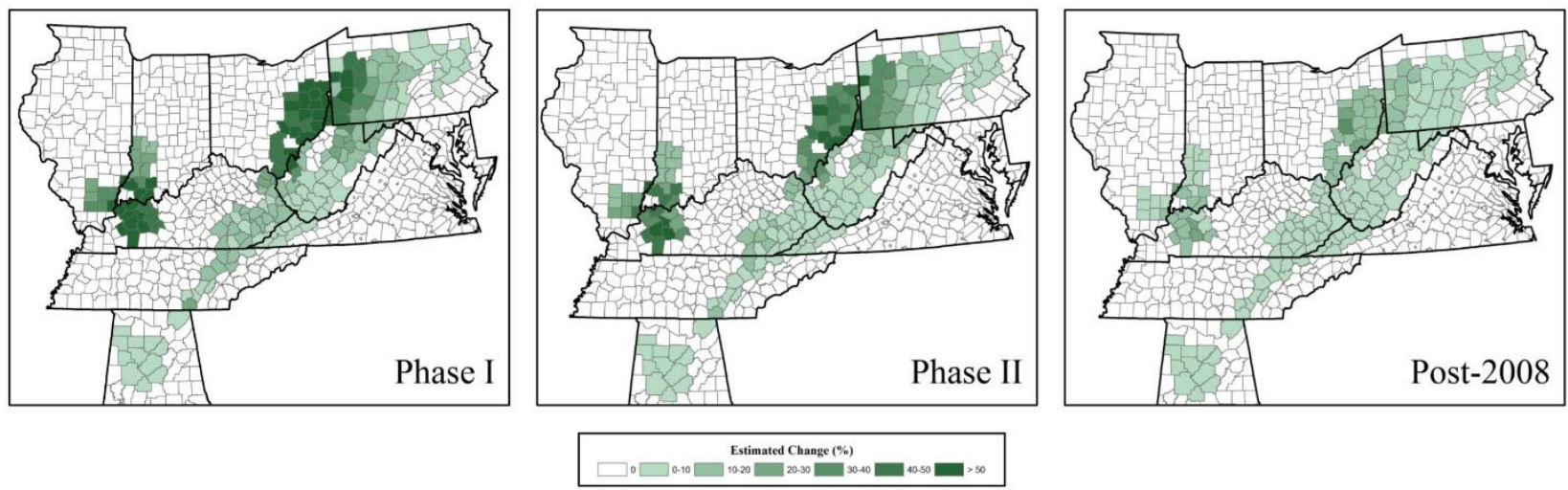

Figure 6 combines the two effects shown in figures 4 and 5, and colors correspond to values of $\beta_{1}\left(P 1_{t}\right)+\beta_{2}\left(P 2_{t}\right)+\beta_{3}\left(P C_{t}\right)+\beta_{4}\left(S C_{i} * P 1_{t}\right)+\beta_{5}\left(S C_{i} * P 2_{t}\right)+\beta_{6}\left(S C_{i} * P C_{t}\right)+\beta_{7}\left(\right.$ Tot $\left.M W D_{i t}\right)+$ $\beta_{8}\left(S C_{i} * S c b M W D_{i t} * P 1_{t}\right)+\beta_{9}\left(S C_{i} * S c b M W D_{i t} * P 2_{t}\right)+\beta_{10}\left(S C_{i} * S c b M W D_{i t} * P C_{t}\right)$, again expressed as a percentage change. Overall, compared to the "pure sulfur effects" shown in figure 4, the introduction of scrubbers increases production in all counties, particularly for Phase 1, and for counties in Ohio, western Kentucky, and Alabama. These effects are less pronounced for of regulation.

Figure 6: Estimated Overall Effects of CAA Policy and Scrubbers on Coal Production
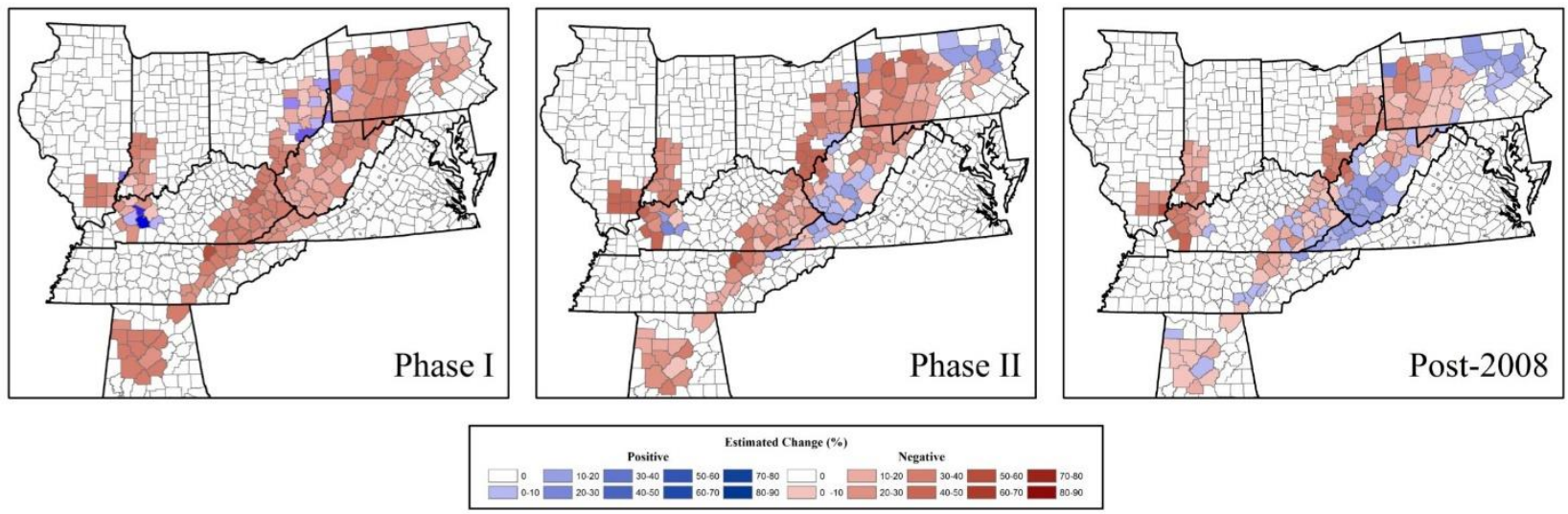

\subsection{Regulation Year Specification}

Our assignment of policy years aligns with when the given policies were enacted, but knowledge of these policies was widespread prior to their implementation. While it is possible that some plants adjusted to the new policy regimes immediately upon their implementation, it is likely that some began their mitigating strategies, buying emissions permits, changing fuel sources or installing scrubber units on boilers, before the regulation was in place. Given the uncertainty that was present surrounding the development and modifications of the ARP, this seems likely even if it cost the plant more in the short- 
run. If this is the case, then the assignment of policy years directly on their implementation would not capture the entirety of the policy period's effect. We therefore test this effect by changing the years associated with each policy period forwards and backwards three years each ${ }^{10}$. Results are qualitatively similar for lagged models (moving the starting date back), however the original model produces the lowest AIC and BIC values. Similarly we modify just the initial policy period's timing, and find the most preferable model starting in 1995.

We also test the model for the existence of a prior trend in our dependent variable. An omitted variable causing the parameter to change could potentially create problems of the identification of our policy variables. We estimate the model in equation (3) with all cross-sectionally invariant variables removed but year and sulfur-year interaction variables $\left(\mathrm{SO}_{2} *\right.$ year) added. A graph of the added coefficients and their $95 \%$ confidence intervals are displayed in figure 7: the yellow line represents the path of Eastern lower-sulfur coal relative to the baseline (1983), and the blue line represents the year-sulfur interaction terms. These can be interpreted as the deviation of higher-sulfur coal from the path of lower-sulfur coal, again relative to the base year. The influence of PRB is clearly shown in the yellow line, where the sharpest decreases occur in years where the PRB have the largest increases. The interacted year and $\mathrm{SO}_{2}$ variables are never significantly different relative to 1983 levels. Together, these suggest that no prior trend was present in the market that would potentially drive results other than the policy changes.

Figure 7: Year and Year*SO2 Coefficients, with 95\% Confidence Intervals

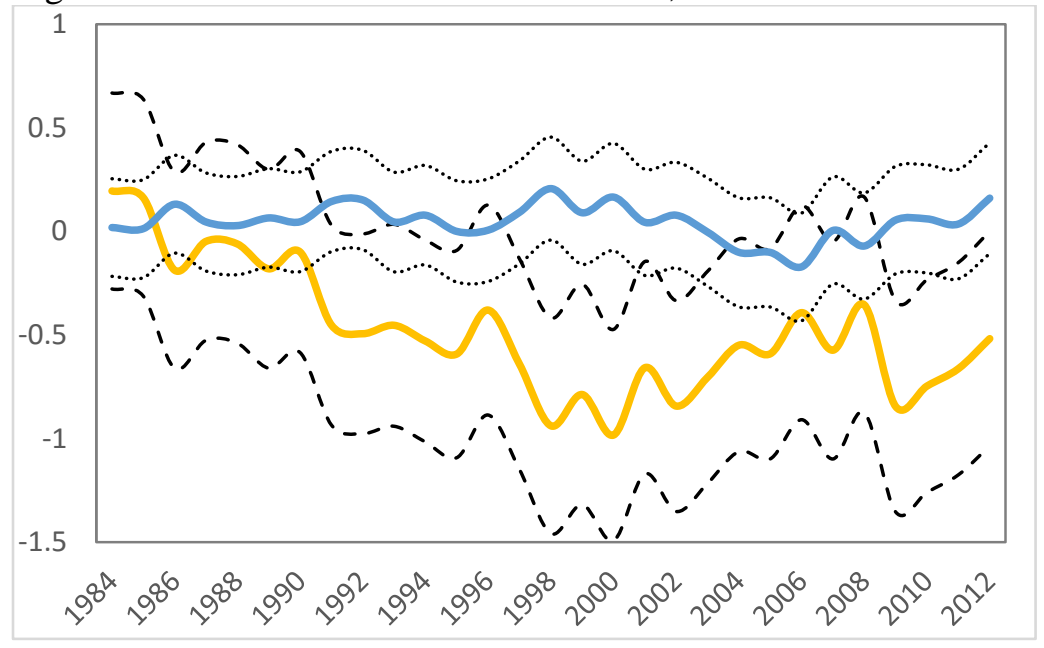

\section{Sulfur Price Elasticity}

We also examine the relationship between allowance permit pricing and coal production. Twenty years' worth of allowance trading data (1993-2012) are available; however, we examine effects only in the years

\footnotetext{
${ }^{10}$ For example: Modeling ARP Phase I as spanning from 1994-1998 and Phase II 1999-2007 etc.
} 
1993-2008, as allowance availability became a non-binding constraint on power plant operations after 2008. To measure the sulfur price elasticity of coal production, we regress logged production values on allowance prices and relevant policy and other control variables, including county fixed effects.

$$
\begin{aligned}
& \ln \left(y_{i t}\right)=\beta_{0}+\beta_{1}\left(\ln \left(A P_{t}\right)\right)+\beta_{2}\left(S C_{i} * \ln \left(A P_{t}\right)\right)+\beta_{3}\left(P 1_{t}\right)+\beta_{4}\left(P 2_{t}\right)+ \\
& \beta_{5}\left(S C_{i} * P 1_{t}\right)+\beta_{6}\left(S C_{i} * P 2_{t}\right)+\beta_{7}\left(\text { TotMW }_{i t}\right)+\beta_{8}\left(S C_{i} * S c b M W D_{i t} * P 1_{t}\right)+ \\
& \beta_{9}\left(S C_{i} * S c b M W D_{i t} * P 2_{t}\right)+\beta_{10}\left(\text { PriceRatio }_{t}\right)+\beta_{11}\left(\ln \left(T P R B_{t}\right)\right)+\beta_{12}\left(R P C_{i, t}\right)+ \\
& \beta_{13}\left(R P r_{t}\right)+\beta_{14}\left(Y r_{t}\right)+u_{i, t}
\end{aligned}
$$

where $A P_{t}$ is the Sulfur Allowance Price in year $t$ and other variables are as defined above.

Fixed-effects regression results are presented in table 5, along with pooled-OLS results for comparison. During the modeled years of sulfur permit trading (1993-2008), the elasticity should depend on the sulfur content of the county's coals. The allowance price coefficient $\beta_{1}$ may be interpreted as the sulfur allowance price elasticity of production for coals with zero sulfur content. Its positive coefficient suggests that allowances and low-sulfur coal are substitutes. The estimated coefficient $\beta_{2}$ is negative for the interaction-term between sulfur content and allowance price, indicating that the elasticity of substitution between low-sulfur coal and allowance permits declines with increasing sulfur content; that is, that coal sulfur content and $\mathrm{SO}_{2}$ allowance permits are complements. Using results from the county-level fixed effects model, the overall allowance-price elasticity of coal production is negative for the 90 of 188 (47\%) counties whose coals contain more than $1.5 \mathrm{lb} / \mathrm{mmBtu}$ of sulfur. Within our data set, the allowance price elasticity estimates range from -1.0 to +0.5 for the highest and lowest sulfur-content counties respectively. 
Table 6: Sulfur Elasticity Regression Results

Dependent Variable: $\ln ($ County Production)

\begin{tabular}{|c|c|c|}
\hline Independent Variables & County Fixed Effects & Pooled OLS \\
\hline \multirow[t]{2}{*}{$\ln$ (Sulfur Allowance Price) } & 0.0497 & 0.0653 \\
\hline & $(0.0444)$ & $(0.0438)$ \\
\hline \multirow[t]{2}{*}{$\mathrm{SO} 2 \times \ln ($ Sulfur Allowance Price $)$} & $-0.0329 *$ & $-0.0417 * *$ \\
\hline & $(0.0173)$ & $(0.0166)$ \\
\hline \multirow[t]{2}{*}{ ARP Phase I } & 0.231 & 0.209 \\
\hline & $(0.162)$ & $(0.164)$ \\
\hline \multirow[t]{2}{*}{ ARP Phase II } & 0.204 & 0.154 \\
\hline & $(0.192)$ & $(0.193)$ \\
\hline \multirow[t]{2}{*}{ SO2 x Phase I } & $-0.348 * * *$ & $-0.317 * * *$ \\
\hline & $(0.116)$ & $(0.116)$ \\
\hline \multirow[t]{2}{*}{ SO2 x Phase II } & $-0.259 * * *$ & $-0.235^{* *}$ \\
\hline & $(0.0949)$ & $(0.0953)$ \\
\hline \multirow[t]{2}{*}{ Total MWD } & $0.00317 * *$ & $0.00439 * * *$ \\
\hline & $(0.00124)$ & $(0.000872)$ \\
\hline \multirow[t]{2}{*}{ SO2 x Phase I x ScrubMWD } & $0.00214 * * *$ & $0.00190 * * *$ \\
\hline & $(0.000640)$ & $(0.000629)$ \\
\hline \multirow[t]{2}{*}{ SO2 x Phase II x ScrubMWD } & $0.00126 * * *$ & $0.00118 * * *$ \\
\hline & $(0.000398)$ & $(0.000398)$ \\
\hline \multirow[t]{2}{*}{ ln(Total PRB Production) } & $-2.045 * * *$ & $-2.185 * * *$ \\
\hline & $(0.769)$ & $(0.757)$ \\
\hline \multirow[t]{2}{*}{ Relative Production Costs } & $-0.291 * * *$ & $-0.248 * * *$ \\
\hline & $(0.0741)$ & $(0.0737)$ \\
\hline \multirow[t]{2}{*}{ Natural Gas / Coal Price } & -0.00741 & -0.00955 \\
\hline & $(0.0184)$ & $(0.0185)$ \\
\hline \multirow[t]{2}{*}{ Year } & $0.0850 * *$ & $0.0975 * * *$ \\
\hline & $(0.0365)$ & $(0.0350)$ \\
\hline \multirow[t]{2}{*}{ Constant } & $-145.3 * *$ & $-170.4 * * *$ \\
\hline & $(69.06)$ & $(65.87)$ \\
\hline Observations & 3008 & 3008 \\
\hline Number of FIPS & 188 & 188 \\
\hline & $\begin{array}{l}\text { ors in parentheses } \\
* \mathrm{p}<0.05, * \mathrm{p}<0.1\end{array}$ & \\
\hline
\end{tabular}

This relatively high sulfur threshold requirement for complementarity is perhaps surprising. However, much of the discussion of the Acid Rain Program in the literature (see especially Bohi and Burtraw, 1996, and Schmalensee and Stavins 2013) emphasizes that the sulfur allowance market was affected by many factors that tended to divorce it from contemporaneous coal production. Many allowances were purchased and banked for later use, and the price spike of 2006 was largely attributed to disruptions in rail transport from the PRB region, which would have increased the demand for Eastern coal of all types.

\section{Conclusions}

It is difficult to disentangle the effects of clean air policy from the effects of technological change and market competition, but doing so is of great importance for policy evaluation. Effective environmental regulation will usually be destructive to polluting industries. The perception of regulatory effectiveness matters for determining the political environment in which regulatory policy is made, because an effective 
regulation is worth fighting about, both for those concerned with environmental quality and for those whose livelihood depends on the polluting industries. If we believe that market forces rather than environmental regulation will determine the future state of the environment then we have little incentive to maintain the current regulatory structure.

In this paper, we have presented evidence of the effectiveness of environmental regulation in changing patterns of production in the Eastern coal industry, an industry that produces a product that is undoubtedly both useful and environmentally harmful. We use a fixed-effects model that corrects for sample selectivity bias on county-level panel data for the period 1983-2012. We control for market forces in the form of natural gas prices ${ }^{11}$, PRB coal production, and relative production costs. Taking advantage of cross-sectional variation in sulfur content within Eastern coalfields and variation in mine proximity to coal-fired power plants, we quantify various aspects of the negative relationship between the sulfur content of Eastern coals and their production during each of the three phases of sulfur dioxide regulation.

We find evidence that, after controlling for broad scale market forces, coal production in all counties in the Appalachian and Illinois basins was harmed during Phase 1 of the EPA's Acid Rain Program, though as many as $14 \%$ of the counties may have seen an increase in production as a result of later phases of regulation. In a separate regression, we find that (from 1995 to 2008) increases in allowance prices were associated with reduced production for about $51 \%$ of the highest-sulfur coals, but are associated with positive or zero effects for the remainder. We also find strong evidence that installing flue gas scrubbers in power plants effectively encourages production from high-sulfur mines, as was the intent of coal-state regulators and legislators who implemented policies designed to encourage their installation.

The study has limitations. We make no serious attempt to estimate the causal effect of PRB coal production on Eastern coal production, as our PRB production variable is highly trended and is therefore collinear with other trended variables, such as technological change and economic growth. Although our study takes into account the spatial structure of county-level coal markets, more sophisticated modeling methods might be employed. We also make no attempt to explore the local employment or income effects of the estimated changes in production, leaving such considerations to a future study.

Despite these limitations, these results fill a gap in the policy literature. While many previous studies have alluded to changes in coal production associated with Clean Air Act regulations, this is the first, and the most fine-grained, study attempting to quantify these effects on coal production after controlling for market forces. We are entering an era in which new market forces, most obviously the increase in shale gas and oil production, and new regulations related to climate change are reshaping the energy industries

\footnotetext{
${ }^{11}$ Which we find have little or no effect during our period of study. One possible explanation is that the rapid decrease of natural gas prices only began at the end of our sample period
} 
of North America and the world. A continuing effort is needed to improve our understanding of the effects of those regulations and market forces, for good and ill, on industrial structure and personal wellbeing at both the local and global level.

\section{References}

Betz, M.R., Farren, M., Lobao, L., Partridge, M.D. (2015) Coal Mining, Economic Development, and the Natural Resource Curse. The Energy Journal. Forthcoming.

Bragg, L. J., Oman, J.K., Tewalt, S.J., Oman, C.L., Rega, N.H., Washington, P.M., and Finkelman, R.B., 1998, U.S. Geological Survey coal quality (COALQUAL) database; version 2.0. Open-File Report 97-134. [CD-ROM] Available at: http://pubs.usgs.gov/of/1997/of97-134/.

Busse, M.R. and Keohane, N.O. (2007), Market effects of environmental regulation: coal, railroads, and the 1990 Clean Air Act. The RAND Journal of Economics 38: 1159-1179.

Bohi, D. R., \& Burtraw, D. (1997). SO2 allowance trading: How experience and expectations measure up (pp. 97-24). Resources for the Future.

Carlson, C., Burtraw, D., Cropper, M., and Palmer, K.L. (2000). Sulfur Dioxide Control by Electric Utilities: What are the Gains from Trade? Journal of Political Economy 108(6), 1292-1326.

Cicala, Steve (2015). "When Does Regulation Distort Costs? Lessons from Fuel Procurement in US Electricity Generation." American Economic Review, 105(1): 411-444.

Ellerman, A.D., P.L. Joskow, R. Schmalensee, J.-P. Montero, E.M. Bailey (2000). Markets for clean air: The US Acid Rain Program. Cambridge University Press.

Ellerman, D, and J. Montero (1998) The Declining Trend in Sulfur Dioxide Emissions: Implications for Allowance Prices. Journal of Environmental Economics and Management 36:26-45.6-45.

Frey, Elaine F. (2013). Technology Diffusion and Environmental Regulation: The Adoption of Scrubbers by Coal-Fired Power Plants. The Energy Journal 34(1), 177-205.

Gerking, S., and Hamilton, S. F. (2008). What explains the increased utilization of Powder River Basin coal in electric power generation?. American Journal of Agricultural Economics 90(4), 933-950.

Hoag, J. H. (1995). The Impact of the 1969 Coal Mine Health and Safety Act and the Clean Air Acts on Coal Mining Employment in Ohio and Illinois. Journal of Regional Analysis and Policy 25(1), 314.

Hoag, J., and Reed, J. D. (2002). The Impact of the Clean Air Acts on Coal Mining Employment in Kentucky. Journal of Regional Analysis and Policy 32(2), 17-30.

Lange, I., \& Bellas, A. S. (2007). The 1990 clean air act and the implicit price of sulfur in coal. The BE Journal of Economic Analysis \& Policy, 7(1). 
Lile, Ron, and Burtraw, D. (1998) "State-Level Policies and Regulatory Guidance for Compliance in the Early Years of the SO2 Emission Allowance Trading Program." Resources for the Future, Discussion Paper 98-35.

Schmalensee, R, Stavins, R.N. (2013) The SO2 Allowance Trading System: The Ironic History of a Grand Policy Experiment. Journal of Economic Perspectives 27(1): 103-22.

U.S. Energy Information Administration (EIA 2014a) Coal Production Data. Available at: http://www.eia.gov/coal/data.cfm\#production

U.S. Energy Information Administration (EIA 2014b) Form EIA-860 Data. Available at: http://www.eia.gov/electricity/data/eia860/

U.S. Energy Information Administration (EIA 2014c) Form EIA-923 Data. Available at: http://www.eia.gov/electricity/data/eia923/

U.S. Energy Information Administration (EIA 2014d) Quarterly Coal Report, June 2014. Available at http://www.eia.gov/coal/production/quarterly/pdf/t32p01p1.pdf

U.S. Energy Information Administration (EIA 2011), Today in Energy May 11, 2011. Available at http://www.eia.gov/todayinenergy/detail.cfm?id=1330

U.S. Environmental Protection Agency (EPA 2014) Annual Auction Data. Available at: http://www.epa.gov/airmarkets/trading/auction.html 


\title{
Chapter 3 - Essay \#2: Turbulent Times: Uncovering the Origins of US Natural Gas Price Fluctuations Since 1993
}

\author{
With Xiaoli Etienne
}

\begin{abstract}
In this paper, we investigate supply and demand shocks in the US natural gas market, focusing on how the effects of these shocks have changed over time. We apply a sign-identified structural vector autoregression (SVAR) model that allows for both time-varying parameters and stochastic volatility. Using quarterly data from 1976 to 2015 , we model how the price elasticities of supply and demand have changed, finding that both supply associated with aggregate demand and demand have become more elastic since the shale boom. Further, we find the price of natural gas has become more (less) responsive to aggregate demand (supply) shocks since the sharp decrease in prices. And finally, we evaluate three historical price episodes and estimate the role played by each variable. This comprehensive analysis will be of interest to anyone studying natural gas, the energy industry, or macroeconomic trends.
\end{abstract}




\section{Introduction}

Natural gas is a critical component of the energy industry in the US. The Energy Information Administration (EIA) estimated that in 2014, approximately 26.7 trillion cubic feet of natural gas was consumed in the US, supplying roughly $27 \%$ of electricity generation and $19 \%$ of all residential heating ${ }^{12}$. In commercial manufacturing, natural gas is widely used as both a primary fuel source and raw material. At the macro-scale, the domestic natural gas industry is closely tied to economic development, employment, and industrial output, and its growth is often considered as contributing to US energy independence. In his 2013 State of the Unions speech, President Obama claimed that the domestic production of natural gas "has led to cleaner power and greater energy independence". As the burning of natural gas emits fewer greenhouse gas emissions relative to coal, the following year he highlighted natural gas as the "bridge" fuel that can transition the US economy from its traditional reliance on fossil fuels.

However, little is known about the price fluctuations in the US natural gas market and their specific causes. As figure 1 demonstrates, natural gas prices in the US have experienced significant volatility over the past three decades. Behind these price fluctuations are fundamental structural changes in the natural gas market driven mainly by exogenous supply and demand shocks. In the aftermath of the supply disruptions caused by hurricanes Katrina and Rita in 2005, natural gas prices hit a record high in both nominal and real terms, followed by a more than $50 \%$ drop as weather conditions unexpectedly improved $^{13}$. Then during the financial crisis of 2008, natural gas prices experienced significant shifts, a pattern shared by many other commodities. Most recently, domestic production from shale and other lower-permeability formations has become economically profitable, sparked by the popularization of the combined use of horizontal drilling and hydraulic fracturing techniques. These new techniques have completely revolutionized the market. In 2007 shale production roughly $10 \%$ of US dry natural gas production, while in 2014 it increased to over $53 \%{ }^{14}$. Despite these enormous changes, studies of the driving forces behind natural gas price movements still lag behind those from other energy markets.

\footnotetext{
${ }^{12}$ See EIA natural gas consumption data at: https://www.eia.gov/dnav/ng/ng_cons_sum_dcu_nus_a.htm

${ }^{13}$ See EIA price data at: https://www.eia.gov/dnav/ng/hist/n9190us3m.htm

${ }^{14}$ See shale gas production data at: https://www.eia.gov/dnav/ng/ng_prod_shalegas_s1_a.htm
} 
Figure 1. Natural Gas Producer Price Index in the US and Its One-Year CVs (1975-2015)
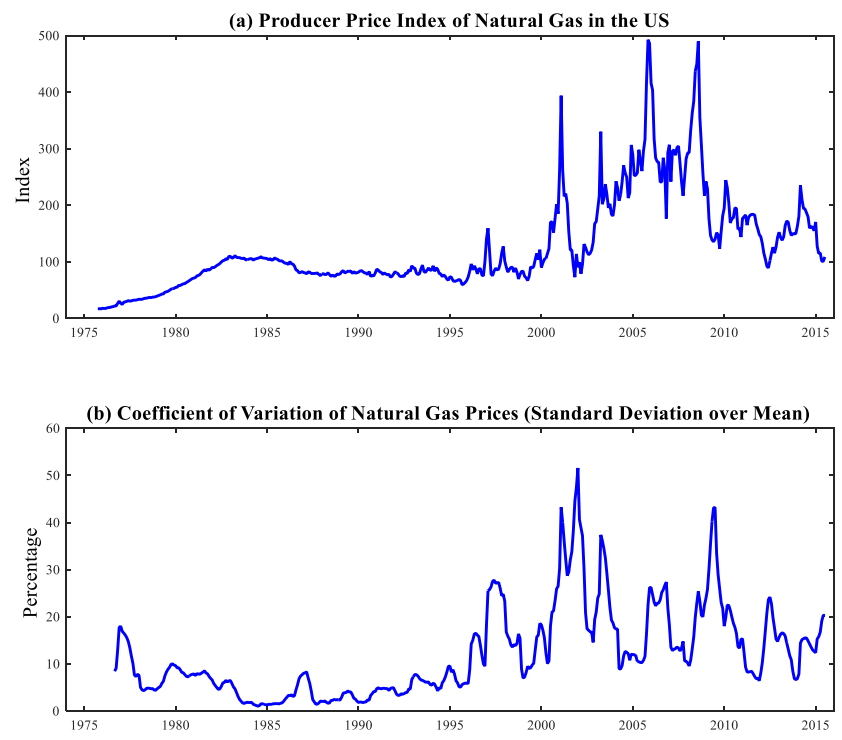

The purpose of this paper is to disentangle supply and demand shocks in the US natural gas market and investigate how the effects of these shocks have changed over time. Using a sign-identified structural vector autoregression (SVAR) model that allows for both time-varying parameters and stochastic volatility (Baumeister and Peersman, 2013a, b), we estimate the time-varying effects of these shocks on the evolution of US natural gas prices, calculate price elasticities due to shifts in the supply or associated demand curve, and evaluate their relative importance on price variations during historical episodes characterized by large price fluctuations.

Overall, estimation results suggest that the impacts of different structural shocks have evolved considerably since markets were formally deregulated in 1993 . We find that an unanticipated supply decrease raises natural gas prices, reduces the aggregate demand, and lowers inventory demand. Unanticipated decreases in aggregate demand, on the other hand, depress prices, reduce production, and encourage inventory demand. We find that both the price elasticities of supply and demand have increased in magnitudes in recent years, possibly reflecting the greater flexibility in production and in fuel switching due to technological advances. Though precautionary inventory demand is shown to have a greater impact over time, its magnitude remains small. The main drivers of natural gas price movements appear to be the supply and aggregate demand shocks.

The remainder of this paper is organized as follows. The next section briefly reviews relevant literature on estimating the supply and demand structure in the natural gas market. Section three describes the 
econometric procedure used in the analysis, and section four presents the data used in this analysis. In section five, we report the estimation results from a time-varying structural VAR model that allows for stochastic volatility. In section six, we investigate a few historical episodes and estimate the relative role of supply and demand in these events, and section six concludes the paper.

\section{Brief Literature Review}

Only a handful of studies have attempted to understand the supply-and-demand structure in the US natural gas market, with the majority focusing on the spatial pricing efficiency in regional gas markets and natural gas' price relationship with other energy commodities. For instance, Mohammadi (2011) demonstrates that while prices of oil and coal are determined globally and by long term contracts respectively, natural gas prices are determined regionally. Olsen et al. (2015) find cointegration between North American natural gas markets, though the degree of integration varies depending on location. Siliverstovs et al. (2005) find integration of natural gas prices within European and US markets, but not between. Similar results are found in Renou-Maissant (2012) and Park et al. (2007), among others. The pricing relationship between natural gas and crude oil and other energy commodities has as well received much attention from the literature, as for many applications, natural gas and refined petroleum products are close substitutes. Though fuel switching may be limited in the short-run due to technological constraints, researchers overall agree that (1) natural gas and crude oil prices were strongly linked before 2008, and (2) natural gas prices tend to be more influenced by oil prices, rather than the other way around (e.g. Atil et al. (2014), Brigida (2014), Brown and Yücel (2008), Hartley and Medlock (2014), Ji et al. (2014), and Ramberg and Parsons (2012)).

A core problem in the natural gas market is understanding how natural gas prices respond to different market shocks and the relative importance of each shock in driving price movements. Recently, Nick and Thoenes (2014) analyze the German natural gas market, and the impact that three significant supply shocks have had on prices using a structural VAR model. They argue that in the short-run temperature, storage, and supply shortfalls play an important role. Woo et al. (2014) find that end-use prices of natural gas generally reflect cost of wholesale, with only a small time-period of adjustment. $\mathrm{Mu}$ (2007) highlights the importance of weather on natural gas prices. Hulshof et al. (2016) conclude that the day-ahead gas prices at the Dutch gas hub are predominantly determined by gas-market fundamentals. Brown and Yücel (2008), by contrast, argue that after accounting for weather, inventories, and supply disruptions, oil price fluctuations remain the primary determinants of natural gas prices. 
Given that the market for natural gas has undergone significant changes over the past decades, studies have also attempted to include structural breaks when modeling natural gas prices. Qin et al. (2010) find that the importance of fundamentals change depending on market regime, playing a larger role in bullish than in bearish markets. They further contend that natural gas price behavior is far more complicated than that predicted by fundamentals, and that volatility unexplained by fundamentals plays an essential role in natural gas price behavior. Several studies have also incorporated the impact of shale boom in shaping natural gas prices. Arora (2014) uses a structural VAR to estimate the supply and demand elasticity of US natural gas prices prior to and after the shale boom. He finds that both the short- and long-run natural gas supply becomes more elastic when the effects of a shale development are included, while the demand becomes either less responsive or similar to price changes after accounting for shale production (post2007). Wakamatsu and Aruga (2013) model the US and Japanese natural gas markets using a one-time structural break from the shale boom, finding that the two markets used to be interlinked before the revolution, but the US market has become more independent after the revolution. ${ }^{15}$

Our analysis is closely related to this last stream of literature, focusing on the time-variation and structural breaks in the natural gas supply and demand dynamics. This work is of particular importance given the increasingly volatile natural gas market that has witnessed significant changes in the market structure over the past two decades. The studies of Wakamatsu and Aruga (2013) and Arora (2014) both impose a onetime structural break to account for the shale gas boom. However, a more comprehensive structure is needed to account for other exogenous shocks that have significantly influenced the natural gas markets. Additionally, as suggested by Primiceri (2005), imposing discrete structural breaks may be inappropriate as aggregation in the private sector can smooth such changes.

Our work contributes to the growing literature on the natural gas markets in a number of ways. First, we construct a comprehensive framework that enables a thorough investigation of the role of supply disruptions, aggregate demand shocks, and speculative inventory shocks on natural gas prices in the US. Second, recognizing both that massive changes have occurred in the natural gas market and that these changes are likely to evolve gradually over time, we consider a time-varying structural VAR model that allows for smooth, continuously-evolving parameters (Baumeister and Peersman, 2013a, b). The estimation procedure enables us to estimate the dynamic effects of various structural shocks on the evolution of natural gas prices. Third, given the apparent changes in natural gas price volatility (figure 1), we explicitly consider residual heteroscedasticity in the VAR model that accounts for both changes in the magnitude of structural shocks and their immediate impacts. Such heteroscedasticity, if overlooked, may

\footnotetext{
${ }^{15}$ In a slightly different vein, Arora and Lieskovsky (2014) find that the shale gas revolution has made the natural gas industry more relevant to the US economic activity by estimating a structural VAR model accounting for different timeframes.
} 
generate spurious inference from the estimated coefficients (Cogley and Sargent, 2005). Finally, unlike previous structural VAR models that often rely on a contemporaneous exclusion or recursive identification strategy, we use sign-restrictions directly implied from economic theory to recover structural shocks. The resulting impulse responses, forecast error variance decompositions, historical decompositions, and elasticity estimates complement the existing literature on modeling the supply and demand structure in the US natural gas market.

\section{Methodology}

Consider the following reduced-form vector autoregression (VAR) model with a lag length of $p$ :

$$
y_{t}=B_{1, t} y_{t-1}+\cdots+B_{p, t} y_{t-p}+e_{t}=X_{t}^{\prime} \theta_{t}+e_{t}
$$

where $y_{t}$ is a $[4 \times 1]$ vector of endogenous variables consisting of the total physical availability of natural gas in the US $\left(\operatorname{prod}_{t}\right)$, aggregate real economic activity $\left(r e a_{t}\right)$, the precautionary inventory demand $\left(i n v_{t}\right)$, and the real price of natural gas $\left(r p o_{t}\right)$. The right-hand side of equation (1) can be simplified as $X_{t}^{\prime} \theta_{t}+\varepsilon_{t}$, where $\theta_{t}$ consists coefficients on the lags of the endogenous variables $B_{1}, \ldots B_{p, t}$, each of which is a [4×4] matrix. The reduced-form residuals $e_{t}$ can be written as weighted averages of the structural errors $u_{t}$, which are commonly assumed to be independently and identically distributed (iid). Following Kilian (2009); Kilian and Murphy (2012); Arora (2014); Arora and Lieskovsky (2014); Kilian and Murphy (2014), we define our four structural shocks as shocks in supply, aggregate demand, speculative inventory demand, and residual demand. The relationship between reduced-form and structural innovations may be written as

$$
e_{t} \equiv\left(\begin{array}{c}
e_{t}^{\text {prod }} \\
e_{t}^{r e a} \\
e_{t}^{\text {inv }} \\
e_{t}^{r p o}
\end{array}\right)=\left[\begin{array}{llll}
a_{11} & a_{12} & a_{13} & a_{14} \\
a_{21} & a_{22} & a_{23} & a_{24} \\
a_{31} & a_{32} & a_{33} & a_{34} \\
a_{41} & a_{42} & a_{43} & a_{44}
\end{array}\right]\left(\begin{array}{c}
u_{t}^{\text {supply shock }} \\
u_{t}^{\text {aggregate demand shock }} \\
u_{t}^{\text {speculative inventory demand shock }} \\
u_{t}^{\text {residual demand shock }}
\end{array}\right)
$$

where $a_{11}, a_{12}, \ldots a_{44}$ refer to contemporaneous relations between endogenous variables. A supply shock refers to unexpected supply disruptions in the natural gas market that displace the supply curve due to technology, weather or policy changes. An economic activity shock incorporates unexpected demand shocks driven by changes in real economic activity in the US not already reflected in supply shocks. Though Kilian (2009) and a number of following papers use an aggregate economic index based on dry cargo shipping rates to represent oil demand shocks driven by global real economic activity, we prefer a regional economic activity measure for the natural gas market. Previous studies have found that unlike oil 
prices which are determined in the global market, natural gas is a regional commodity influenced primarily by region-specific demand and supply conditions (e.g. Mohammadi, 2011). The third shock, to which we refer to as speculative inventory demand shock, includes shifts in the demand for natural gas inventories not otherwise explained by supply or aggregate demand shocks. If market participants are forward-looking and rational, then speculative inventory demand increases if net prices of natural gas (excluding cost of carry) are expected to increase. Kilian and Murphy (2014) argue that the speculative demand shock reflects changes in inventory behavior due to rational market participants reacting to news about future supply or demand conditions. It should be noted that our definition of speculative activity is rather broad - it includes any inventory accumulating (reducing) behavior in anticipation of future supply shortfalls (increases) relative to market demand. Finally, the residual shock refers to innovations in natural gas demand not otherwise accounted for by the three previous shocks. Examples of such residual demand shocks include changes in inventory technology or preferences, residential consumers' preferences changes, changes in consumption pattern due to population shift toward warmer regions, new pipelines, opening import/export markets, increased electricity generation, etc. Similar VAR specifications have been used in various previous studies to disentangle structural shocks in the crude oil and natural gas markets, including Arora (2014), Arora and Lieskovsky (2014), Baumeister and Peersman (2013a), Kilian (2009), and Kilian and Murphy (2014) among others. ${ }^{16}$

While equation (1) can be consistently estimated using standard econometric procedures, restrictions need to be placed on the contemporaneous coefficient matrix (equation 2) to recover the structural innovations $u_{t}$. Previous studies using a structural VAR approach have often imposed a recursive structure of the endogenous variables in the system in which the preceding variable affects the following variable at contemporaneous time, but not vice-versa. Implicit in this approach is the assumption that the very shortrun aggregate demand or supply elasticity equals zero so that the correlations between the error in forecasting quantity and price changes in the next period could be interpreted as the response of aggregate supply or demand to the structural shock (Hamilton, 2015)

Four problems exist with such recursively-identified SVAR models. First, previous studies have often assumed that parameters in an SVAR model remain constant throughout the sample period. As argued earlier, this assumption is unlikely to hold, especially since 1993. Second, even for studies that allow for time-varying parameters, the conventional approach has been to impose a one-time or multiple abrupt

\footnotetext{
${ }^{16}$ Previous studies on natural gas market also consider the impact of weather conditions on price fluctuations. Since our model is estimated on a quarterly basis, short-term weather impacts are likely to be small. In the empirical part, we also deseasonalize our data using quarterly dummies, further removing the seasonality in demand and inventory due to weather variations. Finally, even if weather does play a significant role in the deseasonalized quarterly data, it should show up in the residual demand shocks from residential heating demand.
} 
structural breaks in the data. While such discrete break models may describe the occurrence of unexpected, rapid policy changes in the market, rarely do commodity markets evolve in an abrupt fashion such that the impacts of structural shocks differ dramatically prior to and after the break. In particular, the discrete break model cannot capture changes brought about by the private sector where heterogeneous agents respond to external shocks in a diverse fashion. Aggregation of these heterogeneous behaviors are likely to smooth out the economic impacts of discrete policy changes (Primiceri, 2005). Additionally, if economic agents are rational and forward-looking, the expected policy changes are likely to be incorporated into business forecasting long before the change actually takes place. The learning dynamics of the private sector imply that models only allow for discrete structural breaks are unable to capture how modifications occur in the market transmission mechanism.

A third problem with previous studies is that the error terms in the VAR models are often assumed to be identically distributed (homeoskedastisitic) over time, an assumption that rarely holds in practice. As figure 1 illustrates, natural gas prices have undergone considerable volatility over the past decades. Such heteroscedasticity in the underlying data, if overlooked, may generate fictions dynamics in the coefficients of the model (Cogley and Sargent, 2005). Finally, in a recursively-identified SVAR, structural shocks $\left(u_{t}\right)$ are recovered by orthogonalizing the reduced-form errors $\left(e_{t}\right)$ through a Cholesky decomposition. This approach relies on the assumption that the relationship between endogenous variables follows a particular casual chain such that the preceding variable affects the following variable at contemporaneous time, but not the other way around. This assumption is less appropriate when dealing with data of low frequency (e.g. quarterly). Additionally, unless there is a convincing theoretical rationale for a particular ordering, the resulting analyses for the structural VAR model (e.g. impulse responses, variance decompositions, etc.) are not credible. This problem cannot be alleviated by considering alternative orderings, as restrictions on structural parameters should follow economic rationales rather than sensitivity analysis (Kilian, 2013).

\subsection{Precautionary Demand}

Like many storable commodities, the storable nature of natural gas forces inventories to play a pivotal role in the market dynamics. Along with mitigating the seasonal variation in both production and consumption, the level of inventory available partly reflects how quickly firms can respond to unexpected demand or supply shocks. The theory of storage (e.g., Kaldor, 1939; Working, 1948, 1949; Brennan, 1958) states that firms earn a convenience yield by holding inventory at hand, which prevents disruptions in the flow of goods and services, and in turn reduces production uncertainty. A number of studies have investigated the relationship between prices and inventories (e.g., Wright and Williams, 1991; Miranda 
and Fackler, 2004), finding that inventories not only help absorb price fluctuations, but also reflect the degree to which forward-looking inventory holders expect price to rise or fall in a future period.

Accordingly, the demand for inventory in the natural gas market may be interpreted a speculative demand, as speculators have the ability to put more (less) into storage in anticipation of a substantial rise (fall) in future prices. ${ }^{17}$

\subsection{A Time-Varying Parameter VAR Model with Stochastic Volatility}

Baumeister and Peersman (2013a, 2013b) suggest a VAR model with time-varying parameters and stochastic volatility to resolve the first three problems. Specifically, instead of assuming constant parameters or abrupt discrete changes in parameters over the sample period, they let the coefficient matrices $B_{1}, \ldots B_{p, t}$ in equation (1) to vary in time, or equivalently, $\theta_{t}$ to be time-varying. Further, the disturbance term $e_{t}$ is assumed to be normally distributed with mean zero and a time-varying covariance matrix $\Omega_{t}$ :

$$
\Omega_{t}=A_{t}^{-1} H_{t}\left(A_{t}^{-1}\right)^{\prime}
$$

where $A_{t}$ is a $4 \times 4$ lower triangular matrix that models the contemporaneous correlations among the four endogenous variables and $H_{t}$ is a $4 \times 4$ diagonal matrix that models the stochastic volatility in the residuals. The specific representations of $A_{t}$ and $H_{t}$ are shown in equation (4):

$$
A_{t}=\left[\begin{array}{cccc}
1 & 0 & 0 & 0 \\
\alpha_{21, t} & 1 & 0 & 0 \\
\alpha_{31, t} & \alpha_{32, t} & 1 & 0 \\
\alpha_{41, t} & \alpha_{42, t} & \alpha_{43, t} & 1
\end{array}\right] \quad H_{t}=\left[\begin{array}{cccc}
h_{1, t} & 0 & 0 & 0 \\
0 & h_{2, t} & 0 & 0 \\
0 & 0 & h_{3, t} & 0 \\
0 & 0 & 0 & h_{4}
\end{array}\right]
$$

Now let $\alpha_{t}=\left[\alpha_{21, t}, \alpha_{31, t}, \alpha_{32, t}, \alpha_{41, t}, \alpha_{42, t}, \alpha_{43, t}\right]^{\prime}$ be a vector of elements from $A_{t}$ that are both nonzero and non-unity; and $h_{t}=\left[h_{1, t}, h_{2, t}, h_{3, t}, h_{4, t}\right]^{\prime}$ be the diagonal elements of $H_{t}$. To impose time variations in the model, they assume $\theta_{t}$ and the free elements from $A_{t}$ (non-zero and non-unit) to evolve as random walks without drift, and that each element of the vector of volatility $h_{t}$ to follow a geometric random walk (equations (5)-(6)):

$$
\begin{aligned}
\theta_{t} & =\theta_{\mathrm{t}-1}+v_{t}, & & v_{t} \sim N(0, Q) \\
\alpha_{t} & =\alpha_{\mathrm{t}-1}+\zeta_{t}, & & \zeta_{t} \sim N(0, S) \\
\ln h_{i, t} & =\ln h_{\mathrm{i}, \mathrm{t}-1}+\sigma_{i} \eta_{i, t}, & & \eta_{t} \sim N(0,1)
\end{aligned}
$$

\footnotetext{
${ }^{17}$ It should be noted that the amount of natural gas in storage reflects the inventory holders' view toward expected supply shortfalls relative to demand in a future period, rather than future demand or future supply alone.
} 
where the error terms $v_{t}, \zeta_{t}$, and $\eta_{t}$ are independent of each other and normally distributed. Further, a block-diagonal structure is imposed for $S$ (the variance -covariance matrix of the error term $\zeta_{t}$ ), as in equation (8):

$$
S \equiv \operatorname{Var}\left(\zeta_{t}\right)=\operatorname{Var}\left(\left[\begin{array}{c}
\zeta_{21, t} \\
\zeta_{31, t} \\
\zeta_{32, t} \\
\zeta_{41, t} \\
\zeta_{42, t} \\
\zeta_{43, t}
\end{array}\right]\right)=\left[\begin{array}{ccc}
S_{1} & 0_{1 \times 2} & 0_{1 \times 3} \\
0_{2 \times 1} & S_{2} & 0_{2 \times 3} \\
0_{3 \times 1} & 0_{3 \times 2} & S_{3}
\end{array}\right]
$$

where $S_{1} \equiv \operatorname{Var}\left(\zeta_{21, t}\right), S_{2} \equiv \operatorname{Var}\left(\left[\zeta_{31, t}, \zeta_{32, t}\right]^{\prime}\right)$, and $S_{3} \equiv \operatorname{Var}\left(\left[\zeta_{41, t}, \zeta_{42, t}, \zeta_{43, t}\right]^{\prime}\right)$. Since $A_{t}$ models the contemporaneous correlations among the endogenous variables, the block-diagonal structure of $S$ essentially implies that shocks to the contemporaneous correlations are correlated within, but not across, equations. Compared to the general case of $S$ being unrestricted, the block-diagonal structure has the advantage of simplifying the inference and increasing the efficiency of the estimation algorithm (Primiceri, 2005).

The specification outlined above allows for time variation in both coefficient estimates and the variancecovariance matrix of the residuals. The former feature allows us to capture possible non-linearities and time variation in the lag structure of the endogenous variables, while the latter enables us to model not only the heteroscedasticity in the residuals but also changes in the contemporaneous relationships among the endogenous variables. These two features combined allow the data to determine whether the time variation in the structural relationship among endogenous variables is due to changes in the size of the shock and its associated contemporaneous impact, or from changes in the shock transmission mechanism.

\subsection{Identification of Structural Shocks}

Unless the recursive causal chain imposed on endogenous variables is economically justified, a recursively-identified structural VAR model cannot be used to generate plausible economic interpretations (e.g., Kilian, 2013). As an alternative in recent years, a growing number of papers have used sign restrictions for a recursive identification strategy. In a sign-identified structural VAR, each identifiable structural shock is required to generate responses among endogenous variables that follow a unique sign pattern motivated by direct economic theories. Unlike recursive VARs that are exactly identified, a large number of possible solutions are admissible in a sign-identified model as long as the responses of endogenous variables fall within the pre-specified sign pattern. Recent examples of using 
sign-identified structural VARs to disentangle demand and supply shocks in energy markets include Arora (2014), Baumeister and Peersman (2013a, 2013b), Kilian and Murphy (2012, 2014), among others.

Table 1 summarizes the sign restrictions imposed in the present paper to identify structural shocks in the US natural gas market:

Table 1. Sign Restrictions Imposed in the Structural VAR Model

\begin{tabular}{|c|c|c|c|}
\hline & \multicolumn{3}{|c|}{ Shocks } \\
\hline & Supply & $\begin{array}{l}\text { Aggregate } \\
\text { Demand }\end{array}$ & $\begin{array}{c}\text { Precautionary } \\
\text { Demand }\end{array}$ \\
\hline Marketed Production & + & + & + \\
\hline Aggregate Demand & + & + & - \\
\hline Inventories & . & . & + \\
\hline Real price & - & + & - \\
\hline
\end{tabular}

Note: All structural shocks are assumed to be positive. Missing entries (denoted ".") signify that no sign restriction is implied in the corresponding impulse response function in the immediate period.

Our assumptions of how short-run demand and supply contemporaneously respond to structural shocks (table 1) follow Arora (2014) and Kilian and Murphy (2014) closely. Conditional on all past data, a positive supply shock shifts the natural gas supply curve to the right along the demand curve, and hence lowers natural gas prices and increases real economic activity within the same time horizon. The responses of natural gas prices and aggregate demand to positive supply shocks at contemporaneous time are thus restricted to be non-positive and non-negative, respectively. Kilian and Murphy (2014) argue that the impact of supply shocks on speculative inventory demand are ambiguous ex ante. In the event of supply disruptions, storage holders may sell out inventories as the opportunity cost associated with storing natural gas is high. However, additional natural gas may be put into storage in anticipation of increases in future prices due to supply shortfalls. It is hard to anticipate which effect will dominate the inventory market when supply shocks occur, so no restrictions are placed on the responses of precautionary inventory demand to supply innovations.

Our second structural shock stems from unanticipated innovations to aggregate demand not already captured by supply shocks. Conditional on all past information, a positive aggregate economic demand 
shock shifts the downward-slopping demand curve to the right along the supply curve. This shock is assumed to not only raise the total supply and real price of natural gas, but also stimulate aggregate real economic activity demand at the same period. Similar to supply shocks, no sign restrictions are placed on the contemporaneous response of speculative inventory demand to aggregate economic shocks, as inventory holders may either increase or decrease their holdings of natural gas.

Our third structural shock is associated with news about unanticipated changes in future supply and demand of natural gas not already embedded in current supply and aggregate economic shocks, which we term "speculative inventory demand shock". If a tighter future supply-and-demand relationship is anticipated, such a positive speculative demand shock not only increases the inventory demand in the current period, but also shifts the short-run contemporaneous total demand curve to the right along the supply curve (conditional on all past information), effectively raising current-period prices. Examples of positive speculative demand shock include the news that (1) recoverable reserves of underground natural gas are less than the numbers released by the EIA, (2) anticipated technical advances that allow natural gas to be used more efficiently and more cleanly, or (3) expectation of increased natural gas exports due to future investment in infrastructure that expands the existing pipeline capacity, to name a few. As inventory accumulates in anticipation of future supply shortfalls relative to demand, current economic activity would be depressed, as less natural gas is available for industrial consumption. Further, the expectation that future supply-and-demand conditions will tighten would encourage larger natural gas production in the present period, facilitating inventory accumulation.

Our last shock is considered a residual demand shock, reflecting unanticipated changes in the demand of natural gas not already captured by supply, aggregate economic activity, and speculative demand shock. As pointed out by Kilian and Murphy (2014), the residual shock is usually hard to interpret economically as it is a conglomerate of idiosyncratic demand shocks in the market. Hence, we do not place any restrictions on the responses of endogenous variables to the residual shock.

\subsection{Implementation of the Estimation and Identification Procedure}

Following Baumeister and Peersman (2013a, 2013b), the VAR model with time-varying parameters and stochastic volatility is estimated using the Bayesian methods of Kim and Nelson (1999). Below, we briefly describe the estimation procedure.

Setting prior distributions. We first obtain the time-invariant OLS estimates of the VAR model (equation (1)) for a pre-specified training sample. Denote $\hat{\theta}_{O L S}, \widehat{V}\left(\hat{\theta}_{O L S}\right)$, and $\hat{\Sigma}_{O L S}$ as estimates of the coefficient matrix, the covariance matrix of the coefficient estimates, and the variance-covariance matrix 
of the reduced-form errors, respectively. Define the Cholesky factorization of $\hat{\Sigma}_{O L S}$ as $\hat{\Sigma}_{O L S}=A D A^{\prime}$, where $A$ is a lower unit triangular matrix and $D$ is a diagonal matrix with the diagonal elements equal to the variances of the residuals (denoted as $\mu_{0}$ ). Further, we stack the elements of $A^{-1}$ below the diagonal row by row so that $\hat{a}_{0}=\left[\hat{\alpha}_{21,0}, \hat{\alpha}_{31,0}, \hat{\alpha}_{32,0}, \hat{\alpha}_{41,0}, \hat{\alpha}_{42,0}, \hat{\alpha}_{43,0}\right]^{\prime}$. We set the prior distributions of the model parameter as follows: (1) $\theta_{0} \sim N\left[\hat{\theta}_{O L S}, 4 \hat{V}\left(\hat{\theta}_{O L S}\right)\right]$, (2) $\ln \left(h_{0}\right) \sim N\left[\ln \left(\mu_{0}\right), 10 \times I_{4}\right]$, where $I_{4}$ is a 4 by 4 identity matrix, and (3) $a_{0} \sim N\left[\hat{a}_{0}, \widehat{V} \mid\left(\hat{a}_{0}\right)\right]$, where $\widehat{V} \mid\left(\hat{a}_{0}\right)$ is a diagonal matrix and the each of the diagonal elements equals ten times the absolute value of the corresponding element. As noted by Benati and Mumtaz (2007) and Baumeister and Peersman (2013a, 2013b), the scaling of the variance-covariance matrices is arbitrary, but are used primarily to make the prior only weakly informative and to account for the relative magnitude of the elements in each matrix from the prior distribution. For hyperparameters, we follow Baumeister and Peersman (2013a, 2013b) and assume that $Q, S_{i}(i=1,2,3)$ all follow an inverseWishart distribution such that $Q \sim I W\left(\bar{Q}^{-1}, T_{0}\right), S_{i} \sim I W\left(\bar{S}_{l}^{-1}, i+1\right)$, where $T_{0}$ equals the length of the training sample, $\bar{Q}=(0.01)^{2} \widehat{V}\left(\hat{\theta}_{O L S}\right)$, and $\bar{S}_{1}, \bar{S}_{2}, \bar{S}_{3}$ are diagonal matrices with the relevant elements in $\hat{a}_{0}$ multiplied by $10^{-3}$. Finally, the variances of the innovations in equation (7) are assumed to follow an inverse-Gamma distribution such that $\sigma_{i}^{2} \sim \operatorname{IG}\left({\frac{10^{-4}}{2}}^{-4} \frac{1}{2}\right), i=1,2,3,4$.

Simulating the posterior distribution. The next step in implementing the Bayesian time-varying VAR model is to use the Markov Chain Monte Carlo (MCMC) algorithm to generate the joint posterior densities for four blocks of parameters: $\theta^{T}$ (coefficients), $A^{T}$ (the contemporaneous correlation matrix), $H^{T}$ (the variance), and $M$ (the hyperparameters including the elements of $Q, S, \sigma_{i}^{2}, i=1,2,3,4$ ), where $T$ represents whole sample up to period $T$. Specifically, posteriors for each block of the Gibbs sampler are generated conditional on the data $Y^{T}$ and the other parameters obtained at previous steps. In step (1), we first obtain the joint posterior density of the VAR parameters using the Bayes rule conditional on $A^{T}$, $H^{T}, M$, and $Y^{T}$, and then compute their means and variances via forward and backward recursions. A similar algorithm is applied in step (2) to calculate the posterior of $A^{T}$ conditional on $\theta^{T}, H^{T}$, $M$, and $Y^{T}$. The volatility states $\left(h_{i, t}\right)$ are drawn in the third step following the univariate algorithm of Jacquier et al. (1994). Given $\theta^{T}, A^{T}, H^{T}$ and $Y^{T}$, the conditional posterior distribution of the hyperparameteres $M$ can then be calculated. The joint posterior distribution $p\left(\theta^{T}, A^{T}, H^{T}, M \mid Y^{T}\right)$ is obtained by performing 100,000 iterations of the Gibbs sampler and discarding the first 50,000 draws.

Imposing sign restrictions. We obtain one random draw from the joint posterior of the time-varying lagged coefficients and hyperparameters from the Gibbs sampler at time $t$, and simulate the future paths of the four variables based on the variance-covariance matrix 20 quarters ahead. This accounts for all 
sources of uncertainty, including variations in lagged coefficients, changing fundamental relationships between the four endogenous variables, and additional shocks. To obtain $B_{0, t}$, we set $P_{t} D_{t} P_{t}^{\prime}$ equal to the eigenvalue-eigenvector vector decomposition of the decomposition of the covariance matrix $\Omega_{t}$ in equation (8). A $Q R$ decomposition of $K$, an $N \times N$ matrix distributed $N \sim(0,1)$, yields a matrix $Q$ with columns orthogonal to each other. The structural impact matrix is then calculated as $B_{0, t}=P_{t} D_{t}^{1 / 2} Q^{\prime}$, and together with a $4 \times 1$ vector $\varepsilon_{t}$ distributed $N \sim(0,1)$, the reduced form innovations are calculated $u_{t}=B_{0, t} \varepsilon_{t}$. The impulse response functions are calculated by finding the difference between the levels of the four variables with and without a shock. We retain only the impulse response functions that satisfy the entire set of sign restrictions, and iterate until we have a set of 500 estimates for each point in time. Median and the $16^{\text {th }}$ and $84^{\text {th }}$ percentile values are presented in our analyses. Section 5.3 adds additional restrictions on permissible models based on elasticities estimated in Arora (2014), with only minimal differences in results.

\section{Data}

The data set adopted in this study follows Arora (2014) and Arora and Lieskovsky (2014) closely. Real natural gas prices are the US Producer Price Index (PPI) of natural gas published by the Bureau of Labor Statistics (BLS), in which October 1982 is used as the baseline. Compared to the conventional Henry Hub spot prices used in many previous studies, the natural gas PPI from BLS has the advantage of being a composite price of different natural gas prices in the US, and is available for a relatively long history that allows for a greater degree of freedom in econometric analysis. Additionally, it does not need to be deflated. To model the supply of natural gas, we use the marketed US natural gas production published by the EIA that measures the gas generated in the production process before liquids (such as propane and butane) are extracted, in order to exclude the amount of gas consumed either in extraction or processing. Aggregate demand for natural gas is represented by an index of industrial production and capacity utilization (G.17) constructed by the Federal Reserve Bank. This demand is primarily driven by changes in US economic activity. Lastly, the EIA natural gas inventory data is used to measure the precautionary inventory demand in anticipation of changes in future supply-and-demand conditions.

The data period considered begins in 1976 and ends in 2015, and is sampled at a quarterly frequency. We use data from 1976Q1 to 1992Q4 as the training sample in the Bayesian time-varying VAR model, and use the data from 1993Q1 to 2015Q2 for time series analyses. Our choice of the time period used in separating training and estimation periods is motivated by the formal deregulation of the natural gas market in 1993. Under the Natural Gas Act of 1938, gas rates in the US had been traditionally regulated under the Federal Power Commission. Though the 1978 Natural Gas Policy Act attempted to deregulate 
the natural gas market, the Natural Gas Wellhead Decontrol Act of 1989 accelerated this process, formally ending all price regulations by January 1993. Combined with FERC order 636, which in 1992 mandated the unbundling of pipeline services (previously pipelines were able to combine sales and transportation), this effectively ended all government control over the market (Joskow, 2013). Finally, based on results from the Augmented Dickey-Fuller test, we transform the four variables into their logarithmic differences, which essentially measures the quarterly growth rate of each variable. To account for the apparent seasonality in consumption and inventory data, we further deseasonalize the four variables using seasonal dummies.

\section{Estimation Results}

In this section, we discuss the results from the Bayesian VAR model with time-varying parameters and stochastic volatility. Results are organized into sub-sections containing impulse response functions, elasticities, forecast error variance decompositions, historical decompositions, and analyses of historical events. ${ }^{18}$

\subsection{Responses to Natural Gas Supply and Demand Shocks}

Standard time-series analysis often reports the impulse response functions of endogenous variables given one standard deviation structural shocks. The resulting trajectory of impulse responses traces out the average reactions of current and future values of an endogenous variable to a shock to the current value of one of the structural innovations. Such an approach, however, may generate misleading results in a timevarying VAR model as not only the magnitude of each shock differs from period to period, but the propagation mechanism through which a structural shock affects the endogenous variables is not constant. It is impossible to know ex ante whether a change in response was due to a change in the relationship of the variable to each innovation or a change in the magnitude of an innovation. Here, we follow Baumeister and Peersman (2013b) and consider shocks comparable along some dimensions of observed market changes. We do not attempt to determine the sources of variations, but instead only to establish benchmark scenarios against which the changes in impulse responses can be compared across time periods. Specifically, in the first scenario, we normalize each structural shock such that each results in a $1 \%$ decrease in marketed US natural gas production. In the second scenario, impulse responses are normalized such that each structural shock generates a $10 \%$ increase in the real price of natural gas.

\footnotetext{
${ }^{18} \mathrm{~A}$ lag length of two is used in the estimation. We also considered longer lag lengths, but the results appeared to be qualitatively similar.
} 
Figure 2 plots the median cumulative responses of four endogenous variables to each structural shock which produce a $1 \%$ decrease in the marketed natural gas production ${ }^{19}$. Each response in figures 2-5 are accompanied by the $16^{\text {th }}$ and $84^{\text {th }}$ percentiles of their posterior distributions. Consistent with previous studies, results in figure 2 suggest that natural gas prices respond to shocks in supply and demand rather differently, and that the impact responses vary significantly over time. An unanticipated supply disruption, as shown in column (a), generates a rise in natural gas prices, from 5\% in 1993 to its highest value of $12 \%$ in 2000 . This dramatic increase in price responsiveness coincides with the formal market deregulation in 1993, suggesting an adaptive learning process undertaken by market participants as they developed a better understanding of how market functions without government interventions.

Figure 2. Median Cumulative Impulse Reponses of Aggregate Demand, Inventory Demand, and Price to Structural Shocks Normalized on $1 \%$ Supply Shortfalls
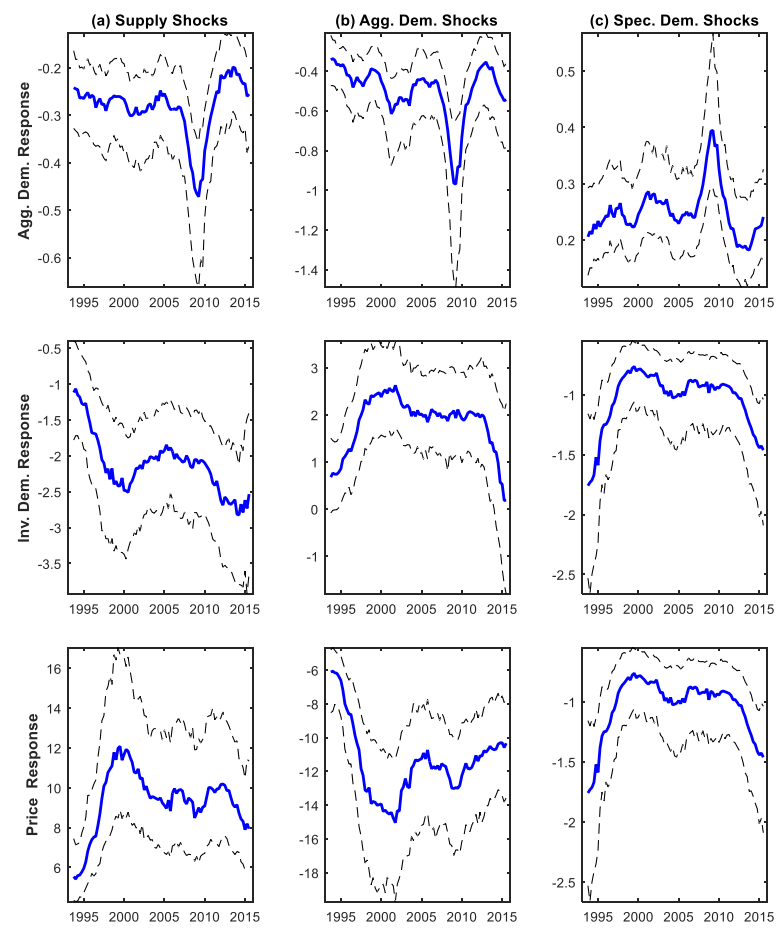

A negative supply shock is also associated with a reduction in aggregate real economic activity in the US and a decline in speculative inventory demand. However, the impact of supply disruptions on aggregate demand is rather limited overall. Even during the great recession of 2007-2009, the median impact response of aggregate economic activity to supply disruptions was at most $-0.6 \%$, which is consistent with

\footnotetext{
${ }^{19}$ Note the responses of natural gas production are omitted from the plot because we have normalized its response to each structural shock to be $-1 \%$.
} 
a number of previous studies that find a limited role of natural gas supply shocks in domestic economic activities in the US (e.g., Kliesen, 2006).

Column (b) of figure 2 displays responses to a negative shock in aggregate demand leading to a $1 \%$ decrease in marketed natural gas production. Consistent with results from supply shocks, a gradual decline in price responsiveness was observed after peaking in 2000, partly reflecting the ability of market participants to better manage price risks from unforeseen demand shocks in an increasingly maturing natural gas market after deregulation. Comparing columns (a) and (b) of figure 2, it is apparent that speculative demand responds differently to unanticipated shocks to supply and aggregate demand. A negative aggregate demand shock leads to an increase in speculative inventory demand, whereas a negative supply shock leads to a decrease. These findings are consistent with previous theoretical work on storable commodities that inventory plays a vital role in mitigating price fluctuations due to supply and demand shocks (e.g., Working, 1949; Pindyck, 2001). However, it should be noted that starting from 2013, the increase in inventory after a negative aggregate demand shock is minimal, reflecting market participants' bearish expectation that low natural gas prices are likely to prevail for an extended period of time with the apparent oversupply in the market.

Panel (c) of figure 2 suggests that an unanticipated negative speculative demand shock is needed to reduce marketed natural gas production. Following a decrease in speculative demand, aggregate demand associated with real economic activity declines marginally and the real price decreases. However, the magnitude of price changes from a speculative inventory demand shock appears to be significantly smaller than either a supply or an aggregate demand shock.

In the second scenario, we normalize our impulse responses such that each structural shock raises the real natural gas price by $10 \%$. Results plotted in figure 3 corroborates findings from figure $2 .{ }^{20}$ Additionally, we note in panel (b) of figure 3 that although the responses of natural gas production to a positive aggregate economic shock have changed over the sample period, their relative impacts in recent years are small. Due to the substantial capital investment required for natural gas production, a firm's ability to take advantage of a temporary positive aggregate demand shock is likely to be limited.

\footnotetext{
${ }^{20}$ Note the responses of natural gas prices are omitted because we have normalized its response to each structural shock to be $+10 \%$.
} 
Figure 3. Median Impulse Reponses of Aggregate Demand, Inventory Demand, and Price to Structural Shocks Normalized on 10\% Price Increase
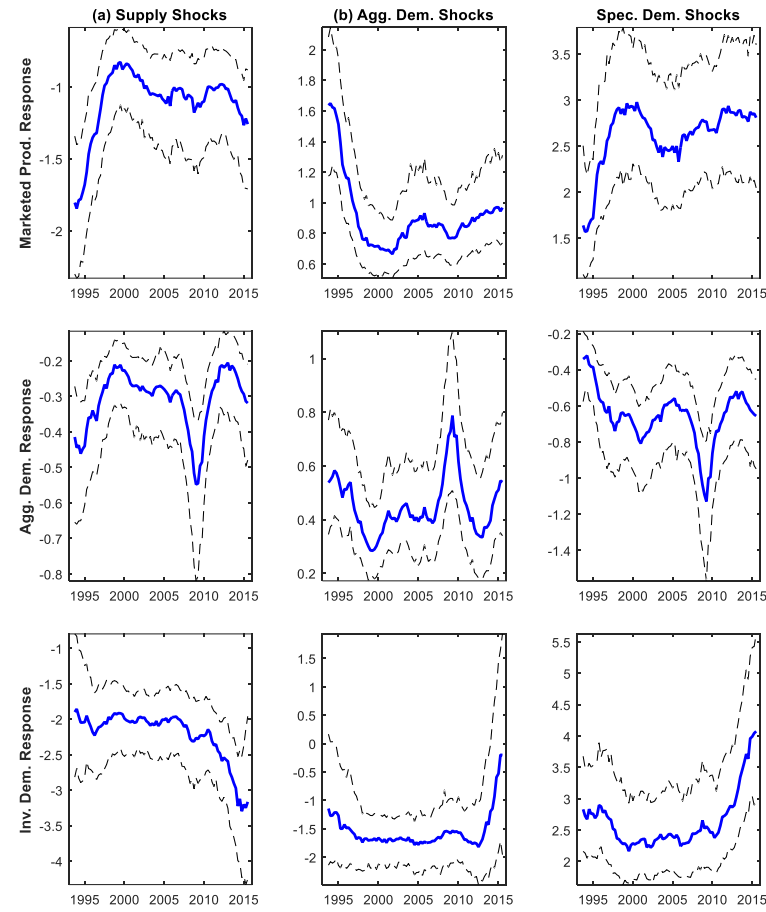

\subsection{Estimating Supply and Demand Elasticities in the US Natural Gas Market}

Direct estimation of price elasticities in the natural gas market is difficult, as the observed movements in quantity and price are often driven by a combination of supply and demand factors that are hard to disentangle. However, in a structural VAR model, structural shocks are by definition mutually uncorrelated, each generating unique reactions in the endogenous variables, with each having direct economic interpretations. In our model, we have identified structural shocks by imposing unique sign patterns in the contemporaneous responses of endogenous variables. Since these structural shocks induce responses in the natural gas market variables by shifting either the demand or supply curve, we can calculate the implied short-run price elasticities from impulse responses associated with each structural shock by dividing the percentage changes in quantity with the percentage changes in prices.

Figure 4 presents the evolution of median short-run price elasticities of natural gas supply and demand in the US between 1994 and 2015. Note that in our analysis we consider three different dimensions of demand shocks each of which can shift the demand curve upward or downward. Hence we trace out the curvature of the supply curve associated with aggregate demand and inventory demand shocks. As can be seen, elasticity estimates presented in figure 4 confirm our findings from impulse responses that the 
supply of natural gas in the US responds differently depending on the nature of the demand shock. Except the early part of the sample, the median supply elasticities associated with aggregate demand shocks have been rather stable, oscillating between 0.06 and 0.1 (panel (a), figure 4). Even during the period of rapid shale production, the supply elasticity associated with aggregate demand shock has only increased slightly, settling at around 0.1 in 2015 .

Figure 4. Median Natural Gas Price Elasticities of Demand and Supply Derived from Impulse Responses Estimates (1993-2015)
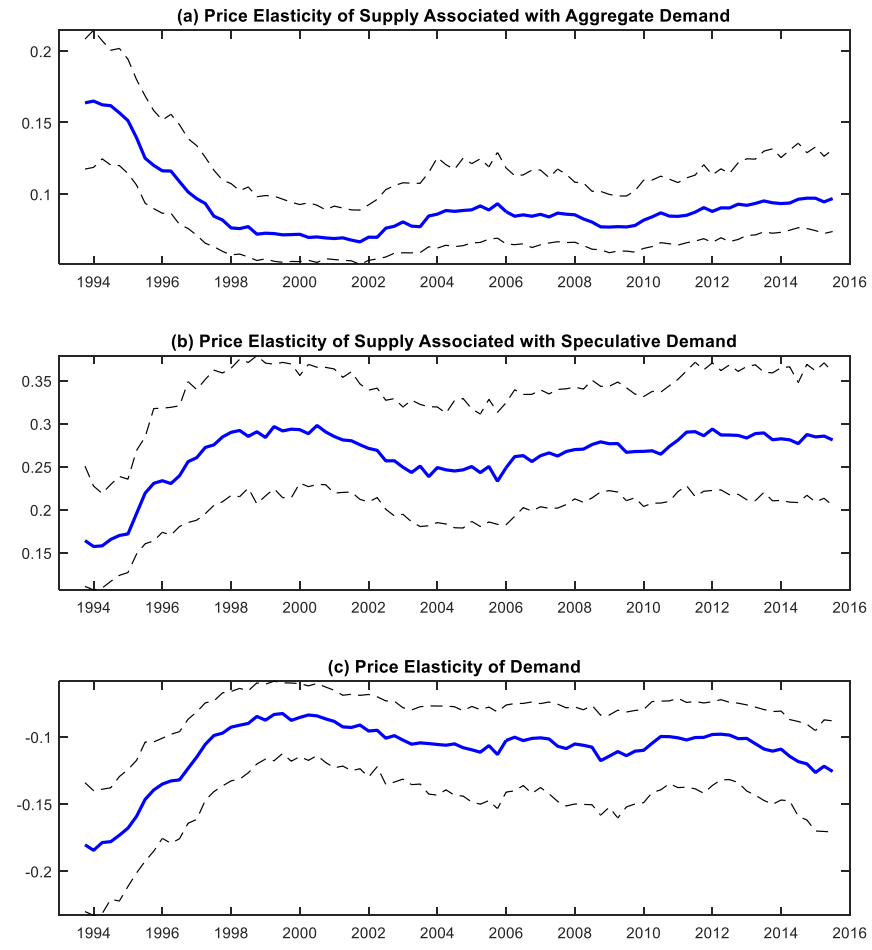

The evolution of supply elasticity due to speculative demand shocks is presented in panel (b) of figure 4 . Much larger variations are observed for the first ten years of the sample (1994-2003), but since then the curvature of the supply curve derived from speculative demand shocks has remained close to 0.25. Results suggest that natural gas supply in the US may have been more responsive to precautionary inventory demand shocks than aggregate demand shocks. Additionally, though natural gas supply in the US is inelastic overall, elasticity has increased slightly since the shale boom. Arora (2014) argues that such increases in elasticity should not be surprising as production can take place faster when extracting natural gas from shale formation as compared to conventional production methods. Overall the increase in supply elasticity is small. 
Panel (c) of figure 4 plots the median price elasticities of demand derived from shifts in the supply curve. ${ }^{21}$ After a decrease in the magnitude of elasticity (steeper demand curve) in the first five years of the sample, the demand elasticity in the US natural gas market remained relatively stable for the following 15 years, fluctuating around -0.10 . Recently, however, the demand curve has somewhat flattened, possibly reflecting a greater flexibility in energy substitution as industrial, commercial, and residential users are better able to switch among different fuel sources. As a result, a similar price change induces a larger impact in quantity demanded than before.

Our elasticity estimates are in general consistent with the numbers reported in Arora (2014) using quarterly data. Excluding the shale boom period (1993-2007), Arora (2014) finds that while quarterly demand elasticities remained similar, the supply was considerably less elastic $(0.01$ and 0.10 for elasticities derived from aggregate demand and inventory demand shocks, respectively). Our results, by contrast, suggest a smaller increase in price elasticity of supply after the shale production boom. Additionally, our results are comparable with several previous supply elasticity estimates in the US natural gas market. Dahl (1992) and Barret (1992) estimated domestic price elasticity of supply to equal 0.41 and 0.014 respectively, however both studies use data sampled at the yearly interval. Krichene (2002) estimated the long-run price elasticity of supply at the world level to be 0.6 , and at the short-run elasticity to be -0.06 during 1918-1999. At the monthly interval, Ponce and Neumann (2014) estimate that after one month, the price elasticity of supply is equal to 0.056 , similar to our estimate of response associated with aggregate demand.

\subsection{Robustness Checks}

Kilian and Murphy $(2012,2014)$ argue that using sign restrictions alone only provides weak identification of structural shocks in a VAR model. In addition to sign restriction, elasticity bounds should be used to reduce the set of admissible models. By retaining only models that produce plausible estimates of elasticities, it can be ensured that results are associated with economically reasonable interpretations. However, as identified in Arora (2014), very few papers in the literature have investigated the quarterly supply elasticities of the natural gas market in the US, and the demand elasticity has mostly focused on the residential demand side. For a check on the robustness of our results, we use twice the median elasticity estimates of Arora (2014) obtained for the 1993-2013 period as a bound to construct ranges for model admission. Specifically, we postulate that the short-run elasticity of demand elasticity cannot

\footnotetext{
${ }^{21}$ Kilian and Murphy (2014) and Arora (2014) differentiate price elasticity of demand between those in use and in production. Here we only consider the price elasticity of demand in production
} 
exceed -0.28 , and that the supply elasticities associated with aggregate and speculative demand shocks cannot exceed 0.1 and 0.26 , respectively.

Figure 5 plots the median impulse response functions from admissible models that fall within the elasticity bounds, normalized on $1 \%$ decreases in marketed natural gas production. In general, results appear qualitatively similar when no restrictions are imposed. A comparison between figures 2 and 5 suggests that shocks to production are virtually identical with or without bounds. While there are noticeable differences in results with other impulse response functions, they maintain the movements, and are only a small percent difference. Two exceptions are the price responses to aggregate and speculative demand shocks (last chart of panels (b) and (c)). Larger magnitudes are observed for these two impulse responses toward the end of the sample, indicating that aggregate demand and speculative inventory shocks are playing a greater role in recent years. These results are not unexpected as rather stringent restrictions are imposed on demand and supply elasticities - a similar shock would on average generate larger price responses. Regardless, our results without elasticity bounds are qualitatively comparable to those with elasticity bounds. 
Figure 5. Robustness Check - Median Cumulative Impulse Reponses of Aggregate Demand, Inventory Demand, and Price to Structural Shocks Normalized on 1\% Supply Shortfalls after Imposing Elasticity Bounds
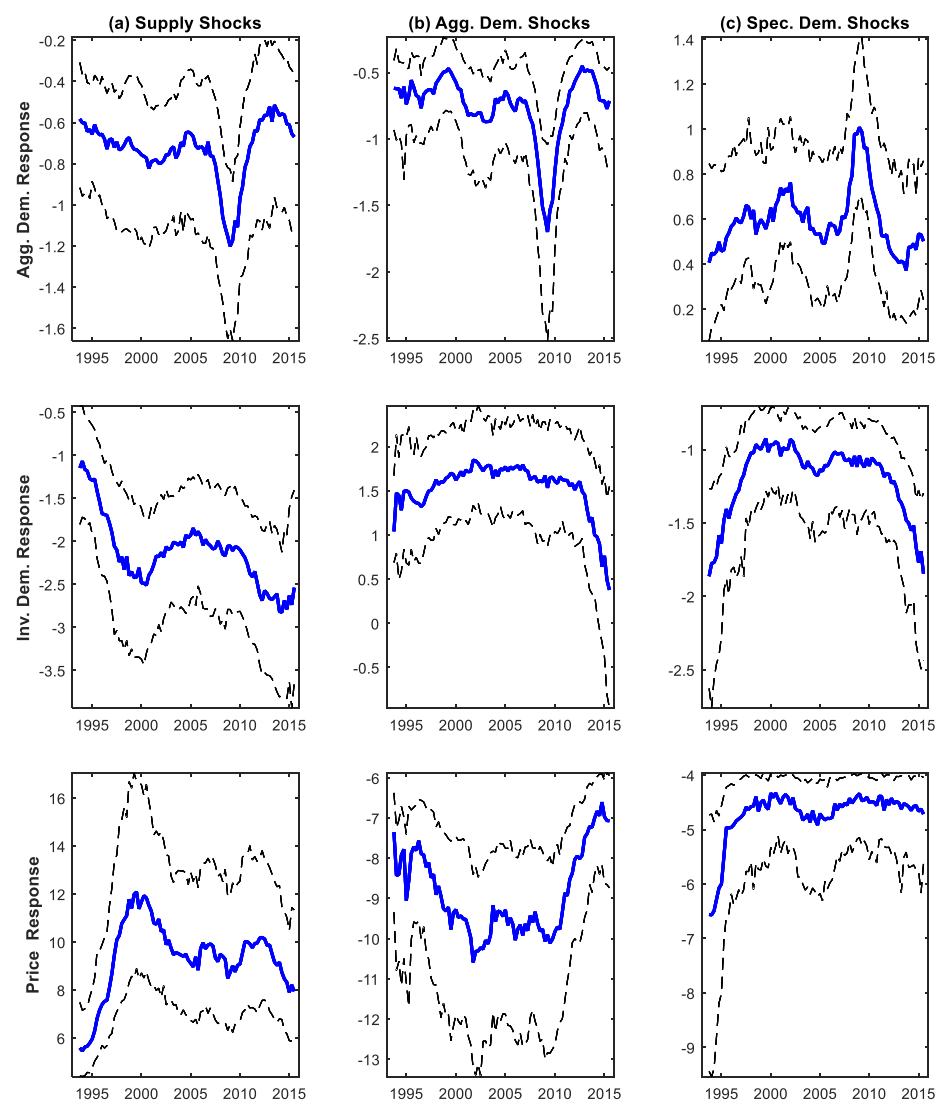

\section{What Drives Variations in the Real Price of Natural Gas?}

Impulse response functions and elasticity estimates provide useful information on the responses of endogenous variables following a one-time structural shock. However, they do not consider the relative importance of each structural shock on the evolution of price movements over time. To shed light on this issue, we investigate the forecast error variance decompositions (FEVD) and historical decompositions (HD) of natural gas prices following the structural VAR estimation.

Figure 6 plots the median contribution of each structural shock to the forecast error variance of real prices, along with their $16^{\text {th }}$ and $84^{\text {th }}$ percentile posterior distributions. It can be seen that the explanatory power of supply shocks peaked in 1999, 2005, and again in 2013, accounting for approximately 35 percent of the error variance of real natural gas price forecasts. Noticeable declines are observed during 
the great recession and another after 2013. Regardless, the relative contribution of supply disruptions to the total variance of the natural gas price forecast error has been consistently above $25 \%$ throughout the sample period, suggesting the important role played by supply shocks in the US natural gas market since deregulation.

Figure 6. Medium FEVD of Real Natural Gas Prices in the US (1993-2015)
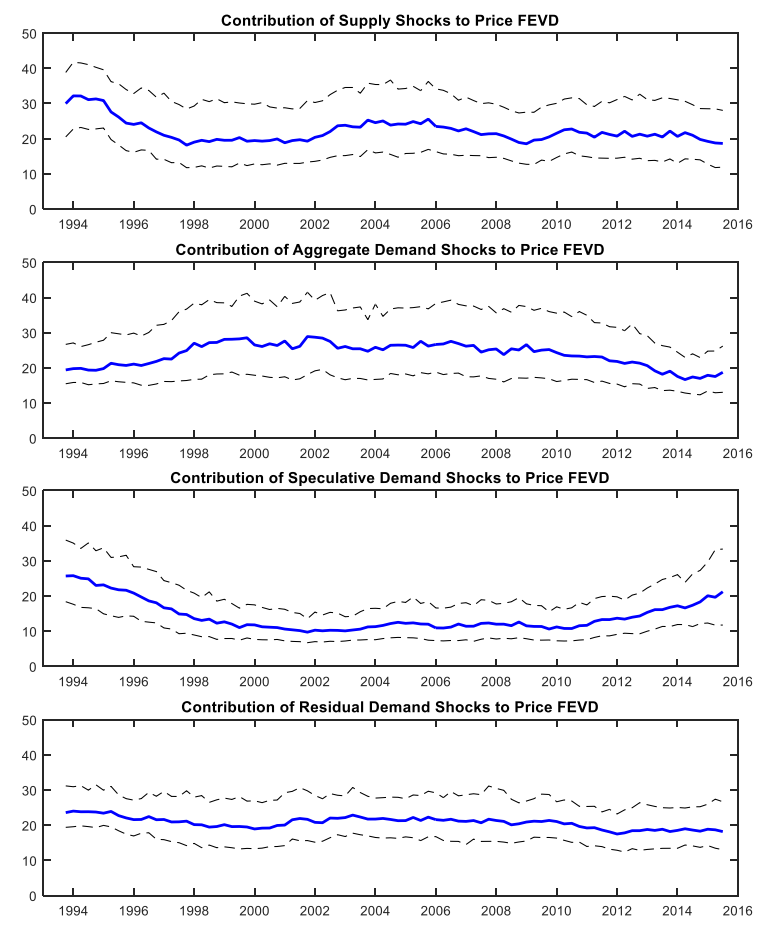

Panel (b) of figure 6 suggests that a similar fraction of the price forecast error variance is attributable to shocks in aggregate economic demand prior to 2009 , after which its explanatory power dramatically declined to about $20 \%$, though a small rebound was observed at the very end of the sample. By contrast, with the exception of the pre-2000 period, residual shocks (other natural gas market demand shocks not accounted by the other three shocks) have consistently accounted for about 30 percent variation in the natural gas price movements. Results suggest that much of the natural gas price variability in the US may be due to market-specific demand factors such as consumers' preference changes, technology improvement that enabled more efficient uses of household appliances, substitution with other energy sources in electricity generation, demographic movements, etc.

Compared with the other three shocks, the relative importance of precautionary inventory demand shocks in shaping price movements has changed considerably. As shown in figure 6, close to $20 \%$ of the forecast error variances of prices can be explained by inventory demand shocks in mid-1990s. For the next decade, 
however, only between $5-8 \%$ of the error variance is attributable to inventory demand shocks. In recent years its explanatory power has increased again, accounting for over $10 \%$ of the variation in natural gas prices in 2015. Our results highlight the important role that inventories perform, regulating the prices of storable commodities as forward-looking agents increase or decrease inventory in anticipation of changes in future supply-and-demand conditions. However, it should be noted that precautionary inventory demand shocks remain a small force in the US natural gas market compared to shocks from fundamentals.

Figure 7 plots the median historical contribution of the four structural shocks to the evolution of natural gas price returns in the US. The solid black line shows the deviation of the deseasonalized natural gas price returns from its mean, and the dashed blue line traces the cumulative effect of the specific structural shock to the evolution of natural gas prices assuming occurrence of no other structural shocks. In other words, the historical decomposition indicates how the price of natural gas would have evolved had only one structural shock occurred. ${ }^{22}$ As is evident in figure 7 , the cumulative effect of each structural shock to natural gas price fluctuations has changed significantly from period to period. Below, we examine three historical episodes characterized by large price volatility to shed light on the relative importance of each structural shock in the US natural gas market.

\footnotetext{
${ }^{22}$ Note that since we deseasonalized our data prior to estimating the time-varying VAR model, the solid black line may behave differently from the actual price movements.
} 
Figure 7. Historical Decomposition of Demeaned Real Natural Gas Price Changes (Demeaned Data in Black and Contribution of the Structural Shock in Blue)
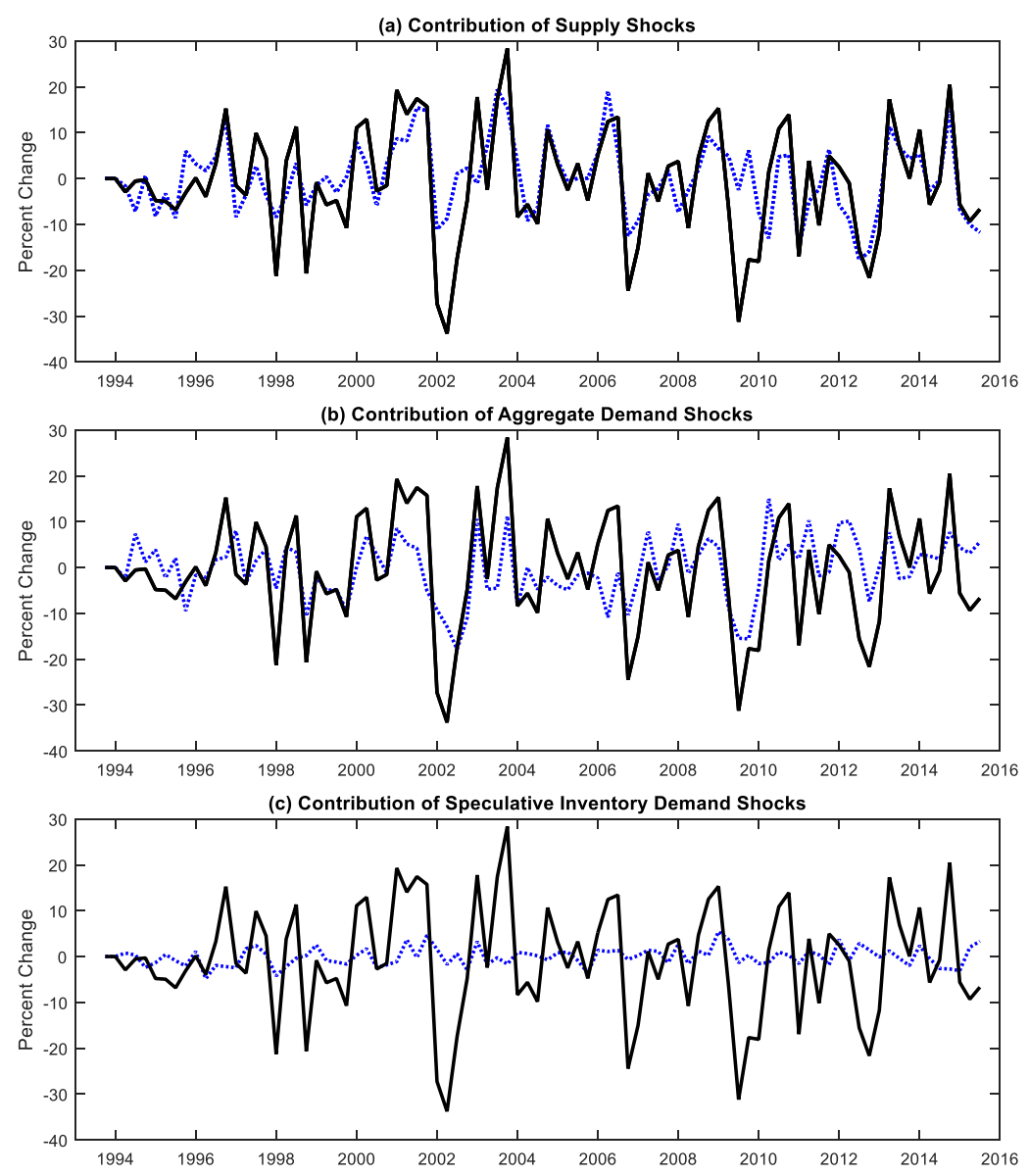

\subsection{How Much Did Shale Production Contribute to the Collapse of Natural Gas Prices?}

Technological advances in drilling methods have made it profitable to extract natural gas from shale and other low-permeability formations. Since 2006, the popularization of combined hydraulic fracturing and horizontal drilling technologies have revolutionized the US natural gas market. Prior to the mid-2000s, natural gas production in the US had been on a slow decline for more than three decades. However, between 2006 and 2015, US dry natural gas production has increased by $39.04 \%{ }^{23}$, largely attributable to the substantial increase in gas from unconventional sources. Meanwhile, natural gas prices in the US have plummeted, dropping more than $82 \%$ from their peak in 2008 at approximately $\$ 10.79$ per thousand cubic

${ }^{23}$ See EIA dry production data at: https://www.eia.gov/dnav/ng/hist/n9070us2a.htm. 
feet to $\$ 1.89$ in May $2012^{24}$, though a small rebound was observed afterwards. Economists and market analysts have largely attributed such dramatic price declines to expansion in shale gas production.

Our results in figure 7 indicate that shocks to natural gas production have played a much more significant role in recent years compared to the pre-shale era. Their importance is particularly evident after 2010, when the line indicating projected price movements with only supply shocks virtually overlaps the actual price line during this period. However, the role of aggregate demand and speculative inventory demand shocks cannot be ignored. As is evident, price movements assuming only aggregate demand shocks have largely followed the same trend as the actual price fluctuations in the post-shale period, highlighting again the importance of real economic activities in the natural gas market. Further, it appears that precautionary inventory demand shocks could explain part of the price movements at the end of 2012, and again in 2014.

\subsection{The Price Escalation in 2007-2008}

Among all the historical events in the US natural gas market that experienced a dramatic price volatility, its price escalation in 2007-2008 is perhaps the least understandable and the most complex (e.g., Smead, 2010). In the beginning of 2007, wellhead prices in the US were still fluctuating between $\$ 6$ and $\$ 7$ per thousand cubic feet. However, by the summer of 2008, the price of natural gas had almost doubled, exceeding $\$ 10$ per thousand cubic feet 25 . At the same time, shale production started to expand and the market was in fact in over-supply. EIA data suggested that the domestic gas production in the first quarter of 2008 was almost $10 \%$ higher than the same quarter of 2007, with consumption rates (the difference between total availability and inventory) essentially flat. This appears to be inconsistent with classic demand and supply theory. So, why did the price of natural gas increase so much in such a short time period?

To understand this phenomena, three relevant facts need to be considered. First, historically the price of natural gas has been closely linked to oil prices. The two prices have been linked for more than two decades since the formal deregulation of the natural gas market in 1993. Economists have generally believed that there exists a long-run relationship (cointegration) between the two price series. Crude oil prices started their run in 2007, increasing more than $245 \%$ in less than two years, peaking at $\$ 133.88 /$ barrel in the summer of 2008 before plummeting to $\$ 41.12 /$ barrel in December 200826. Second,

\footnotetext{
${ }^{24}$ See EIA natural gas price data at: https://www.eia.gov/dnav/ng/hist/n9190us3m.htm.

${ }^{25}$ See EIA natural gas wellhead price data at https://www.eia.gov/dnav/ng/hist/n9190us3m.htm.

${ }^{26}$ See EIA crude oil data at https://www.eia.gov/dnav/pet/hist/LeafHandler.ashx?n=PET\&s=RWTC\&f=A.
} 
a large number of commodities, including energies, grains, softs, and metals all experienced similar price run-ups during this period. A common view in the literature is that speculators partly, if not fully, caused the systematic price increases in commodity markets. Third, even prior to the financial crisis, the housing market had already started its collapse in 2007. Previous literature has proposed a "bubble migration" theory in which financial bubbles first migrated from real estate to the bond market, and then subsequently to the commodity markets (e.g., Phillips and Yu, 2011). In other words, the price rises and falls may have been linked to the overall business cycles in the US and in the world.

Figure 7 suggests that speculation may have indeed partly affected natural gas price movements in 2008 . Assuming only speculative inventory demand shocks, the trajectory of price movements (blue line) appears to closely track the actual price behavior (black line). A similar result may be found in figure 6, which indicates a small increase in the explanatory power of inventory demand shocks on price forecast error variance during this period. In anticipating tighter future demand-and-supply conditions, market participants may have increased their inventory to be carried into future periods for potential profits. However, such an impact is only short-lived, as the actual price behavior drifts away from the path projected by only inventory demand shocks. By contrast, supply and aggregate demand shocks account for the bulk of the price volatility during this period. The projected price movements assuming only supply or aggregate demand shocks appear to line up closely with the line indicating actual price movements.

Overall our results are consistent with previous studies investigating the speculative influences in the natural gas market. Bohl and Stephan (2013) find that financialization in the natural gas market did not significantly increase spot price volatility, while Manera et al. (2014) reported that in the short-run speculation did partially increase price volatility, though this effect becomes negative in the long-run. Meanwhile Geman and Ohana (2009) stated that the correlation between spot price volatility and natural gas inventories is negative only in periods of scarcity, when inventory is below its long run average for natural gas. Results from this study showed that though the impact of speculation cannot be ignored, it plays a very limited role in natural gas price fluctuation in 2008. Instead, price movements predominantly reflect changes in fundamentals.

\subsection{Hurricanes Katrina and Rita in 2005}

Significant supply disruptions occurred to the US natural gas market in the second half of 2005 when hurricanes Katrina and Rita hit the Gulf of Mexico. Before the hurricanes hit, Louisiana and the federal offshore production areas in the Gulf accounted for approximately $20 \%$ of the total natural gas production 
in the US ${ }^{27}$. These back-to-back hurricanes damaged offshore platforms, major processing facilities, and major pipeline segments, resulting in the loss of over 6 billion cubic a feet per day of offshore natural gas supply for an extended period of time. Even months after the storms, the equivalent of $10 \%$ of US consumption remained shut-in due to problems with transportation and production (Kumins and Bamberger, 2005). These prolonged supply disruptions put extreme pressure on the supply-demand conditions in the US natural gas market, as fears rose in anticipation of heightened winter heating costs. As a result, the price of natural gas exceed $\$ 10.3$ per thousand cubic feet in October 2005. However, prices dropped quickly, reaching $\$ 6.85$ in February 2006 as winter that year turned out to be much warmer than anticipated. Low natural gas prices lasted into the rest of the 2006 until the spike in 2008.

This explanation implies that supply shocks in the structural model should account for most of the US natural gas market price surge in 2005. Results in figure 6 suggest that the implied price movements assuming only supply shocks in 2005 line up closely with the actual path of price behavior. Precautionary inventory and aggregate demand shocks, on the other hand, do little to explain the initial price run-ups in 2005. The story changes in 2006, when it appears that aggregate demand shocks do partly explain the natural gas price plunge.

\section{Conclusions}

An integral component of the US economy, the natural gas industry has undergone considerable changes over the past two decades, with the price of natural gas becoming increasingly volatile over time. Effective policy responses to these price changes and other exogenous shocks require a thorough understanding of the underlying drivers behind natural gas price movements. The purpose of this paper is to shed light on this issue by analyzing the time-varying effects of supply and demand shocks on the natural gas market in the US from 1993 to 2015 using a structural vector autoregression model. Specifically, we disentangle the real natural gas prices into four structural shocks: unanticipated supply shocks, aggregate demand shocks, precautionary inventory demand shocks, and residual shocks. Previous studies using a similar approach suffer from four apparent drawbacks: (1) ignoring the time variation in the model parameters, (2) assuming discrete abrupt structural breaks, (3) assuming residual homoscedasticity, and (4) imposing a recursive causal chain in contemporaneous correlations. In this paper, we follow Baumeister and Peersman (2013a, 2013b) and seek to address these four problems using

${ }^{27}$ See EIA Gulf of Mexico dry natural gas production data at: http://www.eia.gov/dnav/ng/hist/rngr20r3fm 1a.htm, and Louisiana dry production data at: http://www.eia.gov/dnav/ng/hist/n9010la2m.htm. 
a sign-identified structural vector autoregression model that allows for both drifting parameters and timevarying volatility.

Overall, we find that natural gas prices respond to shocks in supply and demand rather differently, and the impact responses differ rather significantly over time. An unanticipated supply disruption raises natural gas prices, reduces the aggregate economic demand, and decreases the precautionary inventory demand. Though supply shortfalls overall have a limited impact on aggregate economic demand, their negative effect may have been exacerbated in a bearish market when the overall economy was shrinking. Inventory demand decreases in response to supply disruptions, apparently dominating the positive precautionary demand of inventory by forward-looking market participants who anticipate a potential gain for carrying natural gas into a future period. A negative aggregate demand shock, on the other hand, depresses natural gas prices, reduces natural gas production, and encourages precautionary inventory demand. Consistent with findings from supply shocks, a gradual decline in price responsiveness (smaller magnitudes) was observed after peaking in 2000. The limited response of inventory demand since 2013 possibly reflects the bearish view of market participants toward natural gas prices in anticipation of a prolonged period with abundant natural gas supply.

Based on the estimated impulse response functions, we calculate the price elasticities of supply and demand. With the exception of the early part of the sample, the median supply elasticity associated with aggregate economic demand shocks is estimated to be between 0.06-0.1. The median supply elasticity associated with speculative inventory demand shocks appear to be of larger magnitudes, ranging from 0.15 to 0.3 . For both supply elasticities a small increase in magnitude is observed toward the end of the sample, possibly due to the fact that new drilling technology has enabled increased production. The price elasticities of demand are estimated to be between -0.18 and -0.08 over the sample period. Similarly, the magnitude of demand elasticity increased in recent years, possibly indicating that in the new era characterized with ample natural gas supply, industrial and residential users may have greater flexibility of substitution in fuel use. Our elasticity estimates overall appear to be consistent with the numbers reported in Arora (2014) using quarterly data.

We further investigate the relative importance of the four structural shocks in driving natural gas price movements using forecast error variance and historical decompositions. We find that supply shocks consistently account for over $25 \%$ of the price variation in the post-regulation era. The explanatory power of aggregate demand shocks is high as well, typically accounting for over $20 \%$ of the price forecast error variance over time. We also note that there is a large portion of forecast error variance that cannot be explained by supply, aggregate demand, and speculative demand shocks. 
To put our impact estimates of supply and demand shocks into perspective, we examine three historical episodes. The recent shale boom constitutes the first episode, during which the production of natural gas skyrocketed and its price plummeted due to improved drilling technologies. We find that shocks to natural gas production can explain the bulk of the price movement in this period, a finding consistent with the general view of market analysts. However, the role of aggregate demand and speculative inventory demand shocks cannot be overlooked, as these two shocks combined could explain part of the price movements at the end of 2012 and in 2014.

In the second historical episode, we investigate the 2007-2008 price escalation in the US natural gas market when the production was in fact larger than usual. We find that speculation can at least partly explain the price variation during this period. However, contrary to common belief, the impact is only short-lived and of small magnitude. By contrast, supply and aggregate demand shocks can account for the bulk of the price volatility during this period. In the third episode, we investigate the 2005 price spike during Hurricanes Katrina and Rita, and find that the implied price movements assuming only supply shocks in 2005 line up closely with the actual path of price behavior.

Our analyses provide a comprehensive and innovative framework for understanding the demand and supply shocks and their impacts on prices in the US natural gas market. Results in this study highlight the importance of incorporating time variations in model parameters. Not only have the impulse responses evolved over time, the relative importance of structural shocks in driving natural gas price movements vary rather significantly in different periods as well. Such variability in model parameters, if ignored, could potentially misinform policymakers and lead to policies detrimental not only to the natural gas industry but also the economy as a whole. The estimation and model identification strategy outlined in this study enables us to address this issue by more accurately gauging the effects of supply and demand shocks in the natural gas market over time. 


\section{References}

Arora, V., 2014. Estimates of the Price Elasticities of Natural Gas Supply and Demand in the United States, Working Paper.

Arora, V., Lieskovsky, J., 2014. Natural Gas and US Economic Activity, The Energy Journal. 35(3).

Atil, A., Lahiani, A., Nguyen, D. K., 2014. Asymmetric and Nonlinear Pass-Through of Crude Oil Prices to Gasoline and Natural Gas Prices, Energy Policy. 65, 567-573.

Barret, C., 1992. US Natural Gas Market: A Disequilibrium Approach, Coping with the energy future: markets and regulations. Volume 2.

Baumeister, C., Peersman, G., 2013a. The Role of Time-Varying Price Elasticities in Accounting for Volatility Changes in the Crude Oil Market, Journal of Applied Econometrics. 28(7), 1087-1109.

Baumeister, C., Peersman, G., 2013b. Time-Varying Effects of Oil Supply Shocks on the US Economy, American Economic Journal: Macroeconomics. 5(4), 1-28.

Benati, L., Mumtaz, H., 2007. US Evolving Macroeconomic Dynamics: A Structural Investigation.

Bohl, M. T., Stephan, P. M., 2013. Does Futures Speculation Destabilize Spot Prices? New Evidence for Commodity Markets, Journal of Agricultural and Applied Economics. 45(04), 595-616.

Brennan, M. J., 1958. The Supply of Storage, The American Economic Review, 50-72.

Brigida, M., 2014. The Switching Relationship between Natural Gas and Crude Oil Prices, Energy Economics. 43, 48-55.

Brown, S. P., Yücel, M. K., 2008. What Drives Natural Gas Prices?, The Energy Journal, 45-60.

Cogley, T., Sargent, T. J., 2005. Drifts and Volatilities: Monetary Policies and Outcomes in the Post WWII US, Review of Economic dynamics. 8(2), 262-302.

Dahl, C. A., 1992. Regional Costs of Natural Gas, American Gas Association, Forecast Review. 1, 21-38.

Geman, H., Ohana, S., 2009. Forward Curves, Scarcity and Price Volatility in Oil and Natural Gas Markets, Energy Economics. 31(4), 576-585.

Hamilton, J. D., 2015. Economic Effects of Shocks to Oil Supply and Demand, Econbrowser blog post, available at http://econbrowser.com/archives/2015/10/economic-effects-of-shocks-to-oil-supplyand-demand.

Hartley, P. R., Medlock, K. B., 2014. The Relationship between Crude Oil and Natural Gas Prices: The Role of the Exchange Rate, The Energy Journal. 32(2).

Hulshof, D., van der Maat, J.-P., Mulder, M., 2016. Market Fundamentals, Competition and Natural-Gas Prices, Energy Policy.

Jacquier, E., Polson, N. G., Rossi, P. E., 1994. Bayesian Analysis of Stochastic Volatility Models, Journal of Business \& Economic Statistics. 12(4), 371-389. 
Ji, Q., Geng, J.-B., Fan, Y., 2014. Separated Influence of Crude Oil Prices on Regional Natural Gas Import Prices, Energy Policy. 70, 96-105.

Joskow, P. L., 2013. Natural Gas: From Shortages to Abundance in The United States, The American Economic Review. 103(3), 338-343.

Kaldor, N., 1939. Speculation and Economic Stability, The Review of Economic Studies. 7(1), 1-27.

Kilian, L., 2009. Not All Oil Price Shocks Are Alike: Disentangling Demand and Supply Shocks in the Crude Oil Market, American Economic Review. 99(3), 1053-1069.

Kilian, L., 2013. Structural Vector Autoregressions, in N. Hashimzade and M. A. Thornton eds., Handbook of Research Methods and Applications in Empirical Macroeconomics. Edward Elgar, Cheltenham, UK.

Kilian, L., Murphy, D. P., 2012. Why Agnostic Sign Restrictions are Not Enough: Understanding the Dynamics of Oil Market VAR Models, Journal of the European Economic Association. 10(5), 1166-1188.

Kilian, L., Murphy, D. P., 2014. The Role of Inventories and Speculative Trading in the Global Market for Crude Oil, Journal of Applied Econometrics. 29, 454-478.

Kim, C.-J., Nelson, C. R., 1999. Has the US economy become more stable? A Bayesian approach based on a Markov-switching model of the business cycle, Review of Economics and Statistics. 81(4), 608-616.

Kliesen, K. L., 2006. Rising Natural Gas Prices and Real Economic Activity, Federal Reserve Bank of St. Louis Review(Nov), 511-526.

Krichene, N., 2002. World Crude Oil and Natural Gas: A Demand and Supply Model, Energy economics. 24(6), 557-576.

Kumins, L. C., Bamberger, R., 2005. Oil and Gas Disruption from Hurricanes Katrina and Rita. Congressional Research Service, Library of Congress.

Manera, M., Nicolini, M., Vignati, I., 2014. Modelling Futures Price Volatility in Energy Markets: Is There A Role for Financial Speculation?, Energy Economics.

Miranda, M. J., Fackler, P. L., 2004. Applied Computational Economics and Finance. MIT press, Cambridge, MA.

Mohammadi, H., 2011. Market Integration and Price Transmission in The US Natural Gas Market: from the Wellhead to End Use Markets, Energy Economics. 33(2), 227-235.

Mu, X., 2007. Weather, Storage, and Natural Gas Price Dynamics: Fundamentals and Volatility, Energy Economics. 29(1), 46-63.

Nick, S., Thoenes, S., 2014. What Drives Natural Gas Prices?-A Structural VAR Approach, Energy Economics. 45, 517-527. 
Olsen, K. K., Mjelde, J. W., Bessler, D. A., 2015. Price Formulation and the Law of One Price in Internationally Linked Markets: An Examination of the Natural Gas Markets in the USA and Canada, The Annals of Regional Science. 54(1), 117-142.

Park, H., Mjelde, J. W., Bessler, D. A., 2007. Time-Varying Threshold Cointegration and the Law of One Price, Applied Economics. 39(9), 1091-1105.

Phillips, P. C. B., Yu, J., 2011. Dating the Timeline of Financial Bubbles During the Subprime Crisis, Quantitative Economics. 2(3), 455-491.

Pindyck, R. S., 2001. The Dynamics of Commodity Spot and Futures Markets: A Primer, The Energy Journal, 1-29.

Ponce, M., Neumann, A., 2014. Elasticities of Supply for the US Natural Gas Market, Working Paper.

Primiceri, G. E., 2005. Time Varying Structural Vector Autoregressions and Monetary Policy, The Review of Economic Studies. 72(3), 821-852.

Qin, X., Bessler, D. A., Leatham, D. J., Wu, X., Gan, L., 2010. Fundamentals and US Natural Gas Price Dynamics, 2010 Annual Meeting, February 6-9, 2010, Orlando, Florida. Southern Agricultural Economics Association.

Ramberg, D. J., Parsons, J. E., 2012. The Weak Tie Between Natural Gas and Oil Prices, The Energy Journal. 33(2).

Renou-Maissant, P., 2012. Toward the Integration of European Natural Gas Markets: A Time-Varying Approach, Energy Policy. 51, 779-790.

Siliverstovs, B., L'Hégaret, G., Neumann, A., Von Hirschhausen, C., 2005. International Market Integration for Natural Gas? A Cointegration Analysis of Prices in Europe, North America and Japan, Energy Economics. 27(4), 603-615.

Smead, R. G., 2010. Price Instability in the US Natural Gas Industry Historical Perspective and Overview, Navigant Consulting, Inc.

Wakamatsu, H., Aruga, K., 2013. The Impact of The Shale Gas Revolution on the US And Japanese Natural Gas Markets, Energy Policy. 62, 1002-1009.

Woo, C. K., Zarnikau, J., Horowitz, I., Shiu, A., 2014. Transparency of Retail Energy Pricing: Evidence from the US Natural Gas Industry, Managerial and Decision Economics. 35(4), 300-308.

Working, H., 1948. Theory of the inverse carrying charge in futures markets, Journal of Farm Economics. 30(1), 1-28.

Working, H., 1949. The Theory of Price of Storage, American Economic Review. 39(6), 1254-1262.

Wright, B. D., Williams, J. C., 1991. Storage and Commodity Markets. Cambridge University Press, Cambridge, UK. 


\title{
Chapter 4 - Essay \#3: How Sub-State Policies Affect the Western US Residential Solar Market: an Application of a Bayesian Spatial Hierarchical Model
}

\begin{abstract}
This paper adds to the literature by applying a hierarchical spatial model to investigate whether municipal, county, and utility policies drive residential solar photovoltaic (PV) adoption. Spatial econometric techniques are utilized to account for the peer effects and spatial clustering that have been found recently in residential PV markets. A hierarchical model is chosen to account for nested structure of the influencing policies. The properly reported marginal effects suggest that after controlling for solar resource, environmental preference, and other demographic information, the local policies are an important driver in the residential solar PV market. The average sub-state solar policy is associated with a 7.7 increase in per capita installed residential capacity in the individual county, and a total of 12.7 percent increase across all counties. Further, the residential market exhibits a moderate but significant amount of spatial autocorrelation at the county level.
\end{abstract}




\section{Introduction}

A market failure exists when the price mechanism fails to account for all associated costs and benefits in the market. The emission of heat-trapping greenhouse gases (GHGs) generated by the production of electricity from non-renewable sources is one such failure. These GHGs represent a significant externality to production. Accordingly, the social costs of production are higher than those felt privately, leading to lower equilibrium prices and higher consumption of carbon-based electricity than what would be otherwise realized at the social optimum. With increased understanding of both this market failure and its implications to current and future economic development, policymakers tried to provide incentives to promote renewable energy generation.

Solar is one such option. As a substitute to non-renewable electricity production, it is an attractive noncarbon based option: increased solar generation could help reduce carbon-based generation to socially optimal values while helping meet the predicted increase in consumption levels. Of the three main noncarbon based generation methods, wind, solar, and hydro, only wind and solar have large potential to increase their capacity, as nearly all optimal dam locations have been utilized. While certainly intermittent, solar generation will always have a baseline generation capacity, as even on the cloudiest days some generation is possible. There are trade-offs for large-scale solar generation: large land requirements in potentially sensitive environments have caused some activist groups, otherwise in support of solar generation, to raise concerns. Further, often new or improved transmission lines are required for connecting utility-scale plants to consumption areas. However commercial and residential scale solar are seen by some as more attractive, as the generation infrastructure can fit on existing and available rooftops. In addition to the use of solar energy to heat and light a home or business, there are two main technologies able to harness solar energy: solar photovoltaic (henceforth solar PV) technologies generate electricity, while solar thermal systems provide water heating. While both replace carbon-emitting electricity production, solar PV does so directly, and has generated significantly more interest in individual homeowners, businesses, and policymakers alike.

The installation of a solar PV generation system requires significant upfront financial resources. According to the National Renewable Energy Laboratory (NREL), a residential PV system costs on average $\$ 3.09$ per watt of installed capacity, or more than $\$ 15,000$ for a $5 \mathrm{~kW}$ system before government and utility financial incentives (Chung et al, 2015). That said, their costs are decreasing. Figure 1 displays the cost reduction in these values: since Q4 2013 the cost of solar has decreased by 7\%, since Q4 2009 that reduction is larger than 55\% (Chung et al, 2015). These costs have continued their descent into 2015, 
with the majority of cost reductions coming from declines in soft costs. However some price declines have been offset by falling incentives (Barbose and Darghouth, 2015).

Figure 1: Costs of Residential Solar PV Installations

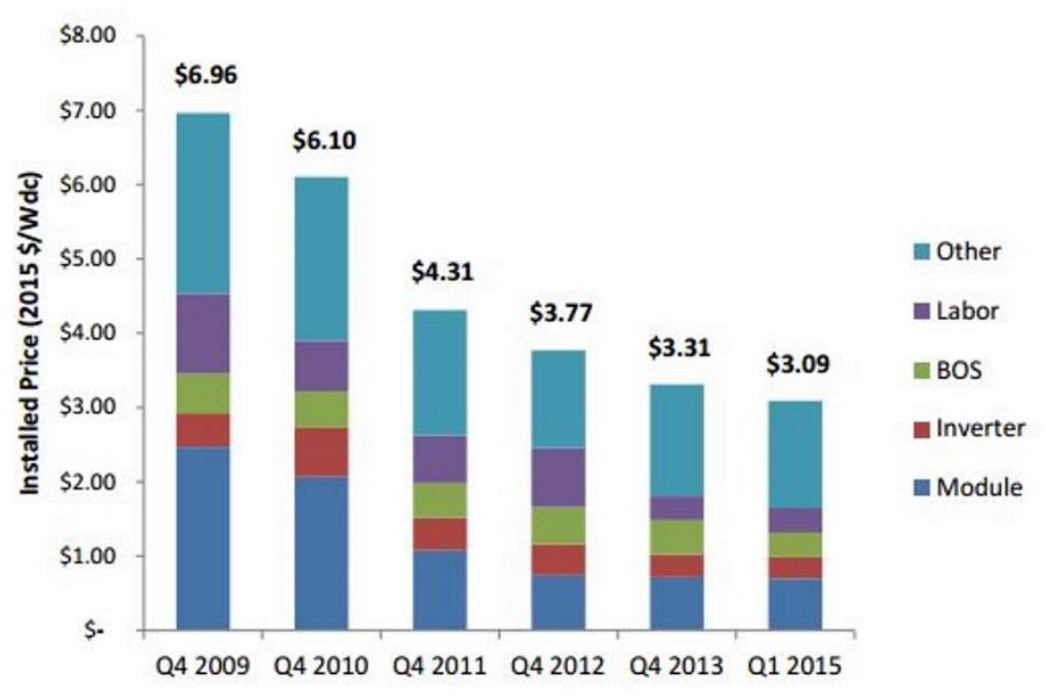

Source: Chung et al, 2015

Even with this reduction the financial benefits of a system, namely the offset of electricity that would be otherwise purchased from a utility, surpass the upfront costs only years after their installation. While the exact timing depends on the costs and financial incentives available to the homeowner, the difference explains a significant amount of the energy efficiency 'gap': the difference between the economically advantageous and actual amount of solar generation installed. A number of third party firms now capitalize on this opportunity by installing and owning entire home systems, while selling the generated electricity either directly to the home or to the connecting utility. Regardless of the financing, the adoption of residential solar is considered a social good, and has received considerable attention recently in the literature.

Borenstein (2015) evaluated the residential solar PV market in California, and found that while it is primarily high-income individuals adopting, that disparity has declined. Further, he finds that adoption is driven by the heaviest electricity-consuming households. California's electricity rate structure is tiered, and adopting households generally pay significantly higher rates for electricity, suggesting that both rate structure and are important considerations. This tiered pricing structure was also found to be significant in California by Dargouth et al. (2011). Bauner and Crago (2015) apply an option value framework to household solar PV decisions, finding that policies that reduce uncertainty could be the most effective stimulants to adoption. 
Alongside household financial and personal characteristics, the financial incentives provided are key drivers in the choice of home solar adoption. From individual municipalities to the federal government, political organizations at nearly every level offer varying forms of financial assistance to help spread the diffusion of solar power. A number of studies have evaluated the impact that specific state policies have had on the solar PV market: Crago (2014) and Sarzynski et al. (2012) evaluate residential markets, and Shrimali and Jenner (2013) look at both residential and commercial. Borchers et al. (2014) find similar effects between specific policies and wind and solar adoption on US farms, however using a different set of state policies. Kwan (2012) also models residential PV adoption, however he measures the effects of an average level of state incentives. There is some recent evidence that increased solar incentive policy is associated with price increases (Gillingham et al., 2016).

None of the preceding study models the effects of federal policy, as those effects are felt everywhere in their study area. Similarly, none measure the impact that sub-state regulatory processes create. This may be an important omission: Two studies (Burkhardt et al, 2015, Dong and Wiser, 2013) highlight how local permitting and regulations can greatly influence both adoption prices and development times. Li and Yi (2014) do investigate sub-state policy's impact on solar PV deployment, finding that along with state policies like RPSs, sub-state policies have positive and significant effects on residential adoption.

However the choice to adopt solar power is not strictly a financial decision. The understanding of solar technology is an important predictor of residential adoption, leading Islam and Meade (2013) to recommend education policies to stimulate solar adoption. Noll et al. (2014) demonstrate how Solar Community Organizations have been an effective means of reducing barriers to adoption. Peer effects are also demonstrated to impact adoption at the zip code level (Bollinger and Gillingham, 2012 and Snape and Rynikiewicz, 2012). Gillinghman et al. (2016) also find that the density of solar installers significantly lowers prices.

There have been recent attempts to quantifying these peer effects. Marcello and Gillingham (2015) find notable clustering in the solar PV adoption, patterns that do not merely follow intuitive spatial patterns of either income of population. Richter (2013) empirically demonstrates small but significant social spillovers in UK installations at the neighborhood level. Balta-Ozkan et al. (2015) further quantify these spatial spillovers in UK solar PV adoption by utilizing spatial econometric methods, which this study follows builds upon looking at the western US market.

The goal of this paper is to follow the analysis of $\mathrm{Li}$ and $\mathrm{Yi}$ (2014) in asking whether sub-state policies have an influential impact on residential solar PV adoption. Using a unique dataset created to 
geographically locate relevant incentivizing policies, this paper improves the literature by providing the first application of a Bayesian hierarchical spatial model to investigate whether sub-state policies are associated with any difference in the amount of per capita residential solar PV capacity. Finding suggest that after controlling for relevant demographic, environmental, and solar potential variables, local policies are found to have a positive and significant impact on the residential market. Further, solar PV adoption is estimated to have a moderate but significant spatial dependence.

\section{Hypothesized Model}

The main empirical goal of this paper is to accurately model the key drivers of solar adoption in the Western United states. Given the cited literature above, I create equation (1) as a hypothesized linear model of the market:

$$
y_{i}=\alpha+X_{i} \beta+P_{i} \gamma+E_{i} \delta+H_{i} \phi+\operatorname{Pol}_{i} \zeta+S_{i} \kappa+S t_{i} \psi+\epsilon_{i}
$$

The dependent variable $y_{i}$ represents the total amount of solar PV capacity in county $i$. In the study area, of the WECC, there are 405 counties. $X_{i}$ is an nxk matrix of k county-level demographic characteristics such as income, age, race, and population and homeownership. Nearly all empirical studies have suggested that income and solar adoption have a strong positive correlation. The level of homeownership is likely an important predictor of residential solar adoption. Similar to other home improvements, renters face little incentive and likely possess less ability to pay the large up-front costs of solar installations. Further, landlords will have significantly less incentive to add solar PV to rental units, especially given the high opportunity cost they would face: those resources could otherwise be spent in ways that would quickly and reliably increase rent, such as newer appliances, better heating, etc.

$P_{t}$ is an nx 1 vector of electricity prices. Solar installations are a substitute to purchasing electricity from a utility. A positive relationship, with higher prices incentivizing greater adoption, is both intuitive and empirically demonstrated in Borenstein (2015) and Dargouth et al. (2011). However this relationship could exhibit a degree of endogeneity, as greater share of electricity generated by solar PV could also impact prices. In fact, utilities often argue increased solar PV integration raises prices, as it requires increased effort to manage its intermittent generation. $E_{i}$ represents an nx1 vector of environmental preferences. There are a number of important positive environmental outcomes from large-scale adoption of solar power, mainly the reduction of GHG emission and improvements in air and water quality caused by a reduction in coal or natural gas emissions. Capturing these preferences likely helps explain the 
household decision ${ }^{28}$. $\mathrm{Pol}_{i}$ is an nxr matrix of solar policies that residents in county $i$ at time $t$ face, where $r$ is equal to the number of geographic levels of policy. For example, a household in Oakland will receive the incentives from any policy run by the city, Alameda County, their electric utility (PG\&E), the state of California, and by the US federal government, and each will vary given the year. Finally, $S t_{t}$ represents a vector of state fixed effects that would capture any additional differences between states affecting solar adoption (e.g. labor costs, construction and connection standards, etc). The states in this sample area likely have significant difference in permitting, labor, and safety regulations. While the impact of each individual regulatory difference on the solar PV market is likely small, aggregated these could make nontrivial differences.

\section{Data}

\subsection{Solar Installations}

Data for residential solar capacity was obtained from the Open PV Project ${ }^{29}$. Produced by the National Renewable Energy Lab (NREL), the Open PV project is a comprehensive dataset of solar PV installations, with data contributed by utilities, installers, and the general public. Data is validated by NREL through a variety of ways, in part based on the trust NREL gives to the reporter. I used data from counties in the Western Electricity Coordination Council (WECC) region of Oregon, Washington, California, Utah, Nevada, Colorado, Wyoming, Arizona, and parts of New Mexico, Montana, Texas, and South Dakota. Individual home installation data are aggregated to the county level. Following Kwan (2012), I limit the upper range of individual solar installations to $10 \mathrm{~kW}$ to ensure that the solar installations included are in fact residential systems $(n=230,152)^{30}$. The distribution of installed solar capacity in 2016 (Figure 2, Panel A) and number of solar PV installations (Figure 2, Panel B) is highly concentrated in the Southwest part of the WECC. Given both the large number of zeros and the rightskewedness of the distribution of county $\mathrm{kW}$ installed capacity, I use an inverse hyperbolic sine transformation, which accommodates zero values but otherwise is directly interpretable as a log transformation (see Burbidge et al, 1988, MacKinnon and Magee, 1990).

\footnotetext{
${ }^{28}$ However strict environmental preference may not be the best explanatory variable: while there is a strong correlation between environmental preference and the political left, energy independence is a trait shared across the political spectrum. There are some for example with strongly divergent views about the importance of air quality who nevertheless support the increase in solar generation

${ }^{29}$ For more information about data methodology, see https://openpv.nrel.gov/about.

${ }^{30}$ As of 4/15/2016
} 
Figure 2: Residential Solar PV Capacity and Number of Installations, 2016

Panel A

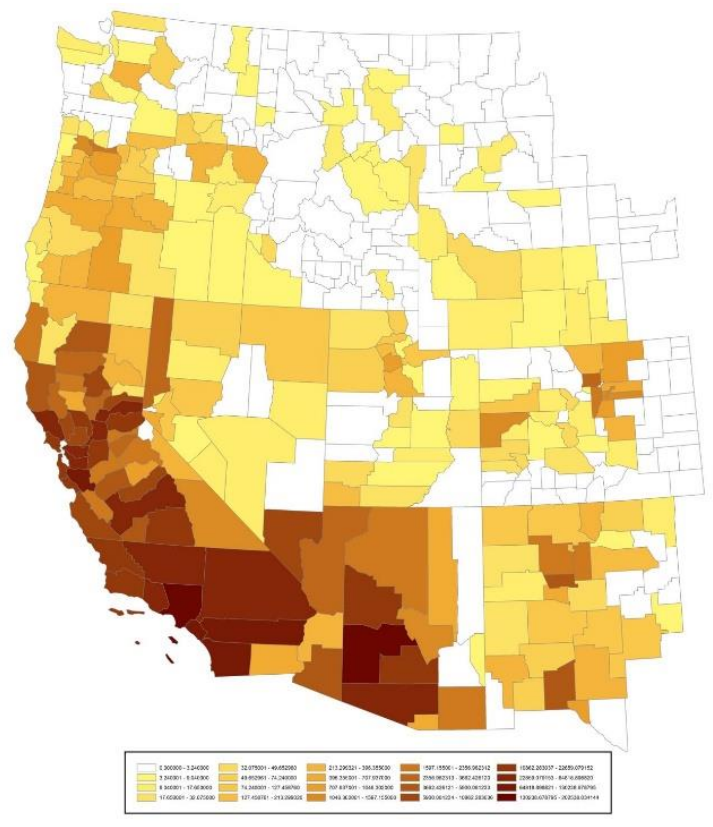

Panel B

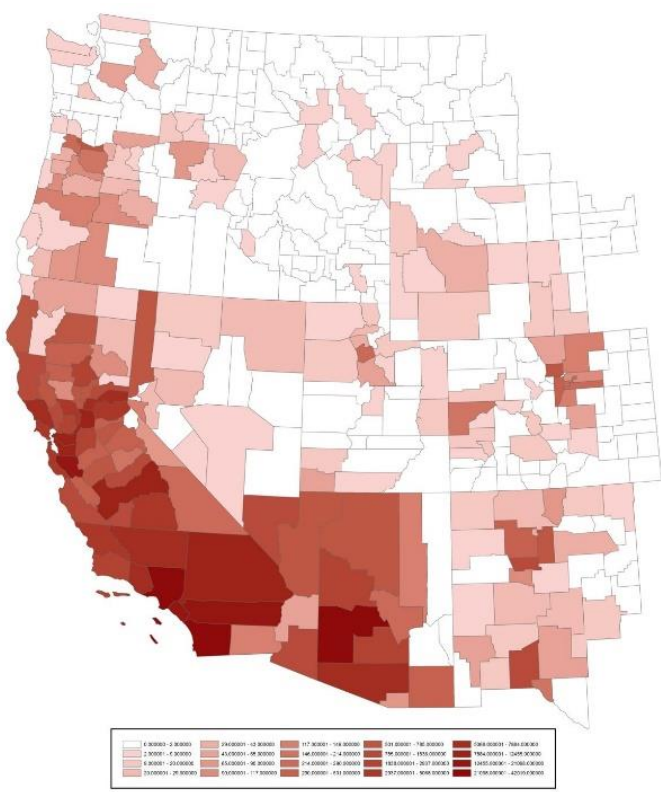

\subsection{Policy Variables}

State, utility, county, and municipality policies are collected from the North Carolina Clean Energy's Database of State Incentives for Renewables and Efficiency (DSIRE, 2015). The DSIRE database is a comprehensive collection of policies and incentives that involve renewable energy and energy efficiency growth in the US. There are 43 categories of renewable policy; from corporate tax credits to feed-in tariffs. From these categories, I select from all but the corporate and utility categories those designated with as solar technologies. While many of these policies are at the state level, a significant number are enacted by cities, counties, and utilities. Dong and Wiser (2013) provide evidence that city-level permitting tangibly affects both the price and development time of residential PV installations. With this in mind, I include both municipality and county policies. However given that demographic data is only available at the county level, I aggregate municipal policies to the county level. Only policies in the county's dominant population center are included, however there were only a small number of municipal policies in a county that were not included at the county level, as in general municipal policies are enacted in larger cities that dominate the majority of the county.

Renewable policies from utilities are important to include in the analysis as well. Investor-owned utilities (IOUs) are generally not interested in measuring and/or correcting for social costs. Further, they have some disincentive for the increase of solar energy: Solar PV is both distributed and intermittent, making 
their job of providing electricity at all hours difficult and often more expensive. However, there are some reasons for IOUs to promote residential solar PV capacity additions: Evidence. Further, municipal utilities and electric cooperatives are generally more attuned to both customer preferences as well as larger problems, and more insulated from the pressure to increase profit. Thus I include solar policies at the utility level. Assigning them to a particular county can be difficult, as their boundaries often do not align perfectly with county jurisdictions. I follow the similar path with that of city-level policies: counties whose main population centers within a utilities coverage area are said to be affected by this policy, and vice versa. Utility coverage areas for most states in the WECC are available through individual states' Public Utility Commissions, with varying degrees of resolution. Only California has utility coverage areas available in shapefile formats: for the rest utility coverage images were georeferenced and interpolated using ArcGIS. I combine these sub-state policies from the utility, county, and municipality level into one 'Local' value for each county, and another reflecting the policies for the state in which the county resides. The distribution of state solar policies are displayed in panel A of figure 3. As can be seen, significant variation happens at the state hole. Non-state policies are displayed panel B, which displays a much smaller amount of variation between counties.

Figure 3: Number of Solar Incentivizing Policies

Panel A

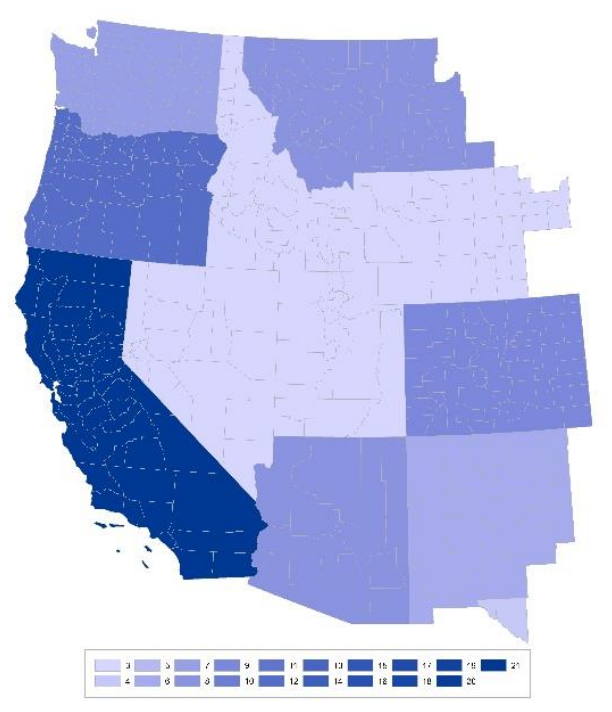

Panel B

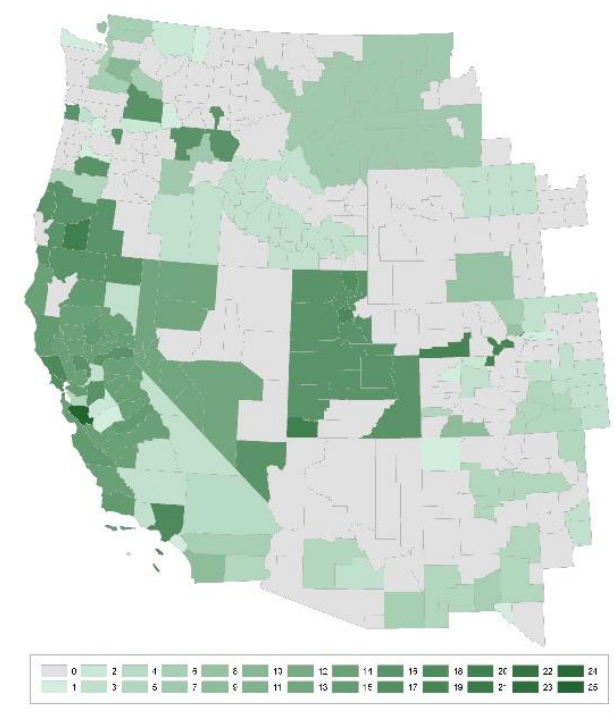

\subsection{Solar Insolation}

To measure the amount of potential a given county has to generate electricity from solar radiation, I use annual solar insolation, the cumulative kilowatts per square meter per day. This data is collected and 
distributed by NREL ${ }^{31}$ and produced by the State University of New York/Albany satellite radiation model. This data is available at 10 kilometer resolution, and each county's annual average values are calculated using ArcGIS's spatial statistics toolbox. These averages are displayed in figure 4.

Figure 4: Average Solar Insolation

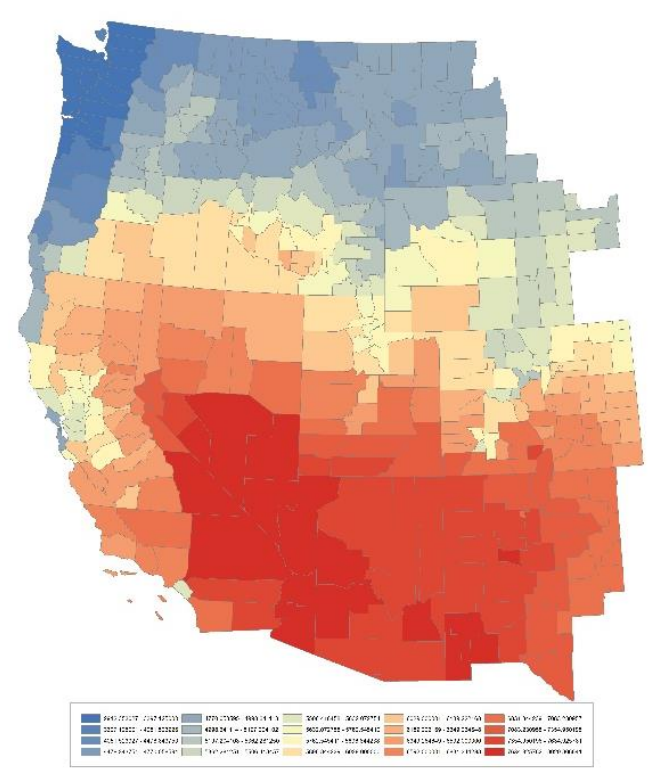

\subsection{Environmental Preference}

To capture county residents' environmental preferences, I use results from the US Presidential elections. Coan and Holman (2008) demonstrate how there has been a long established and intuitive correlation between Democratic Party voting and environmental concern. Further, in his first presidential term and during the 2012 election campaign, President Obama frequently made mention of themes of climate change, energy independence, renewable resources, and a 'green' economy. While the decision for a single office will be a selection of a number of non-policy issues, and thus provide a weaker proxy for a single preference, given the recent rise in political polarization in the US the difference in voting record from individual elections will likely matter less.

I also include the number of Whole Foods locations in each county to further capture environmental preference is. Whole Foods is an upscale food retailer, specializing in food certified as natural and/or organic. It caters to a population with a willingness to pay higher prices for food perceived to be healthier and more ethically produced, which is assumed to be highly correlated with the environmental

\footnotetext{
${ }^{31}$ Available: http://www.nrel.gov/gis/data_solar.html
} 
preferences that would drive solar adoption. To my knowledge, this is the first time Whole Food locations have been used to measure environmental performance. However many similar measures have been used, such as organic food sales and hybrid and electric vehicle penetration (Crago and Chernyakhovskiy, 2014).

\subsection{Electricity Prices, County Demographics}

Average residential electricity prices come from EIA's Form 861, which provide average electricity prices at the residential level from each utility, which are averaged at the state level. County demographic information comes from US Census' American Community Survey, using the American FactFinder website $^{32}$. Using their five year ACS estimates ${ }^{33}$, I use income per capita and county median age. Summary statistics for demographic information and all other variables are displayed at the county level in Table 1.

Table 1: Summary Statistics

\begin{tabular}{l|cccc} 
Variable & Mean & Stdv & Min & Max \\
\hline Capacity & 3810.708 & 17691.01 & 0 & 202219.9 \\
Population & 182443.9 & 652019 & 485 & $1.01 \mathrm{E}+07$ \\
WattsPC & 1.180418 & 1.56461 & 0 & 5.182375 \\
LocalPol & 5.175309 & 6.155283 & 0 & 25 \\
PCIncome & 40350.32 & 13185.71 & 21779 & 194485 \\
lnPCIncome & 10.57138 & 0.2420296 & 9.988702 & 12.17811 \\
PctDem & 39.03862 & 16.77843 & 5.772967 & 93.38633 \\
WhlFds & 0.3555556 & 1.6441441 & 0 & 26 \\
ElectPr & 11.57128 & 2.240555 & 8.67 & 16.25 \\
MedAge & 40.58296 & 7.00558 & 23 & 61.2 \\
Homeowner & 68.92686 & 8.102741 & 36.60472 & 92.92375 \\
wBach & 25.40346 & 10.26913 & 7.5 & 67.8 \\
SolPot & 5783.208 & 1135.074 & 2912.353 & 8020.807 \\
NumOwd & 36990.74 & 110930.2 & 165 & 1503915 \\
lnNumOwn & 8.946272 & 1.719836 & 5.105946 & 14.22358 \\
Detached & 70.7642 & 9.507747 & 20 & 93.9 \\
StatePol & 8.659259 & 5.755965 & 3 & 21
\end{tabular}

\section{Empirical Model}

A limitation of the model in equation (1) is that it ignores any spatial influence on the adoption of solar power. As explained in the previously cited literature, there are likely strong spatial influences in an empirical model estimating the adoption of residential solar, from peer effect causing industry and/or adoption clustering. Failing to include influential explanatory variables into the model would create

\footnotetext{
32 Available: http://factfinder.census.gov/faces/nav/jsf/pages/searchresults.xhtml?refresh=t

${ }^{33}$ Sampled over five years: 2009-2014
} 
omitted variable bias (LeSage and Pace, 2009). To test the spatial effects presented in equation (1), I generate a Moran's I statistic ${ }^{34}$, and in comparing it to a chi-squared distribution with 1 degree of freedom, I strongly reject the null hypothesis of no spatial autocorrelation.

\subsection{Spatial Hierarchical Methodology}

Given this significant presence of spatial autocorrelation, I follow Balta-Ozkan et al. (2015) in applying spatial econometric methods to solar PV market, modeled in equation (1). I start with the Spatial Durban Model (SDM), which controls for spatial autocorrelation of the dependent variable as well as the spatially weighted independent variables:

$$
y_{i}=\rho W y_{i}+X_{i} \beta+W X_{i} \Theta+\epsilon_{i}, \epsilon_{i} \sim N\left(0, \sigma^{2}\right)
$$

where $X$ is an nxk matrix of independent variables for each county. $W$ is a binary nxn spatial weight matrix describing contiguous neighbors created from Delaunay triangles, and $\rho$ is the average spatial spillover of the dependent variable. For global models, with spatial spillovers propagating over the entire sample area, the SDM is preferred over more common spatial models including the Spatial Autoregressive Model (SAR) and the Spatial Error Model (SEM): As the SDM nests both the SAR and SEM, it will produce unbiased coefficients even if the true DGP is the SAR or SEM (see LeSage and Pace, 2009). Conversely, using a SAR or SEM when the true DGP is an SDM will lead to either omitted variable bias or a loss in efficiency, or both (Ellhorst, 2010).

In this application, a serious limitation to these common spatial approaches comes from the structure of the data: individual counties are nested within states. In addition, each state's unique governance and legal structure affects the residential PV market differently. From the production and/or importing of the solar panels, to the construction permitting process, to the connection to the electrical grid, there are a myriad of levels of regulation that an installation of solar panels must go through. Capturing this significant source of heterogeneity among individual states is necessary to understand any policy effect. Given this, I apply a hierarchical SDM model similar to that proposed in Lacombe and McIntyre (2016). At the first level, counties within the WECC, I model:

$$
y_{i, j}=\rho W y_{i}+\Delta \alpha_{j}+X_{i} \beta+W X_{i} \Theta+\epsilon_{i j}, \epsilon_{i j} \sim N\left(0, \sigma^{2}\right)
$$

\footnotetext{
${ }^{34}$ Moran's I Statistic: $5.146, \mathrm{p}$-value: 0.000
} 
where $\alpha$ represents the policy effect that at the county level by the individual state in which they are located. Modeling this parameter happens at the second level, States within the WECC, modeled as:

$$
\alpha_{j}=Z_{j} \gamma+\epsilon_{i}, \epsilon_{i j} \sim N\left(0, \tau^{2}\right)
$$

In this equation $Z$ is a $13 \times 2$ matrix, with the rows representing the 13 states in the sample area, and the columns depicting a constant term as well as the given state's solar incentive policies.

Given this model, we define the full posterior distribution as follows:

$$
\begin{aligned}
& \pi(\Theta, \alpha \mid y) \propto|A| \sigma^{-N} \exp \left\{\frac{1}{2}(A y-\Delta \alpha-D \zeta)^{\prime} C_{\beta}^{-1}(A y-\Delta \alpha-D \zeta)\right\} \\
& \times \tau^{-J} \exp \left\{\frac{1}{2}(\alpha-Z \gamma)^{\prime} C_{\gamma}^{-1}(\alpha-Z \gamma)\right\} \\
& \times \sigma^{-1} \exp \left\{\frac{1}{2 \sigma^{2}} V_{\sigma_{0}^{2}} S_{\sigma_{0}^{2}}^{2}\right\} \\
& \times \exp \left\{\frac{1}{2}(\beta-c)^{\prime} T_{\beta}^{-1}(\beta-c)\right\} \\
& \quad \times \tau^{-1} \exp \left\{\frac{1}{2 \tau^{2}} V_{\tau_{0}^{2}} S_{\tau_{0}^{2}}^{2}\right\} \\
& \times \exp \left\{\frac{1}{2}(\gamma-d)^{\prime} T_{\gamma}^{-1}(\gamma-d)\right\} \\
& \quad \times U\left(-\frac{1}{\lambda_{\min }}, \frac{1}{\lambda_{\max }}\right)
\end{aligned}
$$

Where $C_{\beta}^{-1} \equiv\left(\sigma^{2} I_{n}\right)^{-1}, C_{\beta}^{-1} \equiv\left(\tau^{2} I_{n}\right)^{-1}, A \equiv\left(I_{n}-\rho W\right)$, and $D \zeta \equiv[X \beta, W X \Theta]$. $\lambda_{\min }$ and $\lambda_{\max }$ are the smallest/largest eigenvalue of $W$. The typical row-standardization of $W$ renders the value of $\lambda_{\max }=$ 1. Equations 4 and 5 depict the likelihood functions for both level 1 and level 2 respectively. Priors for level-one error variance $(\sigma)$ and parameters $(\beta)$ are represented in equations 6 and 7. For level two, priors for the error variance $(\tau)$ and parameters $(\gamma)$ are found in equations 8 and 9. MCMC methods, Gibbs/MH estimator is used 


\subsection{Estimation Results}

Estimates for the values of $\beta, \sigma, \alpha, \gamma, \tau$, and $\rho$ are presented in table X. Results suggest a moderate but significant amount of spatial autocorrelation in the model $(\rho=.38)$. While Pace et al. (2012) find much higher $\rho$ values (upwards of .95) in many economic factors such as income and production, at the county level spillovers are still an important part of the market: this results suggests that in the sample area when a county increased its solar PV capacity by $10 \mathrm{~W}$ per capita, neighboring counties will increase theirs by an average of $3.8 \mathrm{~W}$ per capita. This supports arguments put forth above about the importance of both peer effects and spatial clustering in the residential solar market.

State policies are found to have a positive effect on residential adoption - the positive coefficient on $\gamma_{2}$ suggests that the relationship between state policies and PV adoption in the eastern US found by Crago and Chernyakhovskiy (2014) likely hold in the west as well.

Table 2: Bayesian Coefficient Estimates

\begin{tabular}{|c|c|c|c|c|c|c|c|c|}
\hline Variable & Name & Coefficient & Variable & Name & Coefficient & Variable & Name & Coefficient \\
\hline$\beta 1$ & LocalPolicy & 0.0747 & $\beta 11$ & W*LocalPolicy & 0.0044 & $\alpha$ & . & 0.3945 \\
\hline$\beta 2$ & $\ln$ PersInc & -0.0253 & $\beta 12$ & $\mathrm{~W}^{*} \ln$ PersInc & 0.1311 & $\sigma$ & . & 0.9489 \\
\hline$\beta 3$ & PctDem & -0.002 & $\beta 13$ & $\mathrm{~W} *$ PctDem & 0.0065 & $p$ & . & 0.3776 \\
\hline$\beta 4$ & WholeFoods & -0.0474 & $\beta 14$ & W*WholeFoods & 0.0148 & $\gamma 1$ & Constant & -0.1216 \\
\hline$\beta 5$ & ElectricityPrices & 0.0682 & $\beta 15$ & $\mathrm{~W} *$ ElPrices & 0.1075 & $\gamma 2$ & StatePol & 0.0746 \\
\hline$\beta 6$ & MedAge & 0.0229 & $\beta 16$ & $\mathrm{~W} *$ MedAge & -0.0047 & $\tau$ & . & 0.4249 \\
\hline$\beta 7$ & wBach & 0.0173 & $\beta 17$ & $\mathrm{~W}^{*}$ wBach & -0.0314 & & & \\
\hline$\beta 8$ & SolPot & 0.0003 & $\beta 18$ & $\mathrm{~W} *$ SolPot & -0.0003 & & & \\
\hline$\beta 9$ & Detached & -0.0006 & $\beta 19$ & W*Detached & -0.0217 & & & \\
\hline \multirow[t]{2}{*}{$\beta 10$} & lnNumOwn & 0.1489 & $\beta 20$ & $\mathrm{~W}^{*} \ln \mathrm{NumOwn}$ & 0.0062 & & & \\
\hline & & & $\beta 21$ & Constant & -3.4657 & & & \\
\hline
\end{tabular}

With frequentist statistics, parameters are assumed fixed while the data varies. However with Bayesian statistics, the data is presumed fixed while parameters are allowed to follow some distribution. This allows the investigation of the distribution of individual parameters. For our parameter of interest, local policies, the full distribution is presented in figure 5: 
Figure 5: Distribution of $\beta_{2}$, Sub-State Policies

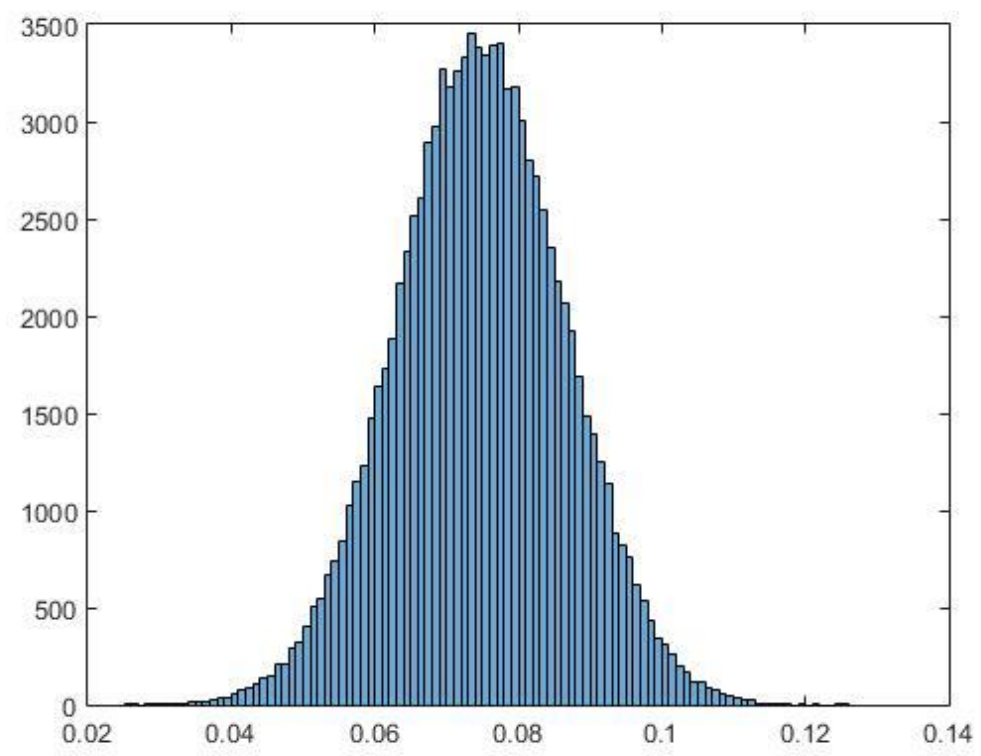

The Gibbs-sampler produced 100,000 iterations (200,000 total, with 100,000 discarded). While suggestive of a positive relationship, it is important to note that the interpretation of non-SEM spatial econometric models requires more care than is generally given. Producing the marginal effects from the SAR requires simple algebra to generate its reduced form:

$$
\begin{gathered}
y_{i}=\rho W y_{i}+X_{i} \beta+\epsilon \\
y_{i}-\rho W y_{i}=X_{i} \beta+\epsilon \\
y_{i}\left(I_{n}-\rho W\right)=X_{i} \beta+\epsilon \\
y_{i}=\left(I_{n}-\rho W\right)^{-1} X_{i} \beta+\left(I_{n}-\rho W\right)^{-1} \epsilon
\end{gathered}
$$

Partially differentiating the reduced form equation with respect to $x_{i, t}$ produces:

$$
\frac{\partial y_{i}}{\partial x_{i}}=S(W)=\left(I_{n}-\rho W\right)^{-1} X_{i}
$$

where $S(W)$ is an nxn matrix displaying the all marginal effects on $y_{i}$ from a change in $x_{i}$. The diagonal elements in this matrix are the marginal effects from county $i$ on the dependent variable in county $i$, known as the direct effects. The off-diagonal elements in $S(W)$ are the effects on the dependent variable in county $i$ from a change in the independent variable in county $j$, called the indirect effects. Total effects sum direct and indirect. While each individual effect can be calculated, LeSage and Pace (2009) 
recommend presenting the average total, direct, and indirect effects. Accordingly, the marginal effects are presented following this method below.

Table 3: Marginal Effects

\begin{tabular}{|c|c|c|c|c|c|c|c|c|c|}
\hline Variable & Direct & \multicolumn{2}{|c|}{ Lower $95 \%$ Upper $95 \%$} & Indirect & \multicolumn{2}{|c|}{ Lower $95 \%$ Upper $95 \%$} & Total & \multicolumn{2}{|c|}{ Lower $95 \%$ Upper $95 \%$} \\
\hline LocalP & 0.0772 & 0.0544 & 0.0999 & 0.0499 & -0.0111 & 0.1107 & 0.1271 & 0.0625 & 0.1911 \\
\hline $\ln$ Pers & 0.0159 & -0.5841 & 0.5518 & 0.1858 & -1.3681 & 1.727 & 0.1699 & -1.4694 & 1.8113 \\
\hline PctDem & -0.0016 & -0.011 & 0.0079 & 0.0087 & -0.0134 & 0.031 & 0.0072 & -0.015 & 0.0294 \\
\hline WhFds & -0.0476 & -0.1184 & 0.024 & -0.0047 & -0.2649 & 0.2548 & -0.0523 & -0.3331 & 0.2288 \\
\hline PrElect & 0.0785 & -0.096 & 0.2545 & 0.2039 & -0.0418 & 0.4515 & 0.2824 & 0.1171 & 0.45 \\
\hline MedAge & 0.0231 & 0.0029 & 0.0431 & 0.0059 & -0.0415 & 0.0533 & 0.0291 & -0.0181 & 0.0762 \\
\hline wBach & 0.0154 & 0.0008 & 0.03 & -0.038 & -0.0752 & -0.001 & -0.0226 & -0.0603 & 0.0151 \\
\hline SolPot & 0.0003 & -0.0001 & 0.0007 & -0.0002 & -0.0007 & 0.0002 & 0.0002 & 0.0001 & 0.0003 \\
\hline Detach & -0.0023 & -0.0152 & 0.0107 & -0.0336 & -0.0678 & 0.0004 & -0.0359 & -0.0715 & -0.0005 \\
\hline $\operatorname{lnNumOwn}$ & 0.1537 & 0.0627 & 0.2445 & 0.0954 & -0.1472 & 0.3377 & 0.2491 & -0.0015 & 0.497 \\
\hline
\end{tabular}

The direct, indirect, and total effect estimate of each level-one variable is presented, along with the upper and lower limits of its $95 \%$ credible interval. The first row presents the average effect estimates for local policies. These results suggest that an additional solar policies at the city, county, and utility level in county $i$ are associated with an increase in installed residential solar PV capacity per capita by 7.7\%. However given the significant spatial autocorrelation estimated in this model, a policy in county $i$ also affects neighboring counties. The average indirect effect of local policies (a policy in county $i$ 's effect across neighboring counties) averages a cumulative 5.0\% increase. Combined, an average sub-state policy is associated on average with a $12.7 \%$ increase in per capita capacity in both the county in which it is enacted as well as all neighboring counties.

This lends support to the arguments put forth in Burkhardt et al. (2015) and Dong and Wiser (2013) that local policies are an important driver of solar adoption. An important distinction is that this study only considers renewable policies, whereas these earlier studies use a more comprehensive set of local construction, connection, and permitting policies. Nevertheless, these results should help direct attention of local municipality and county policies as an important component of residential PV adoption. That there is no significant effect in the change of neighboring counties suggests that the clustering found in Bollinger and Gillingham (2012) is likely limited to within county effects. It is worth noting that these policy impacts likely go beyond adoption: Joern et al. (2013) demonstrate how while incentive policies increase innovation at the firm level, they could be raising the barrier to market entry for new firms. 
The impact of average solar insolation is positive and significantly different than zero ${ }^{35}$ in total estimates. This relationship seems intuitive and indeed potentially overshadowing other relationships: especially in the WECC region, greater amounts of solar insolation would decrease the time required to pay off the upfront investment. However these results suggest that while it is an important consideration, there are other salient factors. Germany for example, with roughly the solar potential of Seattle, leads the world in installed solar PV capacity. Even in cold and cloudy areas, electricity can be generated using solar PV. With sufficient interest, policy incentive and financial resources, a household could still be willing to install a PV system even with relatively limited solar insolation.

The coefficient for wealth, personal income per capita, has the expected sign on its effect estimates, however there is a wide variability in each's credible interval. Per capita personal income be capturing the wealth effect, as the decision to pay for installations comes at the household level. In some counties in the WECC, there are high levels of inequality, such that per capita income would be quite low while some individuals would have sufficient resources to devote to a PV installation. Further, it's important to note the dependent variable, installed capacity, is normalized on population. Areas with higher population densities generally have higher incomes, so increasing wealth would be associated with both higher levels of residential capacity as well as population. In this model, two variables correlated with wealth, age and education, are both positively associated with per capita installed capacity. It could be that this wealth effect is being captured by these other covariates.

Similarly, the effect estimates of the environmental awareness variables are not significantly different from zero. This could be because the percent voting for a popular presidential candidate and number of Whole Foods installations are not good indicators of environmental preference, however it is more likely that there are high correlations between environmental preference and wealth and education. Median county age though is found to be significantly different than zero. Given its correlations with wealth, this may be capturing some of wealth's effect on the residential market.

The positive and significant total value for electricity prices lends weight to the idea that residential solar PV capacity and electricity are substitutes, however it is not clear in which direction the causality runs. It is intuitive that higher electricity prices would push homeowners to consider alternative electricity options, however it could very well be the case (as argued by many utilities frustrated with renewable integration) that the integration of residential capacity raises costs.

\footnotetext{
${ }^{35}$ Here defined as zero lying outside of the $95 \%$ credible interval in the specific effect estimate
} 
Both the percent detached homes as well as the number of units owned in a county have the predicted positive signs on their direct effects, however only the units are significantly different than zero. These effect estimates remain positive in the indirect and total effects, however there is a wider degree of variability. The percent detached has no discernable indirect or total effect, as nearly equal mass of the distribution of the effects lie on either side of zero.

\section{Conclusions}

This paper has contributed to the literature by empirically demonstrated how sub-state policies are important drivers of residential solar PV adoption. Focusing on the largest residential solar market, I created a unique dataset identifying the location of utility, county, and municipality solar incentive policies, and exploit their variation to examine their effects on known residential installations. Given the nested structure of the data (counties within states), I turn to a hierarchical model which incorporates both the unobserved heterogeneity at the state level but also impact that state policies and electricity prices have on the residential PV market. Given the spatial autocorrelation and peer effects found in earlier studies, I also utilize spatial econometric methods to evaluate the spatial spillovers in the market, which while moderate are found significant.

There are a number of important policy considerations from this study. First, a larger focus on local policies and regulations is warranted when considering residential markets. Potential consumers may have a better familiarity of local incentive policies available to them, and those on the margin are likely more influenced by the policies they know. Second, proponents of policies to promote residential solar PV adoption may do well to focus their efforts towards sub-state governments. There the potential to enact policy change might be significantly lower than at the state level, as county commissioners are likely more accessible and amenable to lobbying efforts. Third, residential solar firms may do well to focus their marketing efforts in areas with already high levels of installed capacity, where they could capture the peer-effects and spatial clustering of residential systems. Given the significant spatial autocorrelation displayed in the market, they may well already be doing so.

This study is limited in a number of ways. Only statistical associations are produced by this paper: there is some potential for endogeneity in this study: policy makers could be enacting incentive policies in areas where solar already has a noticeable presence. Future work, similar to Crago and Chernyakhovskiy (2014) discerning the causal relationship is needed for the sub-state level. As mentioned above, this research design is unable to capture the effect of tiered electricity prices and may be omitting an important driver. This study treats all policies as homogeneous, which is unlikely to be the case. One net-metering policy 
may be more favorable than another, whereas PACE financing might offer more incentives in some areas. This variation within and between policy categories is not captured, but could be part of future work. Further, this study was not able to incorporate local permitting or regulatory process efficiency, which may explain a large share of solar PV adoption. However even with these limitations, this study presents new evidence that local renewable policies are a significant driver of solar PV adoption.

\section{References}

Balta-Ozkan, N., Yildirim, J., \& Connor, P. M. (2015). Regional distribution of photovoltaic deployment in the UK and its determinants: A spatial econometric approach. Energy Economics, 51, 417-429.

Barbose, G. L., Darghouth, N. R., Millstein, D., Spears, M., Wiser, R. H., Buckley, M., ... \& Grue, N. (2015). Tracking the Sun VIII: The Installed Price of Residential and Non-Residential Photovoltaic Systems in the United States(No. LBNL-188238). Lawrence Berkeley National Laboratory (LBNL), Berkeley, CA (United States).

Bauner, C., \& Crago, C. L. (2015). Adoption of residential solar power under uncertainty: Implications for renewable energy incentives. Energy Policy, 86, 27-35.

Bollinger, B., \& Gillingham, K. (2012). Peer effects in the diffusion of solar photovoltaic panels. Marketing Science, 31(6), 900-912.

Borchers, A. M., Xiarchos, I., \& Beckman, J. (2014). Determinants of wind and solar energy system adoption by US farms: A multilevel modeling approach. Energy Policy, 69, 106-115.

Borenstein, S. (2015). The Private Net Benefits of Residential Solar PV: The Role of Electricity Tariffs, Tax Incentives and Rebates (No. w21342). National Bureau of Economic Research.

Burkhardt, J., Wiser, R., Darghouth, N., Dong, C. G., \& Huneycutt, J. (2015). Exploring the impact of permitting and local regulatory processes on residential solar prices in the United States. Energy Policy, 78, 102-112.

Burnett, W., \& Lacombe, D. J. (2012). Accounting for Spatial Autocorrelation in the 2004 Presidential Popular Vote: A Reassessment of the Evidence. The Review of Regional Studies, 42(1), 75.

Burbidge, J. B., Magee, L., \& Robb, A. L. (1988). Alternative transformations to handle extreme values of the dependent variable. Journal of the American Statistical Association, 83(401), 123-127.

Coan, T. G., \& Holman, M. R. (2008). Voting Green*. Social Science Quarterly, 89(5), 1121-1135.

Chung, D., Davidson, C., Fu, R., Ardani, K., \& Margolis, R. (2015). US Photovoltaic Prices and Cost Breakdowns: Q1 2015 Benchmarks for Residential, Commercial, and Utility-Scale Systems (No. NREL/TP-6A20-64746). NREL (National Renewable Energy Laboratory (NREL).

Crago, C., \& Chernyakhovskiy, I. (2014). Solar PV Technology Adoption in the United States: An Empirical Investigation of State Policy Effectiveness. In 2014 Annual Meeting, July (pp. 27-29). 
Darghouth, N. R., Barbose, G., \& Wiser, R. (2011). The impact of rate design and net metering on the bill savings from distributed PV for residential customers in California. Energy Policy, 39(9), 5243-5253.

Dong, C., \& Wiser, R. (2013). The impact of city-level permitting processes on residential photovoltaic installation prices and development times: An empirical analysis of solar systems in California cities. Energy Policy, 63, 531-542.

Elhorst, J. P. (2010). Applied spatial econometrics: raising the bar. Spatial Economic Analysis, 5(1), 9-28.

Florax, R. J. G. M., Folmer, H. \& Rey, S. J. (2003) Specification Searches in Spatial Econometrics: the Relevance of Hendry's Methodology. Regional Science and Urban Economics, 33, 557-579.

Gillingham, K., Deng, H., Wiser, R., Darghouth, N., Nemet, G., Barbose, G., Rai, V., \& Dong, C. G. (2016). Deconstructing Solar Photovoltaic Pricing. The Energy Journal, 37(3).

Hoppmann, J., Peters, M., Schneider, M., \& Hoffmann, V. H. (2013). The two faces of market supportHow deployment policies affect technological exploration and exploitation in the solar photovoltaic industry. Research Policy, 42(4), 989-1003.

Islam, T., \& Meade, N. (2013). The impact of attribute preferences on adoption timing: The case of photo-voltaic (PV) solar cells for household electricity generation. Energy Policy, 55, 521-530.

Kwan, C. L. (2012). Influence of local environmental, social, economic and political variables on the spatial distribution of residential solar PV arrays across the United States. Energy Policy, 47, 332-344.

Lacombe, D. J., \& McIntyre, S. G. (2016). Local and global spatial effects in hierarchical models. Applied Economics Letters, 1-5.

LeSage JP, Pace KR (2009) Introduction to Spatial Econometrics. CRC Press, Boca Raton

LeSage, J. P., \& Pace, R. K. (2014). The biggest myth in spatial econometrics. Econometrics, 2(4), 217 249.

Li, H., \& Yi, H. (2014). Multilevel governance and deployment of solar PV panels in US cities. Energy Policy, 69, 19-27.

MacKinnon, J. G., \& Magee, L. (1990). Transforming the dependent variable in regression models. International Economic Review, 315-339.

Pace, R. K., LeSage, J. P., \& Zhu, S. (2012). Spatial dependence in regressors and its effect on performance of likelihood-based and instrumental variable estimators. Advances in Econometrics, 30, 257-295.

Richter, L. L. (2013). Social Effects in the Diffusion of solar Photovoltaic Technology in the UK. Faculty of Economics, University of Cambridge.

Sarzynski, A., Larrieu, J., \& Shrimali, G. (2012). The impact of state financial incentives on market deployment of solar technology. Energy Policy, 46, 550-557. 
Snape, J. R., \& Rynikiewicz, D. C. (2012). Peer effect and social learning in micro-generation adoption and urban smarter grids development? Network Industries Quarterly, 14(24), 2-3.

Shrimali, G., \& Jenner, S. (2013). The impact of state policy on deployment and cost of solar photovoltaic technology in the US: A sector-specific empirical analysis. Renewable Energy, 60, 679-690. 


\section{Chapter 5: Conclusion}

This dissertation has examined three aspects of electricity generation. From the decline of the coal industry, the rapid rise of shale resources in the natural gas market, and the policy drivers of solar PV, I have provided a better and more nuanced view of three methods of generation that both have been and will be important to the state of West Virginia. This dissertation will be useful to anyone interested in state energy policy, as understanding how changes in policies have led to considerable changes in each of these markets. Similarly, anyone interested in competitive energy markets could benefit from this research.

My second chapter investigates the extent to which acid rain regulations created by the federal government, once outside market forces are controlled for, are still associated with the declines in production seen in in the Eastern coal industry. I control for the effect that regulation and market forces had on mine closures, and then empirically demonstrate how the effect of these regulations were felt differently even within the Appalachian and Illinois basins. I also show the mitigating impact that the installation of scrubber units had on production. This provides a more nuanced view of the federal government's role in the decline in coal production, and often contentious issue in the state.

My third chapter models the natural gas industry, paying particular attention to the changes brought about by the rapid increase in production from shale resources. I model how the fundamental relationships in the market have changed since the formal deregulation of the industry in 1993. I also am able to model changes in the elasticities associated with both supply and demand for natural gas, and investigate the importance of specific supply and price disruptions in the past 25 years. These results should be of interest to anyone involved with natural gas markets or modeling their ubiquitous impact on the US economy. This issue is also of particular relevance to West Virginia, a state that has seen dramatic increases in production from shale resources in the past 10 years.

The effect of sub-state level policies on the adoption of residential solar PV capacity is the topic of my fourth chapter. Focusing on one of the largest solar markets in the world, the US southwest, I evaluate the impact of policies at the state, county, municipality, and utility level, finding that local policies have a positive and significant effect on both the number of installations and the total capacity of residential solar PV at the county level. Further, the spatial autocorrelation in the residential PV market is found to be moderate but significant. These results are an important contribution to the literature: by highlighting a previously overlooked area of policy, my results will help direct attention and research more towards substate policies when considering the residential solar market. This is also the first empirical application of a Bayesian spatial hierarchical model. 
In sum, this dissertation contributes to the academic literature by applying econometric techniques to questions concerning the economics of energy production. I take three production methods and provide answers to three important questions: After controlling for market forces, how much of the decline in eastern coal production is attributable to federal acid rain regulation? How have the fundamental relationships in the natural gas market changed over the last 25 years, especially given the rise of production from shale resources? And how do have sub-state policies affected the adoption of residential solar PV? These three questions are especially salient to the state of West Virginia, a state currently facing tough choices about the trade-offs of energy production. This research will help inform current and future policy decisions for the state, region, and nation.

\section{References}

Paredes, Dusan, Timothy Komarek, and Scott Loveridge. 2015. Income and Employment Effects of Shale Gas Extraction Windfalls: Evidence from the Marcellus Region. Energy Economics. 47: 112-120.

US EIA Annual Energy Outlook 2015 (2015).US Department of Energy, Energy Information Administration: DOE/EIA-0383 (96) Washington, DC (1996). 